This is the peer reviewed version of the following article:

Evans, N. H. and Beer, P. D. (2014), Advances in Anion Supramolecular Chemistry: From Recognition to Chemical Applications. Angew. Chem. Int. Ed., 53: 11716-11754.

Which has been published in final form at:

http://onlinelibrary.wiley.com/doi/10.1002/anie.201309937/abstract?campaign=woletoc

This article may be used for non-commercial purposes in accordance with Wiley- $\mathrm{VCH}$ Terms and Conditions for self-archiving. 


\section{Advances in Anion Supramolecular Chemistry: From Recognition to Chemical Applications**}

Nicholas H. Evans* and Paul D. Beer*

Keywords:

supramolecular chemistry template synthesis anion recognition sensors anions anions
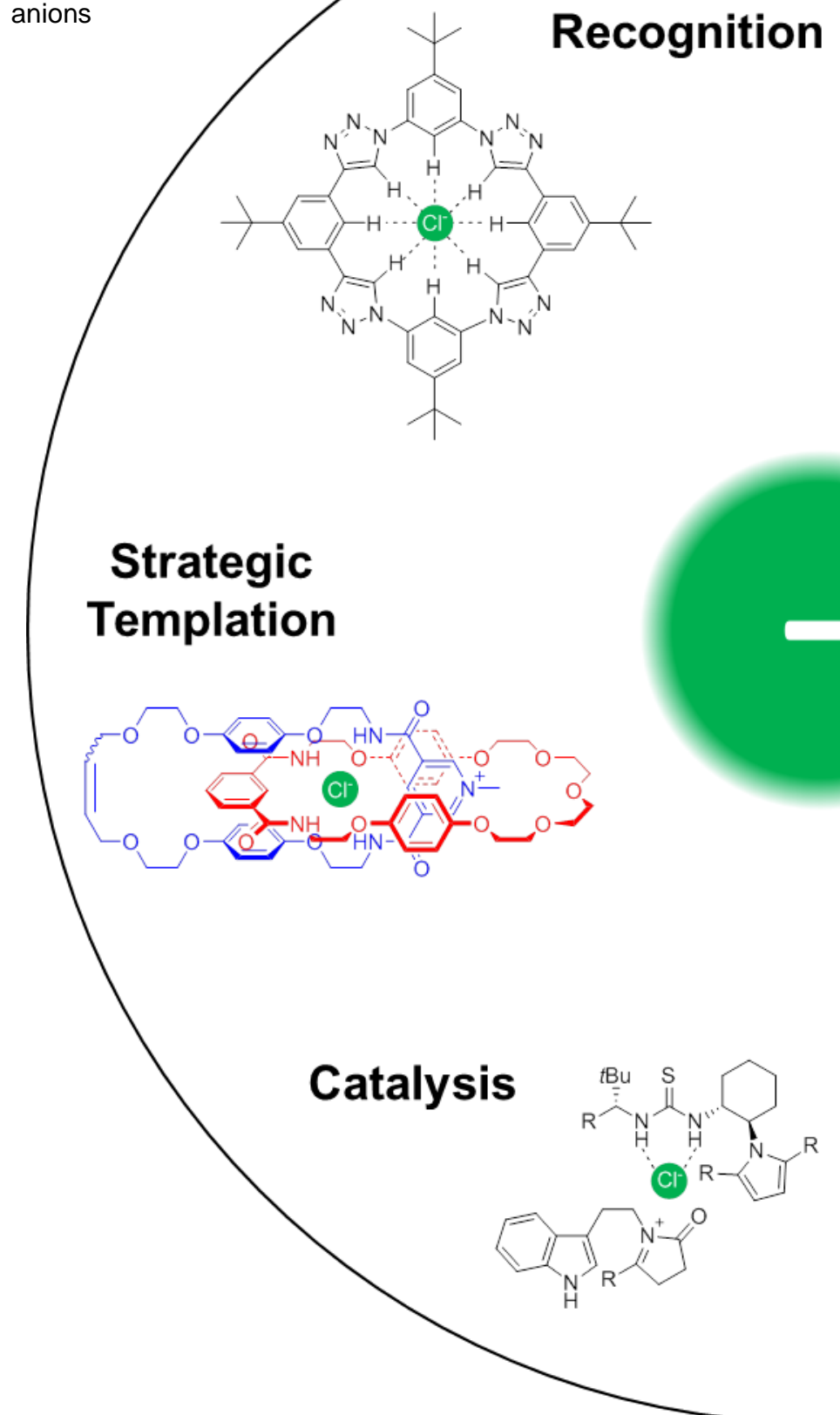

This review is dedicated to Prof. Jean-Marie Lehn on occasion of his $75^{\text {th }}$ birthday.

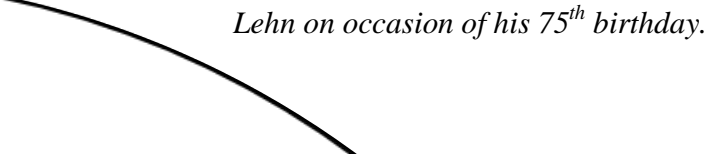


Since the Millennium, remarkable progress in the binding and sensing of anions has been taking place, driven in part by discoveries in the use of hydrogen bonding, as well as the previously under-exploited anion- $\pi$ and halogen bonding interactions. However, anion supramolecular chemistry has developed substantially beyond anion recognition, and now encompasses a diverse range of disciplines. Dramatic advance has been made in the anion templated synthesis of macrocycles and interlocked molecular architectures, while the study of transmembrane anion transporters has flourished from almost nothing into a rapidly maturing field of research. Anion supramolecular chemistry has also found real practical use in a variety of applications such as catalysis, ion extraction and the use of anions as stimuli for responsive chemical systems.

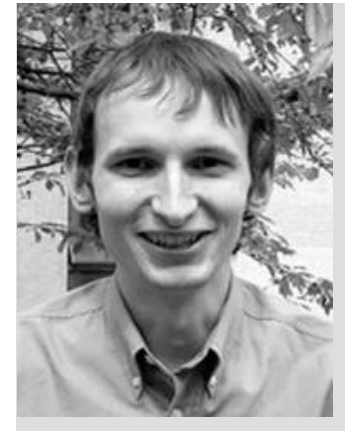

Nick Evans graduated from Wadham College, University of Oxford with a First Class Masters in Chemistry (2006), before obtaining a DPhil in Inorganic Chemistry (2011), having worked upon anion sensing rotaxanes and catenanes in the laboratories of Prof Paul Beer. After undertaking post-doctoral research on chiral lanthanide complexes with Prof David Parker (Durham University), Nick took up a Lectureship in Chemistry at Lancaster University in 2013. His current research programme involves the development of functional supramolecular systems, with a particular focus on guest recognition and sensing.

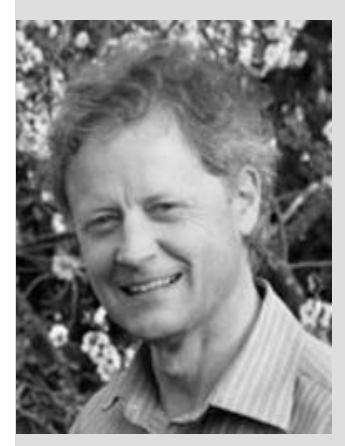

Paul Beer obtained a PhD from King's College London in 1982 with $\mathrm{Dr} C$. Dennis Hall. After a Royal Society European Postdoctoral Fellowship with Prof Jean-Marie Lehn and a Demonstratorship at the University of Exeter, he was awarded a Lectureship at the University of Birmingham in 1984. In 1990, he moved to the University of Oxford, where he became a Professor of Chemistry in 1998. His research interests cover many areas of coordination and supramolecular chemistry, in particular the binding and sensing of anions by macrocycles and interlocked molecular host systems.

\section{Introduction}

Anions have enormous impact upon our lives. Within our own bodies, the carrier of our genetic information - DNA - is anionic, as are the majority of enzyme substrates and cofactors (e. g. ATP). Amongst the halides, chloride is found extensively in extra-cellular fluid, with its misregulation being linked to diseases including cystic fibrosis, ${ }^{[1]}$ iodide is required for the biosynthesis of hormones by the thyroid gland, ${ }^{[2]}$ while fluoride is considered essential for healthy bone and teeth growth, which has led to the (sometimes controversial) artificial fluoridation of water supplies. ${ }^{[3]}$ Of other anions, it is well-established that bicarbonate is vital in the maintenance of $\mathrm{pH}$ levels in the body, whereas cyanide is highly toxic.

Meanwhile, certain anions have an adverse effect on the environment around us. Nitrate and sulfate are key components in the production of acid rain. ${ }^{[4]}$ Excessive use of phosphates and nitrates in fertilizers has led to eutrophication in waterways. ${ }^{[5]}$ Pertechnetate (a by-product of nuclear fuel reprocessing) ${ }^{[6]}$ and perchlorate (arising from manufacture of explosives) ${ }^{[7]}$ are two further examples of anthropogenic pollutants, while arsenate is an example of a naturally occurring one. ${ }^{[8]}$ In short, there has been, and still is, considerable motivation for investigating the binding and sensing of anionic species.

In 1968, Park and Simmons described the binding of halide anions by macrobicyclic ammonium cages (Figure 1a). ${ }^{[9]}$ A year previously, Shriver and Biallas had reported the formation of a chelate between a bis-boron ligand and methoxide ion (Figure 1b). ${ }^{[10]}$ These are generally considered to be the first examples of anion coordination and hence the point of genesis for anion supramolecular chemistry.

[*] Dr. N. H. Evans

Department of Chemistry

Lancaster University

Lancaster, LA1 4YB (UK)

E-mail: n.h.evans@lancaster.ac.uk

Prof. P. D. Beer

Inorganic Chemistry Laboratory

Department of Chemistry

University of Oxford

South Parks Road

Oxford, OX1 3TA (UK)

E-mail: paul.beer@chem.ox.ac.uk

[**] This review is dedicated to Prof. Jean-Marie Lehn on occasion of his $75^{\text {th }}$ birthday. 
(a)

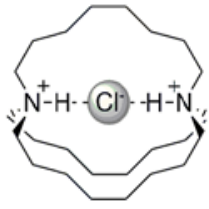

(b)<smiles>C[Pb]1CCB(F)O1</smiles>

Figure 1. First examples of anion coordination: (a) Park and Simmons' macrobicyclic ammonium cage and (b) Shriver and Biallas' boron chelate.

Initially there was very little progress in the coordination chemistry of anions, in comparison to that of cations, where Pedersen's seminal reports on macrocyclic crown ethers ${ }^{[11]}$ heralded the development of an array of cation binding ligands, including Lehn's cryptands ${ }^{[12]}$ and Cram's spherands. ${ }^{[13]}$ This lack of development in the field of anion recognition has been attributed, in part, to a number of intrinsic properties associated with anionic species. Anions are larger than their isoelectronic cations, and hence will have smaller Coulombic interactions with an equivalent charged receptor. Anions may possess $\mathrm{pH}$ sensitivities, i.e. become protonated at low $\mathrm{pH}$ and possibly lose their negative charge. Even simple inorganic anions are known to have a wide range of possible geometries including spherical, linear, trigonal planar and tetrahedral. It has also been noted that anions, in comparison with cations, possess high free energies of hydration. The degree of solvation of an anion in water varies from ion to ion, and is reflected by the Hofmeister series. In a hydrophobic binding site, inaccessible to solvent, less hydrated anions are bound more strongly. On the other hand, anions which are more hydrated are typically held more strongly in receptors with open cavities.

Despite these challenges, research in anion coordination gently began to develop momentum. Seminal early contributions included Lehn and co-workers developing a large number of polyammonium receptors, including macrocycles where optimal binding in aqueous media was observed for dicarboxylate anions of complementary size to the length of the receptor (Figure 2a) ${ }^{[14]}$ and Schmidtchen reporting innovative quaternary ammonium hosts able to bind halides within their cage structure (Figure $2 b$ ) ${ }^{[15]}$ In spite of this slow beginning, anion supramolecular chemistry featured heavily in Lehn's Nobel Prize lecture of 1987. ${ }^{[15]}$ (a)

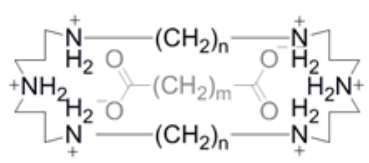

(b)

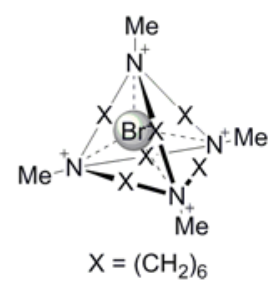

Figure 2. Significant early examples of anion coordination: (a) Lehn's dicarboxylate binding macrocycle and (b) Schmidtchen's tetraammonium cage.

In 2001, Beer and Gale co-authored a review on anion recognition and sensing ${ }^{[16]}$ which in particular highlighted the important advances made in the design and construction of neutral hydrogen bond anion receptors that primarily function in organic solvents, as well as the construction of optical and electrochemical anion sensors.

Since that review, developments in anion recognition have continued to flourish to the extent that today anion supramolecular chemistry has evolved substantially beyond the realms of anion receptor chemistry. While imaginative research continues on the binding and sensing of anions, during the last ten years or so large strides have been made in areas which were new and underdeveloped such as anion templation and transportation and importantly in chemical applications such as catalysis, ion extraction and responsive materials.

Considering the depth and diversity of anion supramolecular chemistry today, we cannot contemplate producing a comprehensive review of the topic. Instead we seek to provide an overview of the most significant and substantial developments in the field since 2001, as well as providing some indication of where we expect the area to develop in the second decade of this century. ${ }^{[17]}$

\section{Fundamental Advances in Anion Recognition}

Previously anion receptors have been usefully classified by consideration of the type of non-covalent interaction used to complex the anionic guest. ${ }^{[16]}$ While receptors employing electrostatic interactions are able to bind anions in water, hydrogen bonding being considerably weaker, has traditionally been considered insufficient to bind anions in aqueous conditions. The directionality offered by hydrogen bonds, however, means that appropriately designed neutral receptors can be constructed to bind anions with different geometries in aprotic polar solvents. Ureas ${ }^{[18]}$ and amides ${ }^{[19]}$ are popular choices of hydrogen bond donating functional groups, partly due to their expedient synthetic preparation. Pyrroles, notably as calixpyrroles, have been shown to be particularly efficient anion receptors in polar organic solvents due to the lack of a competing hydrogen bond acceptor. ${ }^{[20]}$ By combining electrostatics and hydrogen bonding highly effective anion receptors are produced; recent examples of such motifs operable in aqueous solvent media include guanidinium, ${ }^{[21]}$ imidazolium $^{[22]}$ and pyridinium ${ }^{[23]}$. Lewis acidic atoms, being electron deficient, are able to bind anions by participating in the formation of a bonding interaction by orbital overlap with an anion acting as an electron donating species. In addition to boron, ${ }^{[10,24]}$ other elements including silicon ${ }^{[25]}$ and tellurium ${ }^{[26]}$ have been employed to generate such anion receptors.

In this review we do not provide an exhaustive commentary on this research. ${ }^{[27]}$ Here, we concentrate on what may be considered to be the most important fundamental advances in anion recognition since 2001. We first highlight key developments in hydrogen bonding anion receptors. Hydrogen bonding is widely utilized in a range of anion supramolecular chemistry activity (e.g. templation and transportation), and recent developments are often exploited in these applications. Secondly, we discuss the appearance of receptors based on new non-covalent interactions, specifically those using anion- $\pi$ and halogen bonding. 


\subsection{Critical Developments in Receptors Utilizing Hydrogen Bonding}

\subsubsection{New $\mathrm{N}-\mathrm{H}, \mathrm{O}-\mathrm{H}$ and $\mathrm{C}-\mathrm{H}$ containing receptors}

Neutral squaramides - a particular class of N-H hydrogen bond donor, that are derivatives of 3, 4-diamino-cyclobutene-1, 2-dione (Figure 3) - were demonstrated to act as effective anion receptors in competitive solvent media (such as DMSO) as early as $1998 .{ }^{[28]}$ Since the Millennium, numerous examples of squaramide anion receptors have been reported, ${ }^{[29]}$ where their effectiveness is believed to be due in part to an increase of aromatic character of the squaramide ring upon anion complexation. ${ }^{[30]}$ An illustration is provided by a comparison of bis-aryl squaramides, with their analogous ureas by Fabbrizzi and co-workers. ${ }^{[31]}$ With halides, the bis-nitro phenyl squaramide in Figure $3 \mathrm{~b}$ exhibited considerably stronger complexes (by 1 or 2 orders of magnitude) than the analogous urea receptor in acetonitrile. In contrast, oxoanions were bound by each receptor with almost identical association constants. The enhancement of halide binding by the squaramide was attributed to the presence of convergent aryl C-H bonds that can act as additional hydrogen bond donors. (a)

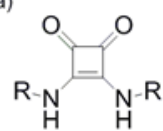

(b)

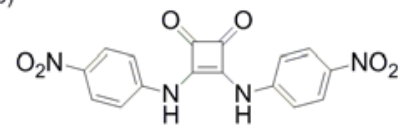

Figure 3. Squaramides as $\mathrm{N}-\mathrm{H}$ hydrogen bond donating anion receptors: (a) the generic structure of a squaramide and (b) Fabbrizzi's bis-aryl squaramide receptor which exhibited particular enhancement of halide anion binding in comparison to the analogous urea receptor.

The indole-containing amino acid tryptophan may be found as a $\mathrm{N}-\mathrm{H}$ hydrogen bond donor in the anion binding site of the sulfatebinding protein. ${ }^{[32]}$ The indole functional group, like pyrrole, lacks competing hydrogen bond acceptors (in contrast to amides and ureas), but is more acidic than its monocyclic counterpart. Indoles, along with carbazoles and indolocarbazoles, are representative examples of heterocyclic $\mathrm{N}-\mathrm{H}$ hydrogen bond donors that have been investigated in recent times (typically in combination with other hydrogen bond donors) as potent anion receptors. ${ }^{[33]}$

For example, Gale and co-workers synthesized pyridine-2, 6dicarboxamide and isophthalamide molecules which possessed pendent indole groups (Figure 4a). ${ }^{[34]}$ These receptors proved to be highly selective for fluoride over chloride (for example) in $\left[\mathrm{D}_{6}\right] \mathrm{DMSO} / 0.5 \%$ water mixtures, attributed to the "twisted" conformation of the receptor encapsulating the smaller fluoride anion, whereas chloride "perches", as evidenced in a solid state crystal structure determination. Previously, Jurczak and co-workers had reported on carbazole/amide receptors (Figure $4 \mathrm{~b}$ ). ${ }^{[35]}$ These molecules were found to bind benzoate and dihydrogen phosphate much more strongly than chloride in $\left[\mathrm{D}_{6}\right] \mathrm{DMSO} / 0.5 \%$ water. The first reports of anion complexation with indolocarbazoles were made by the group of Beer, where it was demonstrated that, in acetone, simple indolocarbazoles bound benzoate strongly (typically $\log K_{\mathrm{a}}>$ 5). ${ }^{[36]}$ Jeong and co-workers have since incorporated indolocarbazoles into a range of macrocyclic receptors (Figure 4c) ${ }^{[37]}$ Chloride is bound more strongly by the smaller cyclic receptor (in $10 \% \mathrm{MeOH} /$ acetone), whereas larger anions investigated were bound more strongly to the larger receptor, indicative of a degree of complementarity between host and guest.<smiles>[X][M]O[C@H]1C=CC=C(C(=O)Nc2cccc3c(C)c(C)[nH]c23)C=[Y]1C(=O)Nc1cccc2c(C)c(C)[nH]c12</smiles>

(b)

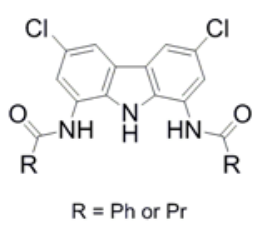

(c)

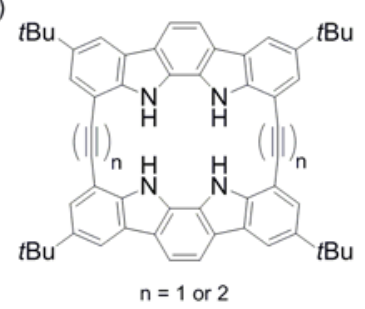

Figure 4. Examples of recent heterocyclic $\mathrm{N}-\mathrm{H}$ hydrogen bonding receptors: (a) Gale's indole containing receptors; (b) Jurczak's carbazole bis-amide receptors and (c) Jeong's indolocarbazole containing macrocycles.

Recently the use of chiral anions to induce helical chirality in $\mathrm{N}-\mathrm{H}$ hydrogen bond donating foldamer anion receptors has been demonstrated. This is exemplified by Jeong's tris-indolocarbazole that forms a chiral helix upon coordination to enantiopure 10-camphorsulfonate in dichloromethane as revealed by circular dichroism (Figure 5). ${ }^{[38]}$ A related example is that of Zhao and $\mathrm{Li}$, who used the chiral glutamate anion to induce helical chirality in a benzamide oligomer. ${ }^{[39]}$

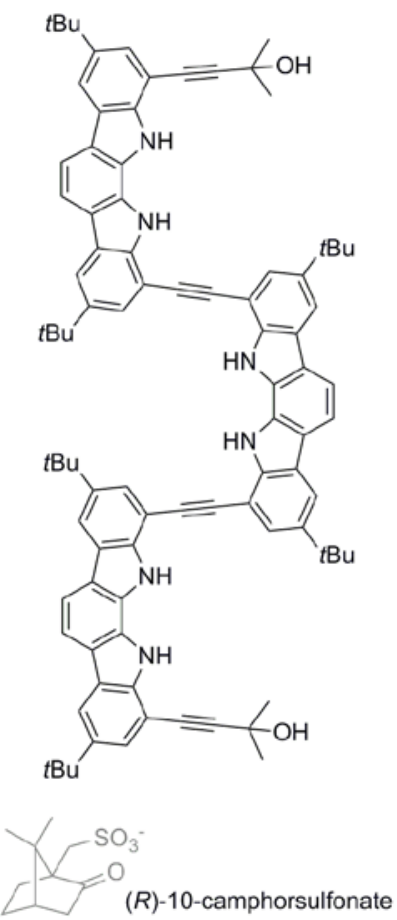

Figure 5. Jeong's indolocarbazole foldamer anion receptor which forms a chiral helix with positive Cotton effect upon addition of $(R)-10$ camphorsulfonate (anion depicted) in dichloromethane. 
As already mentioned in the Introduction, protonated bicyclic $\mathrm{N}-\mathrm{H}$ containing molecules have been known to bind anions for some 45 years. Interest in such cryptand-like receptors was rekindled by Lehn's 1978 report of an aza-oxa cryptand which was shown to selectively bind the linear azide anion in water. ${ }^{[40]}$ This research area has remained remarkably active, and even since 2001 a large number of bicyclic receptors have been reported. ${ }^{[41]}$ Notable among these has been the work of Bowman-James and co-workers, who have studied neutral cryptands (prepared by reacting tris-(2aminoethyl)amine, commonly referred to as "tren", with bisisophthaloyl chlorides), that are able to bind fluoride with $K_{\mathrm{a}}>$ $10^{5} \mathrm{M}^{-1}$ in competitive $\left[\mathrm{D}_{6}\right]$ DMSO (Figure 6a). ${ }^{[42]}$ Recently, Mani et al have described the ability of poly-pyrrolic cryptands to also bind fluoride in $\left[\mathrm{D}_{6}\right] \mathrm{DMSO}$ (Figure $6 \mathrm{~b}$ ). ${ }^{[43]}$ A notable achievement in this field has been the selective recognition of the radioactive pollutant ${ }^{99} \mathrm{TcO}_{4}{ }^{-}$by a protonated cryptand in acidic water (Figure 6c). ${ }^{[44]}$ Amendola and co-workers demonstrated by ITC titrations that the pertechnetate anion was bound more strongly than either nitrate or chloride by two orders of magnitude.
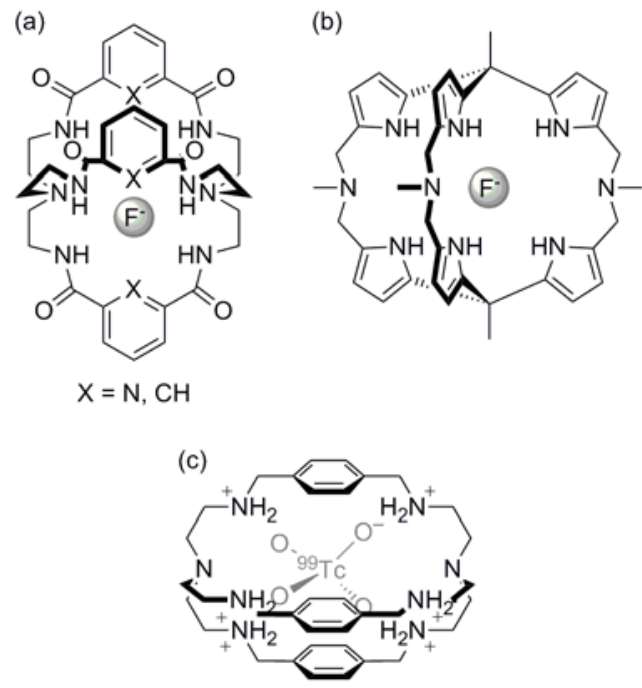

Figure 6. Cryptand-like receptors: (a) Bowman-James' polyamide and (b) Mani's poly-pyrrole cages that bind fluoride; (c) Amendola's polyaza cage that binds pertechnetate.

The simple, commercially available molecule catechol, has been found by D. K. Smith ${ }^{[45]}$ to be a remarkably potent chloride binder in $\mathrm{CD}_{3} \mathrm{CN}\left(K_{\mathrm{a}}=1575 \mathrm{M}^{-1}\right)$ (Figure $\left.7 \mathrm{a}\right)$. Further study revealed catechol exhibited greater affinity and selectivity for chloride (over bromide and iodide) than its structural isomer resorcinol (Figure 7b) ${ }^{[46]}$ However, attempts to functionalize catechol with further hydrogen bond donors proved problematic, with formation of intramolecular 6-membered hydrogen bonding found to inhibit anion binding in a number of the receptors prepared (Figure $7 \mathrm{c}){ }^{[47]}$ (a)<smiles></smiles>

(b)<smiles>c1cc2ccc1OCCO2</smiles>

(c)<smiles>[R]C(=O)N1Cc2cccc(OC)c2OP1</smiles>

Figure 7. Bis-phenols as $\mathrm{O}-\mathrm{H}$ hydrogen bonding chloride anion receptors: (a) mode of chloride binding of catechol; (b) mode of chloride binding of resorcinol and (c) example of functionalized catechol that has reduced chloride affinity due to intramolecular hydrogen bonding.

Recently it has been recognized that the triazole motif may be utilized as a potent $\mathrm{C}-\mathrm{H}$ hydrogen bond donor, with interest in part being driven by the synthetic efficacy of the CuAAC Huisgen azidealkyne cycloaddition "click" reaction. ${ }^{[48]}$ Being similar in size, planarity and dipolar character to an amide linkage, a 1, 2, 3-triazole may be considered peptidomimetic. Flood has demonstrated very strong binding of chloride and bromide by a triazolophane, in dichloromethane (Figure 8a). ${ }^{[49]}$ By careful development of the design, a receptor that binds iodide in a 2:1 "sandwich" complex has also been constructed (Figure $8 \mathrm{~b}) .{ }^{[50]}$

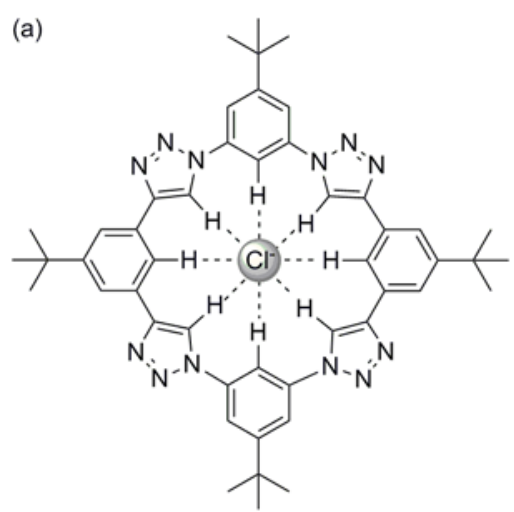

(b)

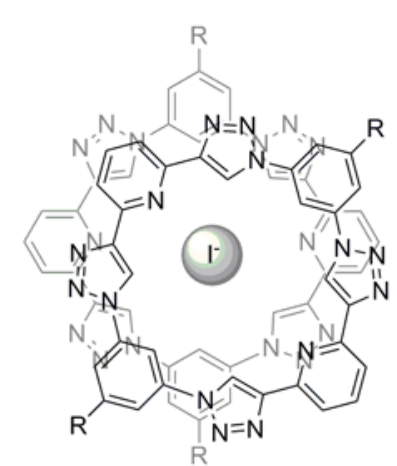

Figure 8. Flood's triazole macrocycles as $\mathrm{C}-\mathrm{H}$ hydrogen bond donating anion receptors: (a) the original triazolophane binding chloride and (b) an alternative triazolophane that binds iodide in a 2:1 "sandwich" complex.

Contemporaneous with Flood's first seminal reports, the groups of Craig ${ }^{[51]}$ and $\mathrm{Hecht}^{[52]}$ described the formation of halide templated oligo-triazoles foldamers in solution. Craig's study revealed his tetratriazole oligomer bound chloride the strongest (in $\left[\mathrm{D}_{6}\right.$ ]acetone) with the 1:1 oligomer:anion stoichiometry confirmed 
by Job Plot analysis (Figure 9a). By the incorporation of chiral centres onto the backbone, Hecht was able to probe the chiroptical properties of his foldamer: intriguingly the handedness of the helix depended on which halide was present (Figure 9b).

(a)

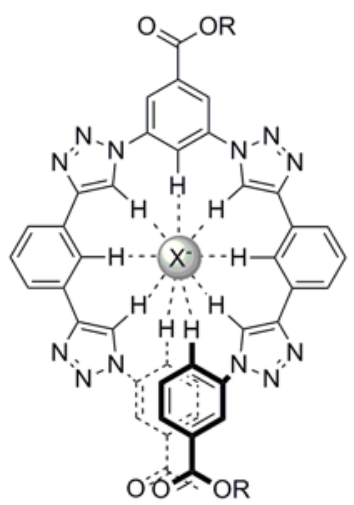

(b)

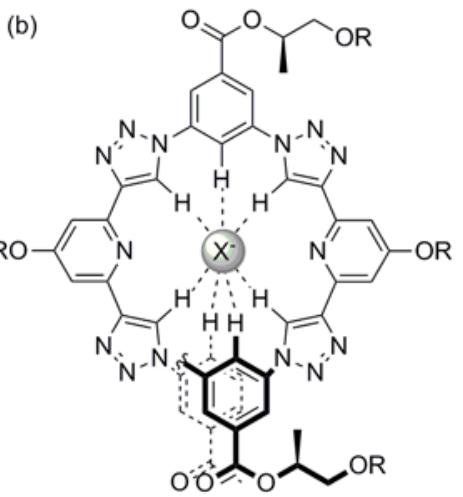

Figure 9. Triazoles as $\mathrm{C}-\mathrm{H}$ hydrogen bond donors in anion templated foldamers: (a) Craig's tetratriazole foldamer and (b) Hecht's chiral oligiotriazole foldamer.

Very recently, Flood and co-workers have demonstrated the ability of an alternative $\mathrm{C}-\mathrm{H}$ bond donor, cyanostilbene, to bind anions. ${ }^{[53]}$ A pentagonal "cyanostar" macrocycle (Figure 10) has been synthesized which binds large anions (e.g. $\mathrm{PF}_{6}{ }^{-}$) as a 2:1 macrocycle/anion sandwich in $3: 2 \mathrm{CD}_{2} \mathrm{Cl}_{2} / \mathrm{CD}_{3} \mathrm{OD}$. The same macrocycle was also incorporated into a [3]rotaxane with a dialkylphosphate axle. Further examples of anion templated rotaxanes will be covered in Section 3.4.

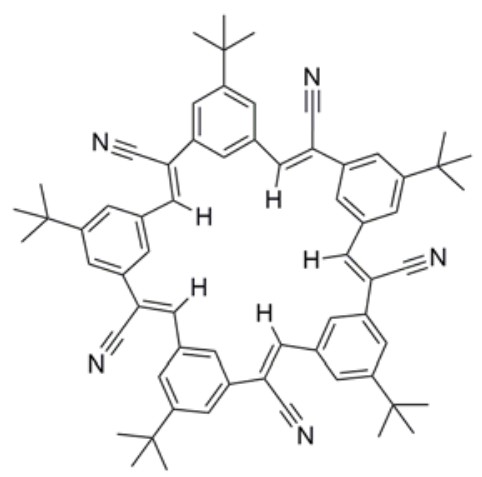

Figure 10. Flood's pentagonal "cyanostar" macrocycle capable of binding large anions in a 2:1 sandwich complex.
Sindelar et al have reported an alternative exploitation of C-H hydrogen bond donors in a family of cyclic glycouril oligomers termed bambus[n]urils (Figure 11). ${ }^{[54]}$ The original bambus[6]uril, was shown crystallographically to hydrogen bond to a chloride anion via $12 \mathrm{C}-\mathrm{H} \cdots \mathrm{Cl}^{-}$hydrogen bonds in the solid state. ${ }^{[54 \mathrm{a}]} \mathrm{An}$ organically soluble analogue was later found to bind halides very strongly in solution (e.g. $K_{\mathrm{a}}\left(\mathrm{I}^{-}\right)=3.8 \times 10^{9} \mathrm{M}^{-1}$ ), albeit in noncompetitive chloroform solvent. ${ }^{[54 \mathrm{~b}]}$

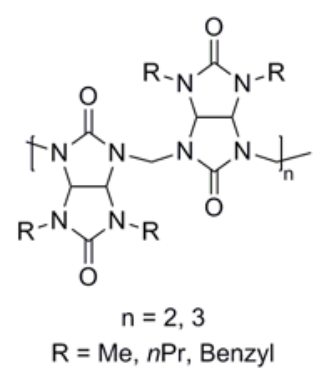

Figure 11. Sindelar's bambus[n]urils capable of the binding of halide anions by $\mathrm{C}-\mathrm{H} \cdot \ldots$ X' hydrogen bonds.

\subsubsection{Binding in aqueous media with neutral hydrogen bond donors}

For medical diagnostics, or for the monitoring of a pollutant in an environmental sample, the ability of a receptor to operate in aqueous media is essential. As already mentioned it has traditionally been believed that synthetic anion receptors solely employing hydrogen bond donors are unable to operate in such arena. However, in the last decade, there have been notable developments in the preparation of neutral receptors capable of functioning in aqueous media.

In a sustained programme of research the group of Kubik has investigated synthetic cyclopeptides containing alternating aromatic and $L$-proline residues that may act as anion receptors in solvent media with exceptionally high aqueous content, even in pure (i.e. $100 \%$ ) water. In their first reports ${ }^{[55]}$ cyclohexapeptide macrocycles were shown to bind anions in 80:20 $\mathrm{D}_{2} \mathrm{O}-\mathrm{CD}_{3} \mathrm{OD}$ solutions. While the macrocycle bound inorganic anions with a 1:1 stoichiometry in pure DMSO, in aqueous solutions, 2:1 association occurred, with the anion being completely desolvated and encapsulated within the sandwich complex (Figure 12a). Furthermore, one of the macrocycles was able to bind sulfate in pure $\mathrm{D}_{2} \mathrm{O}$, admittedly with a modest association constant $\left(K_{\mathrm{a}}=56 \mathrm{M}^{-1}\right){ }^{[56]}$

In subsequent work, covalently linking two cyclopeptides with adipic acid, allowed for "molecular oyster" receptors able to bind sulfate with $\log K_{\mathrm{a}} \sim 5$ in 50:50 $\mathrm{H}_{2} \mathrm{O}-\mathrm{CH}_{3} \mathrm{OH}$ (Figure 12b). ${ }^{[57]}$ The ability of these receptors to operate in such competitive solvent media has been accredited to hydrophobic interactions between the two cyclopeptide rings that encapsulate the bound anion. ${ }^{[58]}$ 


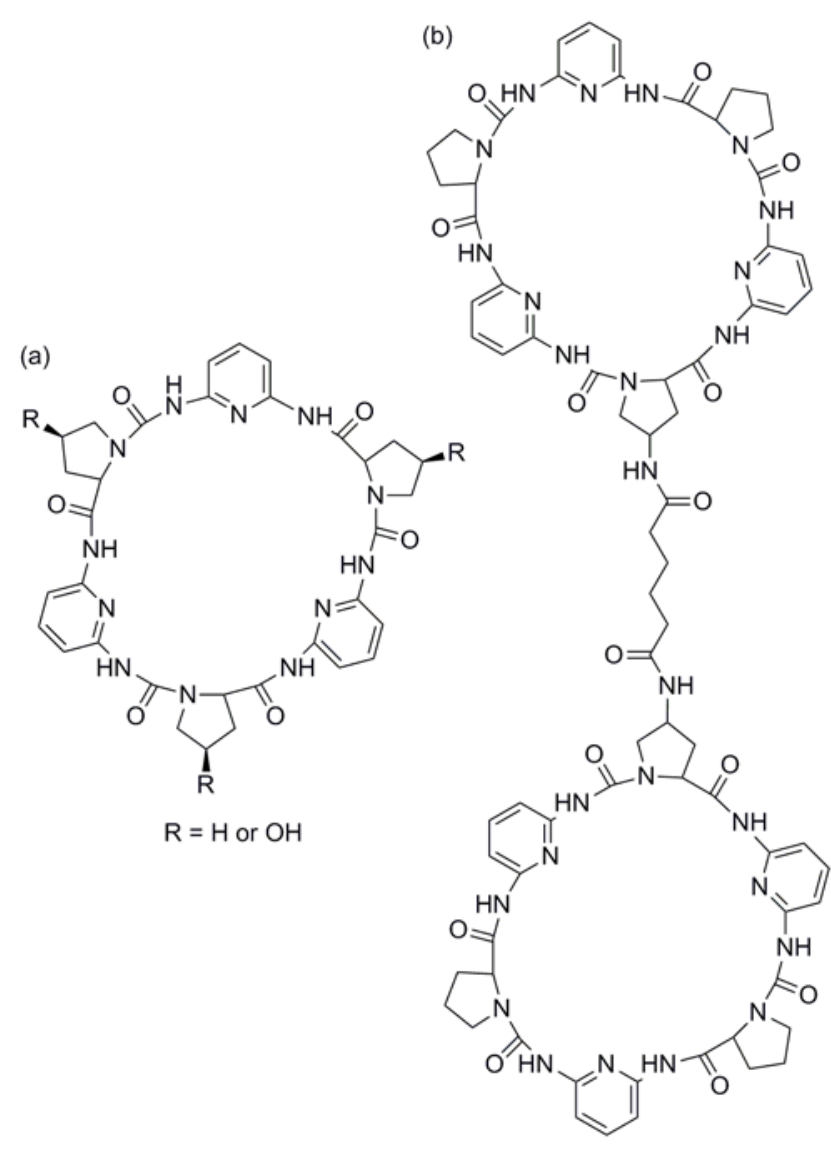

Figure 12. Kubik's cyclopeptide anion receptors: (a) the original hexapeptide macrocycles and (b) two of the macrocycles covalently linked to form a "molecular oyster".

Jeong has reported the formation of indolocarbazole-based foldamers templated by halide anions in water, e.g. $K_{\mathrm{a}}\left(\mathrm{Cl}^{-}\right)=65 \mathrm{M}^{-}$ ${ }^{1}$ (Figure 13). ${ }^{[59]}$ This example is particularly noteworthy, as the required aqueous solubility is being achieved by incorporation of negatively charged carboxylate groups into the structure of the oligomer, which provides an electrostatic repulsive contribution that would oppose the anion binding event.

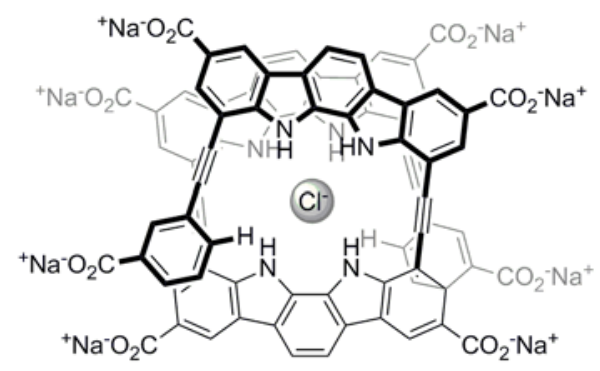

Figure 13. Jeong's water soluble indolocarbazole foldamer.

Gale and co-workers have reported the preparation of dipyrrolylmethane amide receptors capable of binding a range of anions in $\left[\mathrm{D}_{6}\right] \mathrm{DMSO}$ containing $5 \%$ water, and in the case of $\mathrm{H}_{2} \mathrm{PO}_{4}{ }^{-}$(with the receptor where $\mathrm{R}=\mathrm{H}, \mathrm{R}^{\prime}=\mathrm{Me}$ ) in $\left[\mathrm{D}_{6}\right] \mathrm{DMSO}$ containing $25 \%$ water $\left(K_{\mathrm{a}}=234 \mathrm{M}^{-1}\right)$ (Figure 14a). ${ }^{[60]}$ In more recent work, combining indole and urea functionalities has allowed for receptors able to bind anions in $\left[\mathrm{D}_{6}\right] \mathrm{DMSO}$ containing $10 \%$

water, with the binding of $\mathrm{H}_{2} \mathrm{PO}_{4}{ }^{-}$being observed once again in $25 \%$ water solutions $\left(K_{\mathrm{a}}=160 \mathrm{M}^{-1}\right)$ (Figure $\left.14 \mathrm{~b}\right){ }^{[61]}$

(a)

$$
\text { R= } \begin{gathered}
\text { or } \\
\mathrm{R}=\mathrm{Me}, \mathrm{R}^{\prime}=\mathrm{Et}
\end{gathered}
$$

(b)<smiles>[R]c1[nH]c2c(NC(=O)Nc3cccc4c([R])c([R])[nH]c34)cccc2c1[R]</smiles>

Figure 14. Neutral hydrogen bonding receptors capable of binding anions in aqueous DMSO solvent media: (a) dipyrrolylmethane amide and (b) diindolylurea.

The binding of anions in water by neutral hydrogen bond donors is, and will remain, a considerable challenge. ${ }^{[62]}$ For while these few examples demonstrate that receptors with sufficient hydrogen bond donor character can be readily constructed, for such systems to operate in pure water requires sufficient solubility, a property that to date - has proved difficult to concomitantly incorporate.

\subsubsection{Understanding anion complexation vs. deprotonation}

To increase the binding strength of hydrogen bond donors, electron withdrawing groups may be added to a receptor. This increases the acidity of the hydrogen bond donor, which simultaneously increases the likelihood of the receptor being deprotonated, in particular by basic anions such as fluoride or acetate. In depth investigations of this effect have been carried out by the groups of Fabbrizzi ${ }^{[63]}$, Gale ${ }^{[64]}$, and Gunnlaugsson ${ }^{[65]}$ and some illustrative examples are discussed below.

Upon titration of TBAF into DMSO solutions of a simple urea receptor (substituted with electron withdrawing nitrophenyl groups), complex behaviour was observed beyond simple hydrogen bond formation (Figure 15). ${ }^{[66]}$ The first equivalent of fluoride titrated hydrogen bond strongly to the receptor as expected. However, upon addition of a second equivalent deprotonation occurs resulting in the formation of the stable $\mathrm{HF}_{2}{ }^{-}$anion. The solution turns a deep orange due to the formation of a charge transfer state in the deprotonated receptor.

It has been shown that certain amidopyrrole receptors are also sufficiently acidic to be deprotonated. For example, the receptor in Figure 16a was deprotonated by fluoride in $\mathrm{CD}_{2} \mathrm{Cl}_{2} \cdot{ }^{[67]}$ Once again, two equivalents of TBAF were required for proton transfer, to allow for formation of the stable $\mathrm{HF}_{2}^{-}$species. The amido(thio)urea receptor in Figure 16b proved to be so acidic that a greater range of anions caused deprotonation. With fluoride, acetate, benzoate and dihydrogen phosphate, one equivalent of anion was sufficient to induce proton transfer, a process accompanied by the appearance of a new absorption band in the UV-vis spectrum of the receptor. ${ }^{[68]}$ 


$$
\text { (s) }
$$

Figure 15. Hydrogen bonding and subsequent deprotonation of an acidic urea by fluoride.
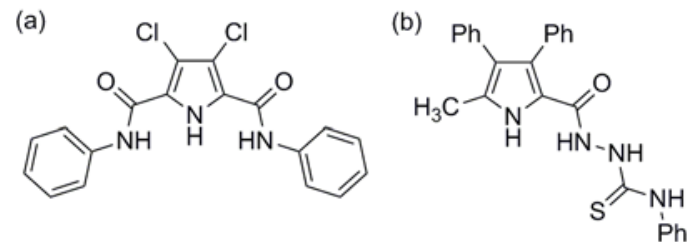

Figure 16. Further acidic receptors deprotonated by basic anions: (a) an amidopyrrole and (b) an amido(thio)urea.

It should be noted that many colorimetric anion sensors previously described are now believed to function via such proton transfer processes. This should always be kept in mind, particularly if the anion guest species is basic such as a carboxylate or fluoride.

An appreciation has also begun to develop that an acidic anion may be deprotonated. Upon titration of excess $\mathrm{TBAH}_{2} \mathrm{PO}_{4}$ into $\left[\mathrm{D}_{6}\right]$ DMSO solutions of butyl diindolylurea receptor (Figure 17) a second set of signals were observed further downfield in the ${ }^{1} \mathrm{H}$ NMR spectrum. This observation was rationalized by hypothesizing that the $\mathrm{p} K_{\mathrm{a}}$ of the bound $\mathrm{H}_{2} \mathrm{PO}_{4}{ }^{-}$is reduced, which allows for proton transfer to unbound anion. Evidence for this is provided by the solid state structure of the phenyl analogue of the receptor (grown in the presence of excess $\mathrm{TBAH}_{2} \mathrm{PO}_{4}$ ) where the coordinated anion is observed to be $\mathrm{HPO}_{4}{ }^{2-[}{ }^{269]}$
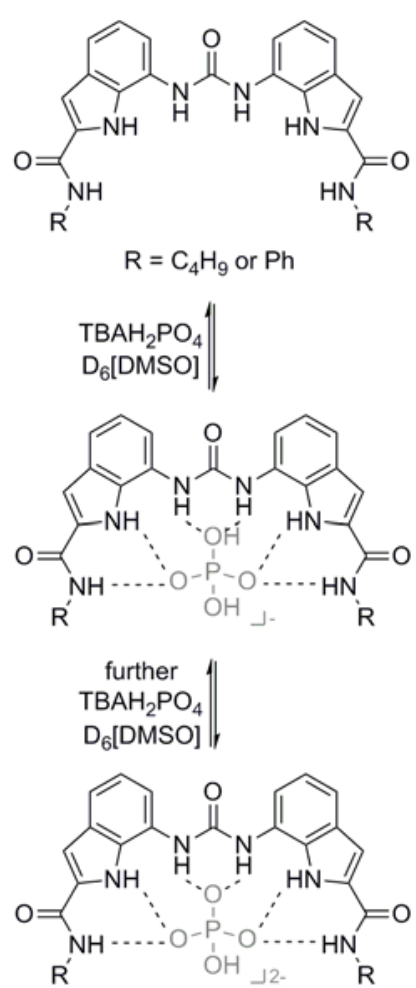

Figure 17. Binding and subsequent deprotonation of dihydrogen phosphate by a diindolylurea receptor.

\subsection{Exploiting New Interactions to Bind Anions}

\subsubsection{Anion- $\pi$ receptors}

The term anion- $\pi$ refers to the attractive force between an electron deficient aromatic $\pi$ system and an anion. ${ }^{[70]}$ It is believed that the interaction principally consists of electrostatic forces and ion-induced polarization. The electrostatic contribution requires the arene to possess a positive quadrupole moment, thus demanding the arene rings to be substituted with electron withdrawing substituents.

Evidence for anion- $\pi$ interactions in the solution phase has only recently been acquired. ${ }^{[71]}$ For example, Berryman and co-workers prepared two molecules each containing a sulfonamide hydrogen bond donor, where one possessed a neighbouring pentafluorophenyl ring, while the other had an unfluorinated phenyl ring (Figure 18a). ${ }^{[72]}$ In $\mathrm{CDCl}_{3}$ they observed no binding of halides with the unfluorinated species. Crucially, weak binding of halides $\left(K_{\mathrm{a}}=20\right.$ $35 \mathrm{M}^{-1}$ ) was noted with the pentafluorophenyl species. In subsequent work, Berryman has demonstrated it is possible to recognize halides solely using anion- $\pi$ interactions (Figure 18b). ${ }^{[73]}$ The substitution pattern of the nitro groups prevents halide anions from hydrogen bonding to the molecule. Despite this, binding of the halides $\left(K_{\mathrm{a}}=\right.$ 26-53 $\mathrm{M}^{-1}$ ) was observed in $\mathrm{C}_{6} \mathrm{D}_{6}$. The unsubstituted, protic analogue, which is capable of hydrogen bonding (but not of anion- $\pi$ interactions) possesses no affinity for the halide anions. Wang et al have reported upon the ability of an electron deficient tetraoxacalix[2]arene[2]triazine receptor to bind halide anions (Figure 18c). ${ }^{[74]}$ The bis-chloro substituted macrocycle can bind chloride $\left(K_{\mathrm{a}}=4036 \mathrm{M}^{-1}\right)$ in $\mathrm{CH}_{3} \mathrm{CN}$, while no binding was observed with the proto-analogue, consistent with a binding mode based on anion- $\pi$ interactions. 
(a)

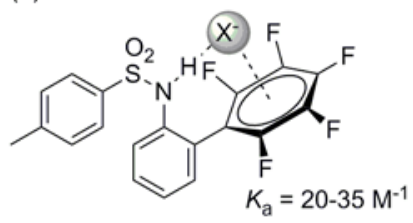

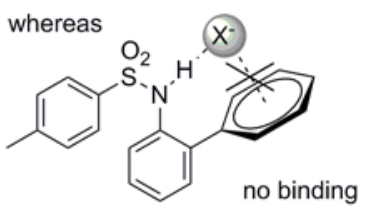

(b)

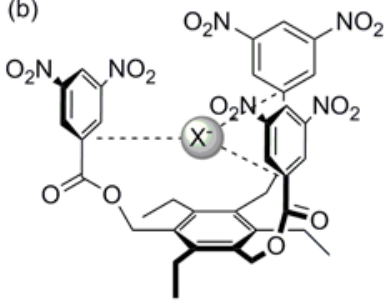

$K_{\mathrm{a}}=26-53 \mathrm{M}^{-1}$

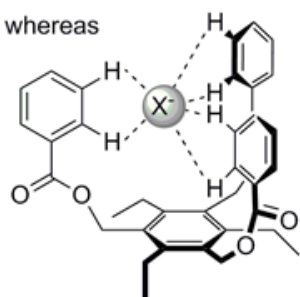

no binding (c)

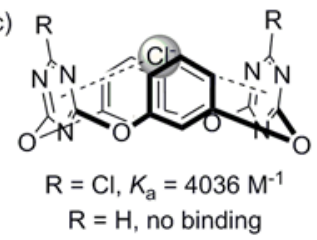

Figure 18. Evidence of anion- $\pi$ interactions binding halide anions in solution: (a) by augmenting hydrogen bonds and (b) \& (c) by interacting solely via anion- $\pi$ contacts.

An anion- $\pi$ prismatic receptor has very recently been studied by Wasielewski and Stoddart (Figure 19). ${ }^{[75]}$ The trisnaphthalenediimide trigonal prism was shown to bind the $\mathrm{I}_{3}{ }^{-}$anion with an association constant, $K_{\mathrm{a}}=25 \mathrm{~L} \mathrm{~mol}^{-1}$ in $\mathrm{CD}_{2} \mathrm{Cl}_{2}$. A solid state structure determination confirms that the anion resides within the prismatic cavity.

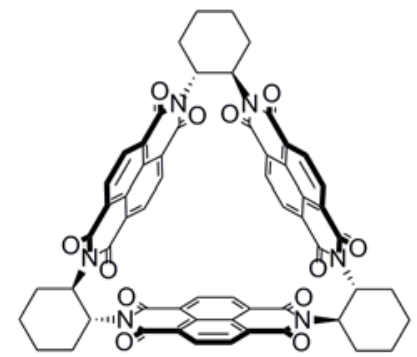

Figure 19. Structure of tris-napthalenediimide trigonal prism capable of binding the triiodide anion by anion- $\pi$ interactions.

Anion- $\pi$ interactions have perhaps been most notably exploited in the construction of anion- $\pi$ slides by Matile and co-workers, systems which are capable of the transmembrane transportation of anionic species. ${ }^{[76]}$ This work will be covered in Section 5.3 of this review.

\subsubsection{Halogen bonding receptors}

Halogen bonding may be represented by $\mathrm{Y}-\mathrm{X} \cdots \mathrm{D}$, where $\mathrm{X}$ is an electrophilic halogen atom, $\mathrm{D}$ is a donor of electron density and $\mathrm{Y}$ is another atom (e.g. $\mathrm{C}$ or $\mathrm{N}$ ). ${ }^{[77]}$ Halogen bonds arise from the appearance of a $\sigma$-hole at the $\mathrm{X}$ end of the $\mathrm{Y}$-X bond, into which electron density may be donated. The strength of the halogen bond follows the trend $\mathrm{X}=\mathrm{I}>\mathrm{Br}>\mathrm{Cl}>>\mathrm{F}$. As the electron poor region sits on the $\mathrm{X}$ pole region of the $\mathrm{Y}-\mathrm{X}$ bond, the halogen bond is considered highly directional, as usually evidenced - but not always $^{[78]}$ - in the solid state. The halogen bonding interaction has perhaps been most often employed in crystal engineering and liquid crystals. It is perhaps surprising that only in very recent times that the application of halogen bonding to anion recognition has begun to be realized.

Taylor and co-workers constructed a receptor containing a convergent array of halogen bond donors, by incorporation of orthosubstituted iodotetrafluroroarenes on to a 2, 4, 6-trimethylbenzene scaffold (Figure 20a). ${ }^{[79]}$ In acetone, this receptor was demonstrated to bind halide anions $\mathrm{Cl}^{-}>\mathrm{Br}^{-}>\mathrm{I}^{-}$, while not exhibiting affinity for the oxoanions $\mathrm{HSO}_{4}{ }^{-}$and $\mathrm{NO}_{3}{ }^{-}$.

By utilizing electrostatics it is possible to achieve anion binding in much more competitive solvent media. Such charge assisted halogen bonding is exhibited by the bidentate bromoimidazoliophane in Figure 20b. ${ }^{[80]}$ The syn isomer is capable of the selective binding of bromide in 9:1 $\mathrm{CD}_{3} \mathrm{OD}-\mathrm{D}_{2} \mathrm{O}$. The protic, hydrogen bonding analogue (which lacks syn/anti isomerism), exhibits weak, unselective binding of halide anions. Analogous halogen bonding naphthalene containing macrocycles have also been prepared; in these examples the syn-iodo and bromo macrocycles are able to selectively sense via fluorescence bromide and iodide respectively in 9:1 $\mathrm{CD}_{3} \mathrm{OD}-\mathrm{D}_{2} \mathrm{O} .^{[81]}$ A simple iodoimidazolium has also been investigated (Figure 20c), and shown to selectively bind $\mathrm{H}_{2} \mathrm{PO}_{4}{ }^{-}$in $\left[\mathrm{D}_{6}\right] \mathrm{DMSO}{ }^{[82]}$ Once again the protic analogue exhibits weak, unselective binding of the anions investigated. A comprehensive isothermal calorimetric study of anion binding with bis-iodoimidazolium systems (Figure 20d) has also been carried out in a range of organic solvents. In this work, the entropic contribution to the overall free energy of binding was found to be very important. ${ }^{[83]}$ (a)

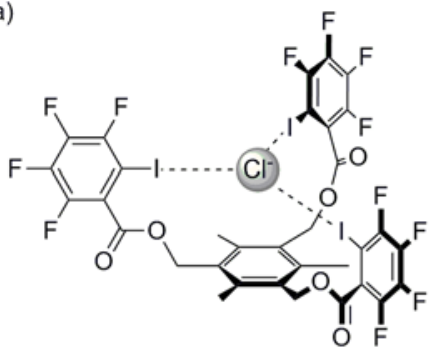

(c)

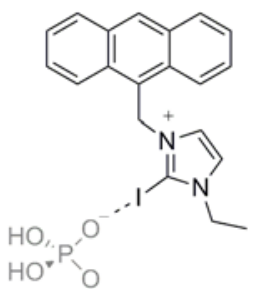

(b)

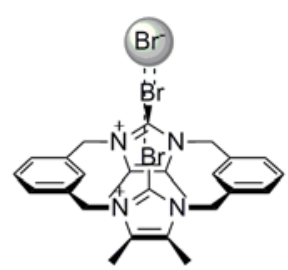

(d)

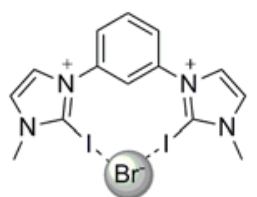

Figure 20. Examples of receptors employing halogen bonds: (a) convergent iodotetrafluoroarenes; (b) bidentate bromoimidazoliophane; (c) monodentate iodoimidazolium and (d) bidentate iodoimidazolium. 
The simultaneous employment of halogen and hydrogen bonding to achieve anion binding has also been demonstrated. Taylor and co-workers measured the contribution of halogen bonding to the free energy of anion binding in a bisiodoperfluorobenzoyl substituted urea by comparison to a perfluorobenzoyl analogue in $\mathrm{CD}_{3} \mathrm{CN}^{\left[{ }^{[8]}\right.}$ They observed a significantly greater halogen bonding contribution was observed for the halides in comparison to dihydrogen phosphate (Figure 21).

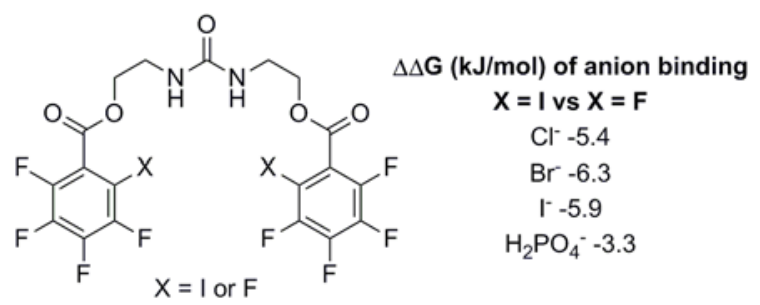

Figure 21. Structures of bis-substituted ureas used by Taylor to calculate contribution of halogen bonding to anion binding.

\section{Anion Templation}

Up to a decade ago, the use of anionic species as templates in self-assembly had been very much in its infancy, with the majority of examples being of the serendipitous kind. Inspection of the literature from this time reveals various isolated, underdeveloped cases such as Mingos' cage ${ }^{[85]}$ and Lehn's helicate ${ }^{[86]}$ (Figure 22), as well as an earlier report by Hawthorne on the role of chloride in the synthesis of anion binding mercuraborane macrocycles. ${ }^{[87]}$
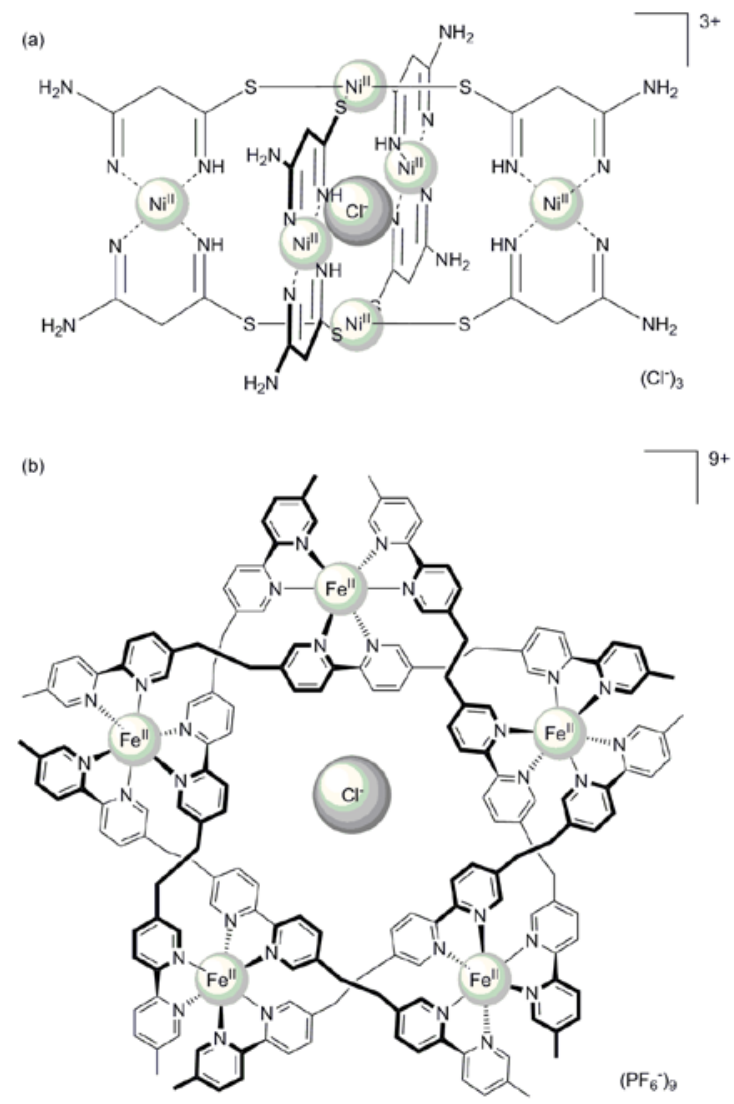

Figure 22. Early examples of anion templation: (a) Mingos' cage and (b) Lehn's helicate.
In the following years, the preparation of a significant number of anion templated molecules has been reported. Salient examples are now discussed with focus being specifically on structures constructed by strategic anion templation. Reviews containing more detailed information on serendipitously produced molecular architectures may be found elsewhere. ${ }^{[88]}$

Traditionally templated synthesis has involved a considered iterative process based on design, manufacture, assessment and redesign (possibly aided by computer modelling). However the advent of dynamic combinatorial chemistry (DCC) provides a powerful alternative strategy. ${ }^{[89]}$ By the DCC approach, a suitably chosen set of building blocks, which may continuously interconvert, is prepared. The addition of a template (e.g. an anion) to this dynamic combinatorial library (DCL) will lead to a shifting of the dynamic equilibria present, driven by the requirement to minimize the free energy of the entire library, resulting in the amplification of certain product member(s) of the DCL, which may then in turn be isolated. Both of these methodological concepts have been utilized in the construction of the anion templated molecules that have been realized in the last ten years.

\subsection{Anion Templated Dimeric Complexes and Capsules}

The use of anions, with multidentate ligands, to template the formation of dimeric structures has been notably exploited in recent years.

For example. Wu and Yang have reported a co-planar acyclic tris-urea ligand that assembles a 2:1 (L:A) complex with either phosphate or sulfate in aqueous-DMSO solutions (Figure 23a). ${ }^{[90]}$ Sulfate was shown by Schubert and co-workers to template the formation of a 2:1 (L:A') complex with a triazole-triazolium ligand in acetonitrile by a combination of hydrogen bonding and electrostatic interactions (Figure 23b). ${ }^{[91]}$ Interestingly, the bistriazolium analogue only formed a 1:1 complex with sulfate.

(a)<smiles>O=C(Nc1ccc([N+](=O)[O-])cc1)Nc1ccccc1NC(=O)Nc1ccccc1NC(=O)Nc1ccccc1NC(=O)Nc1ccccc1NC(=O)Nc1ccccc1NC(=O)Nc1ccc([N+](=O)[O-])cc1</smiles>

(b)

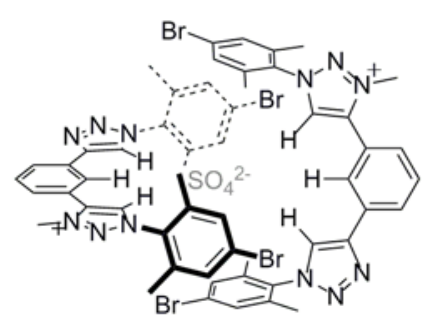

Figure 23. Examples of anion templated "complexes" using flat ligands: (a) Wu and Yang's phosphate template tris-urea dimer and (b) Schubert's sulfate templated triazole-triazolium dimer. 
Two classes of tripodal ligands have been widely utilized for anion templated dimeric "capsule" formation, (a) tris-functionalized tri-alkylbenzenes ${ }^{[92-94]}$ and (b) those based on functionalizing tris(2-aminoethyl)amine or "tren" ${ }^{[95-97]}$.

A representative example of the first class of tripodal ligands is provided by Steed and co-workers' zwitterionic tris-pyridinium carboxylate receptor (Figure 24a). ${ }^{[92]}$ A single bromide anion can be encapsulated by two equivalents of the ligand, being augmented by $\mathrm{C}-\mathrm{H} \cdots \cdot \mathrm{Br}^{-}$hydrogen bonds as identified by X-ray crystallography. In comparison, examples based on functionalized tren, typically form dimeric complexes templated by polyatomic anions such as phosphate or sulfate. This is exemplified by the tri-thio urea of Das et al, which co-ordinates to phosphate by twelve hydrogen bonds, once again verified by X-ray crystallography (Figure 24b). ${ }^{[95]}$

(a)

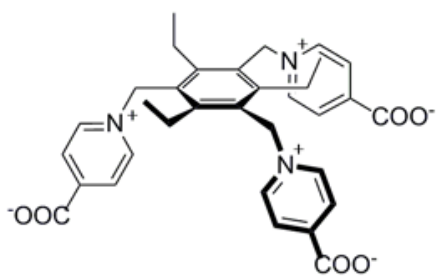

(b)

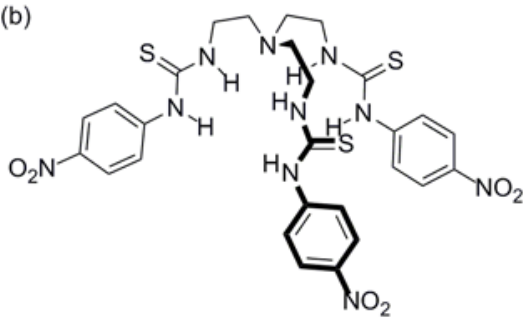

Figure 24. Examples of ligands used in the preparation of anion templated "capsules" using tripodal ligands: (a) Steed's trisethylbenzene tris-pyridinium ligand and (b) Das' tris-tren tris-urea ligand.

It is noteworthy that the use of tren based ligands in industrially useful anionic extraction processes has been demonstrated. Details of these reports can be found in Section 6.2.

\subsection{Anion Templated Macrocycles}

The exploitation of anions to template the synthesis of macrocyclic species has been intensely studied over the last decade. Here, it is notable, that from using simple spherical halide anions, the use of (inorganic and organic) polyatomic anions is now being pursued.

The role of chloride in the formation of a bis-imidazolium macrocycle was reported by Alcalde and co-workers (Figure 25). ${ }^{[98]}$ Their investigations confirmed that cyclization is accelerated by a factor of ten in the presence of chloride, it being proposed the halide anion hydrogen bonds to the imidazole and imidazolium moieties, thus supporting the arrangement of the molecule in a cyclic-shaped transition state which leads to formation of the macrocyclic product.

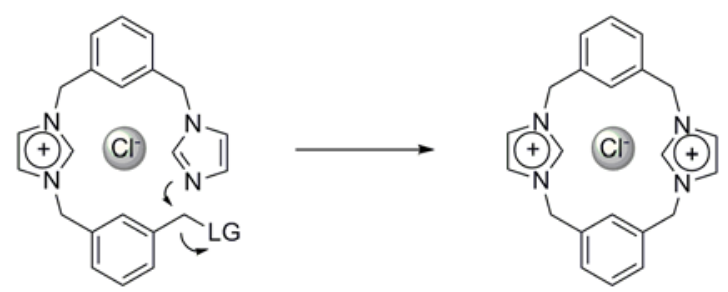

Figure 25. Alcalde's study of the template effect using a chloride anion.

Chloride templation has also been demonstrated by Böhmer and co-workers in the preparation of a remarkable cyclic hexa-urea macrocycle. ${ }^{[99]}$ Reacting the diamine and diisocyanate, depicted in Figure 26, in acetonitrile simply yields the tri-urea macrocycle. However, in dichloromethane the hexa-urea macrocycle is also isolated in a yield of $20 \%$. A crystal structure of this macrocycle (grown in the presence of $\mathrm{TBACl}$ ), revealed a figure-of-eight conformation encapsulating two chloride anions. Evidence of the templating role of chloride in this macrocyclization was provided by the addition of two equivalents of chloride to the reaction mixture, which switched the ratio of formation of the two macrocycles (as determined from crude ${ }^{1} \mathrm{H}$ NMR spectra) from 5:1 to 1:5. Notably, using bromide instead of chloride, the ratio was found to be $1: 3$, and with iodide no difference from the halide-free conditions was observed.

The group of Sessler has reported upon the role of the acid counter-anion in the reaction of a 2, 6-diamidopyridine bis-amine and diformylbipyrrole. ${ }^{[100]}$ The use of hydrochloric or hydrobromic acid resulted in a complicated mixture of products, whereas sulfuric acid led to the formation of the $[2+2]$ macrocycle depicted in Figure 27 in $90 \%$ yield, aided by the dynamic nature of the imine bond in acidic conditions. Upon standing, as the free base in the presence of $\mathrm{TBAHSO}_{4}$ or $\mathrm{TBAH}_{2} \mathrm{PO}_{4}$, this [2+2] macrocycle converts into the larger [3+3] macrocycle, which is the major product if phosphoric acid is used in the original reaction. Anion binding studies in acetonitrile revealed that both macrocycles bound $\mathrm{H}_{2} \mathrm{PO}_{4}{ }^{-}$and $\mathrm{HSO}_{4}{ }^{-}$(both tetrahedral anions) the strongest amongst a range of singly charged anions, including the more basic acetate oxoanion. 
<smiles>CC(C)(C)c1cc(N)c2c(c1)C(C)(C)c1cc(C(C)(C)C)cc(NC(=O)Nc3cc(C(C)(C)C)cc4c3Oc3c(N)cc(C(C)(C)C)cc3C4(C)C)c1O2</smiles>

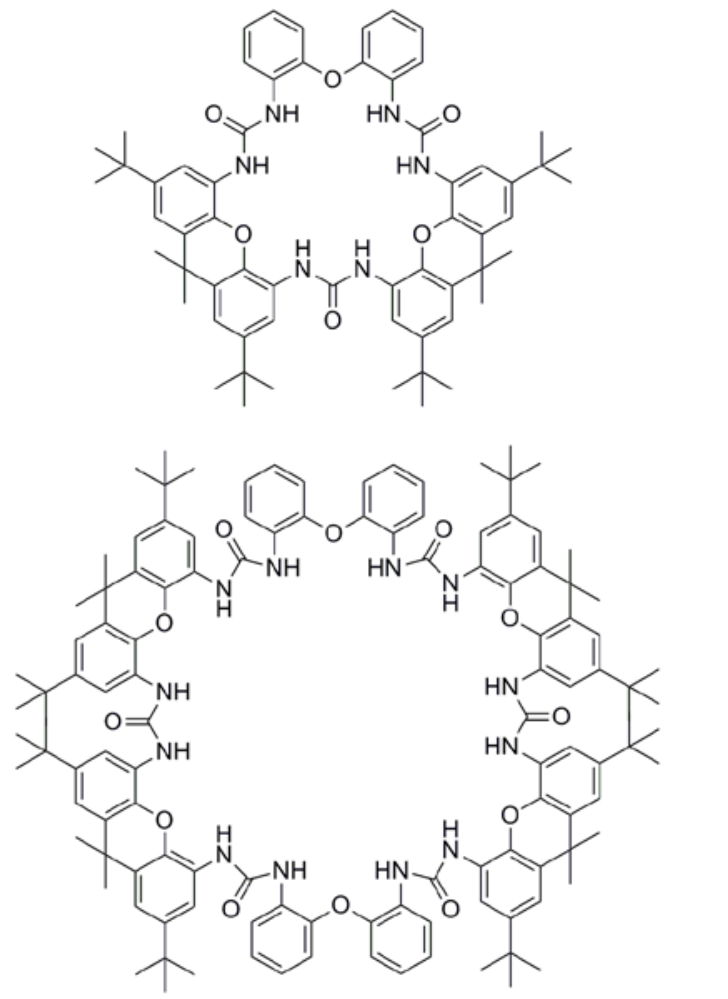

Figure 26. Böhmer's tri- and hexa-urea macrocycles, the latter of which is capable of binding two chloride anions in a figure-of-eight conformation.

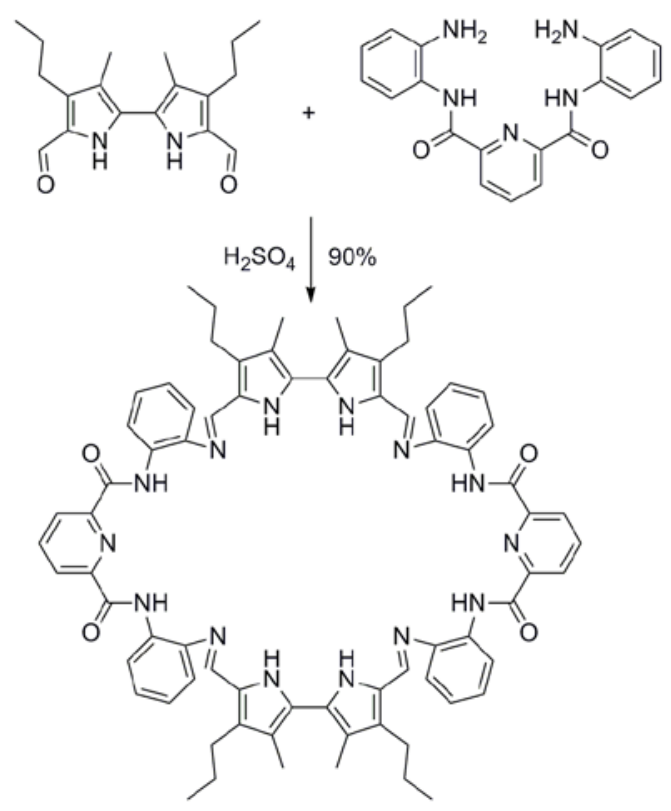

Figure 27. The sulfate-templated synthesis of a [2+2] macrocycle.
Alfonso, Luis and co-workers have thoroughly investigated the anion templated synthesis of pseudo-peptidic macrocycles using aromatic dicarboxylates as templates (Figure 28). ${ }^{[101]}$ Bis(amidoamines) and aromatic dialdehyde precursors were allowed to react in the presence of a dicarboxylate template, to form tetraimine macrocycles which were isolated after in situ reduction of the imine bonds. A notable achievement of this templation strategy is the preparation of "structurally disfavoured" macrocycles. ${ }^{[101 c]}$ This involved taking specific chiral bis-amines which when reacted with 1, 4-bis-benzenealdehyde without the dicarboxylate template simply form a mixture of long-chain oligomers, whilst their stereoisomers spontaneously macrocyclized. The addition of the dicarboxylate template to the reactions of the "disfavoured" substrates led to the formation of the [2+2] macrocyclic product. More recently, replacing the 1,4-bis-aldehyde with 1,3,5-trisbenzaldehyde, and switching the dicarboxylate for a tris-carboxylate template, has enabled the efficient synthesis of macrocyclic cages. ${ }^{[101 \mathrm{~d}]}$<smiles>[R]C(N)C(=O)NCCNC(=O)C([R])NCCNC(=O)C([R])N</smiles><smiles>[R]C(N=Cc1ccc(C=NC([R])C(=O)NCCNC(=O)C([R])N=Cc2ccc(C(=O)O)cc2)cc1)C(=O)NCCNC(=O)C([R])N=Cc1ccc(C(=O)O)cc1</smiles>

Figure 28. Alfonso and Luis' dicarboxylate templated synthesis of pseudopeptidic macrocycles.

\subsection{Anion Templated Metallo-Organic Cages}

Contemporarous with Mingos' chloride templated cage described above, McCleverty and Ward described the formation of a tetrahedral metallo-organic cage templated by a tetrafluoroborate anion (Figure 29). ${ }^{[102]}$ The $\left[\mathrm{M}_{4} \mathrm{~L}_{6}\right]^{8+}$ cage consists of four $\mathrm{Co}^{\mathrm{II}}$ cations at the tetrahedron vertices, with a bis-pyrazolyl-pyridine ligand on each edge. The tetrafluoroborate anion occupies the central cavity and forms multiple hydrogen bonds to the methylene protons of the bridging ligands. Later more detailed solution NMR experiments definitively proved anion templation, by revealing the cage was formed only upon addition of the $\mathrm{BF}_{4}{ }^{-}$anion to a mixture of $\mathrm{Co}^{\mathrm{II}}$ and the ligand. ${ }^{[103]}$ Since these reports a cage that is formed as a single diastereoisomer has been prepared by use of a chiral bridging ligand. ${ }^{[104]}$ 


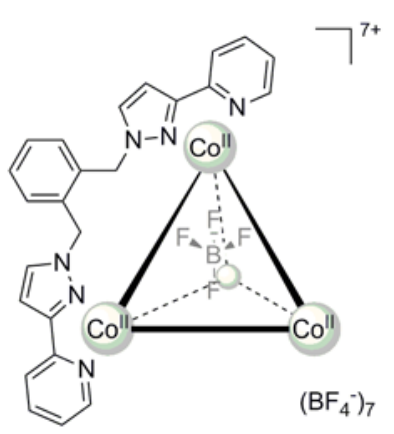

Figure 29. Ward's original tetrafluoroborate templated $\left[\mathrm{Co}_{4} \mathrm{~L}_{6}\right]^{8+}$ tetrahedral cage.

Ward's original system represents an example of serendipitously discovered anion templation. The group of Custelcean, in collaboration with the computationalist Hay, prepared a rationally designed $\left[\mathrm{M}_{4} \mathrm{~L}_{6}\right]^{8+}$ tetrahedral cage templated by a sulfate anion which it strongly binds $\left(K_{\text {app }} \sim 6 \times 10^{6} \mathrm{M}^{-1}\right)$ (Figure 30). ${ }^{[105]}$ In this example, each ligand molecule contains a urea unit, capable of acting as a bidentate hydrogen bond donor. These were calculated and found by crystallography - to form twelve hydrogen bonds to the templating sulfate anion. A very similar sulfate templated cage has also been published by Kaifer and co-workers. ${ }^{[106]}$

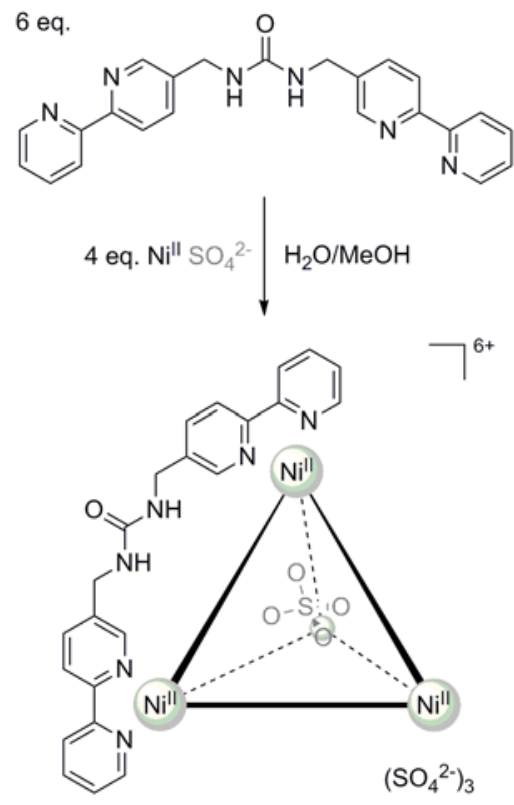

Figure 30. Synthesis of Custelcean and Hay's rationally designed sulfate templated $\left[\mathrm{Ni}_{4} \mathrm{~L}_{6}\right]^{8+}$ tetrahedral cage.

The resulting topologies of anion templated metallo-organic cages are very often unexpected and not simply limited to tetrahedra. As an illustration, Steel has reported a flat prismatic “disc-like" $\left[\mathrm{Ag}_{6} \mathrm{~L}_{2}\right]^{6+}$ cage ( $\mathrm{L}=$ hexa(2-pyridyl)[3]radialene), where a fluoride anion is encapsulated (Figure 31a). ${ }^{[107]}$ Fluoride is believed to act as template, due to the halide anion's encapsulation and the lack of a discrete fluoride anion in the reagents used to prepare the cage. More recently, Su and co-workers have found that a T-shaped pyridyl-bisphosphine ligand, will form "nanotube" $\left[\mathrm{Ag}_{6} \mathrm{~L}_{6}\right]^{6+}$ cages in the presence of $\mathrm{SbF}_{6}{ }^{-}$; the encapsulation of two anions was proved by crystallography (Figure $31 \mathrm{~b}){ }^{[108]}$ (a)

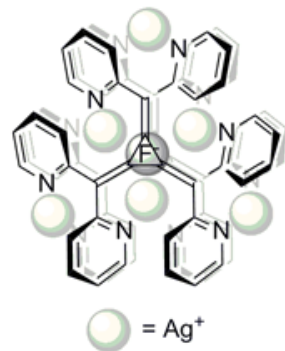

(b)

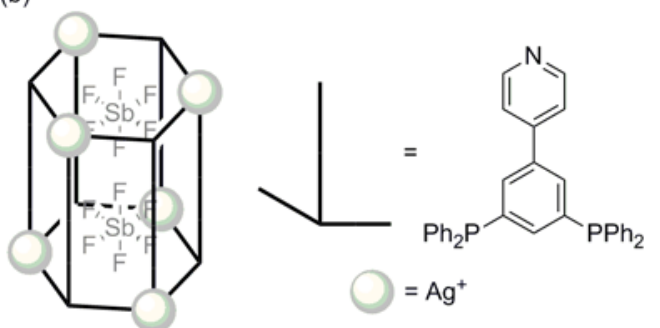

Figure 31. Further examples of anion templated metallo-organic cage formation: (a) Steel's "disc-like" $\left[\mathrm{Ag}_{6} \mathrm{~L}_{2}\right]^{6+}$ cage (viewed from above) and (b) Su's "nanotube" $\left[\mathrm{Ag}_{6} \mathrm{~L}_{6}\right]^{6+}$ cage.

Recent work on anion responsive metallo-organic cages represents one of the most interesting developments in anion supramolecular chemistry. Discussion of this topic is to be found at the very end of this review (Section 6.3.3).

\subsection{Anion Templated Rotaxanes and Catenanes}

Two of the most aesthetically pleasing classes of molecules in chemistry are catenanes and rotaxanes. A catenane is a compound that consists of two or more rings that are mechanically interlocked, while a rotaxane consists of one or more macrocycles threaded over an axle, with bulky stopper groups on the axle component preventing dethreading. The first high yielding syntheses of such species employed either copper (I) cation templation ${ }^{[109]}$ or donoracceptor aromatic interactions. ${ }^{[110]}$ The first example of an anion templated synthesis of a rotaxane was reported by Vögtle: a phenoxide "half-axle" component, being held in place by hydrogen bonding to a macrocyclic isophthalamide motif, was trapped by a half-stopped benzylic electrophile, with the anionic template being consumed in the synthesis of the interlocked structure (Figure 32). [111] 

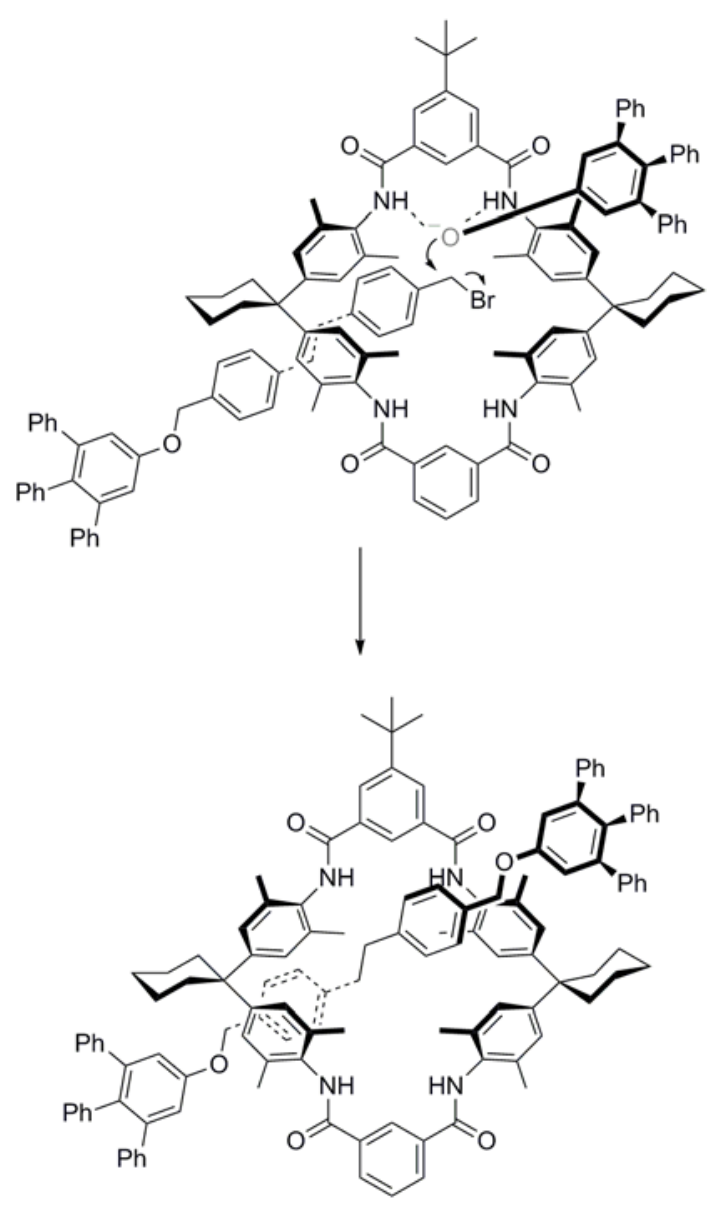

Figure 32. Vögtle's anion templated rotaxane synthesis.

Related rotaxanes have since been prepared by Schalley, where a phenolate-containing thread once again forms a hydrogen bond to an isophthalamide macrocycle, but stoppering in this case furnishes the interlocked structure with the phenolate remaining intact (Figure 33). ${ }^{[112]}$

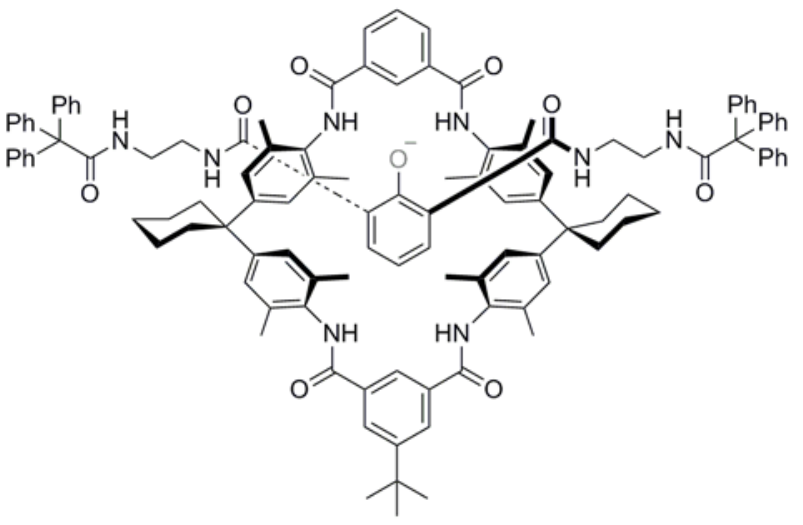

Figure 33. Schalley's phenoxide rotaxane.

In an approach, inspired by that of Sauvage's copper (I) templated methodology, Beer and co-workers synthesized interlocked structures by use of a spherical chloride anion template (Figures $34 \& 35$ ). ${ }^{[113]}$ In preparing the rotaxane ${ }^{[114]}$ and (in what was the first example of an anion templated) catenane ${ }^{[115]}$ species, the chloride anion is held as part of a tight ion pair with a methyl pyridinium bis-amide motif. The halide anion is coordinatively unsaturated, meaning a second, neutral, isophthalamide hydrogen bond donating species can associate, to create an orthogonal array. This assembly is supported by supplementary aromatic donoracceptor interactions and hydrogen bonding. The use of Grubbs' ring closing metathesis catalyst facilitated the [2]rotaxane and [2]catenane being isolated in $47 \%$ and $45 \%$ yields respectively. The necessity of the chloride anion template is demonstrated by no interlocked product being observed in either case, when the hexafluorophosphate salt of the methyl pyridinium component is used. Upon exchange of the chloride anion for the non-coordinating hexafluorophosphate anion, it was shown that the resulting unique interlocked cavities selectively bound chloride over more basic oxoanions such as dihydrogen phosphate and acetate in competitive $\mathrm{CDCl}_{3}-\mathrm{CD}_{3} \mathrm{OD}$ solvent mixtures.
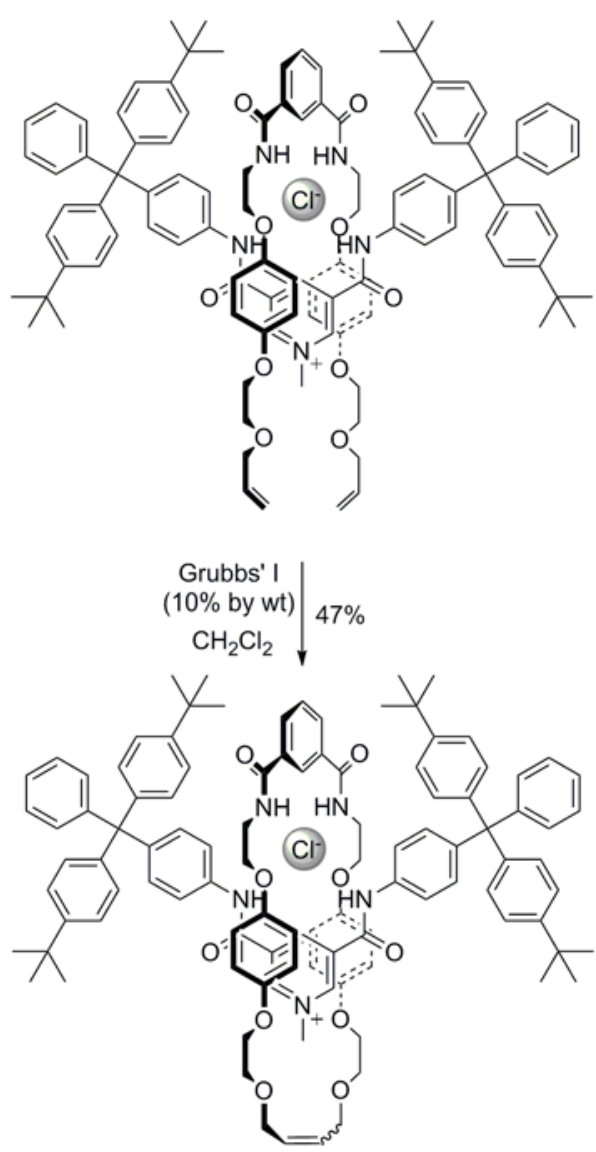

Figure 34. Beer's first synthesis of a chloride templated rotaxane. 


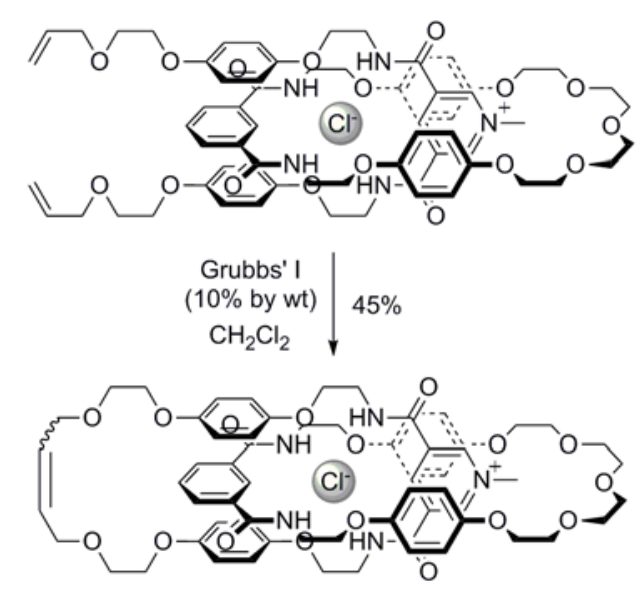

Figure 35. Beer's first synthesis of a chloride templated catenane.

Very recently, bis-triazole pyridinium analogues of these species have been prepared, with both the rotaxane ${ }^{[77]}$ and catenane ${ }^{[78]}$ showing selectivity for the halides $\left(\mathrm{Cl}^{-}\right.$to $\left.\mathrm{I}^{-}\right)$over dihydrogen phosphate in $1: 1 \mathrm{CDCl}_{3}-\mathrm{CD}_{3} \mathrm{OD}$. The pyridinium axle motifs have also been exchanged for imidazolium ${ }^{[118]}$ and triazolium ${ }^{[119]}$ in the construction of further rotaxanes. A rotaxane has also been synthesized where the axle component - an iodo-triazolium coordinates to the halide anion by means of a halogen bond (Figure 26). ${ }^{[120]}$ The hexafluorophosphate salt of the iodo-triazolium rotaxane bound the halides in the order $\mathrm{I}^{-}>\mathrm{Br}^{-}>\mathrm{Cl}^{-}$in 45:45:10 $\mathrm{CDCl}_{3}-\mathrm{CD}_{3} \mathrm{OD}-\mathrm{D}_{2} \mathrm{O}$. The authors attributed this trend to the accessibility of the molecular cavity and the weaker competition for the more lipophilic halide by the aqueous solvent media.

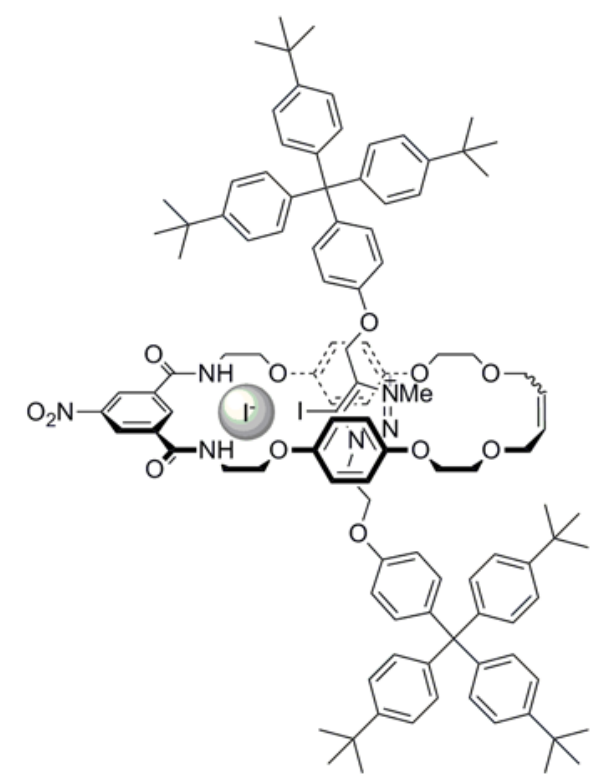

Figure 36. Beer's halogen bonding, iodide selective, iodo-triazolium rotaxane.

Beer and co-workers have also reported upon double cyclization strategies for preparing doubly charged [2]catenanes. For example, two equivalents of methyl pyridinium precursor were templated by one equivalent of chloride anion allowing for catenane formation with a yield of $78 \%$ (Figure 37). ${ }^{[121]}$ Further catenanes have been prepared by cyclizing pyridinium nicotinamide precursors around sulfate ${ }^{[122]}$ and bromo-imidazolium precursors around bromide ${ }^{[123]}$ (Figure 38).

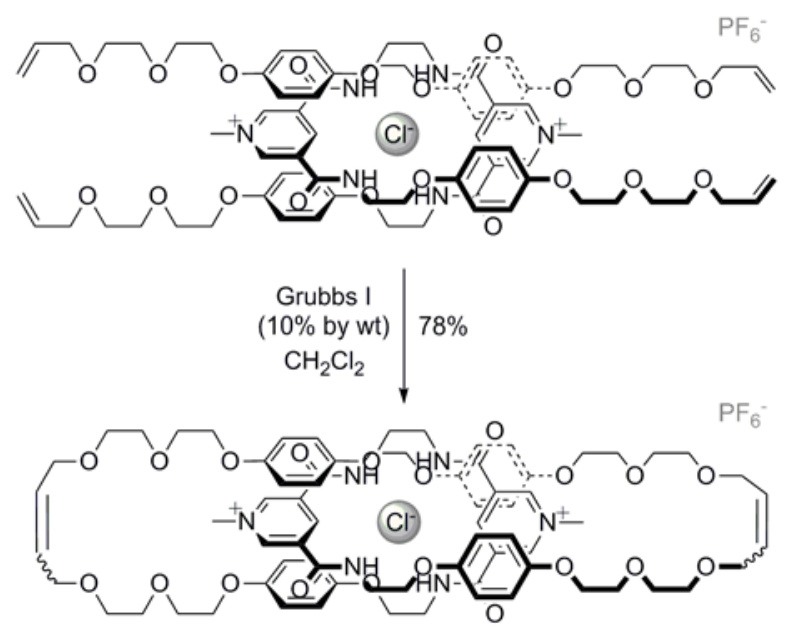

Figure 37. Chloride anion templated [2]catenane synthesis by double cyclization of methyl pyridinium precursors.

(a)

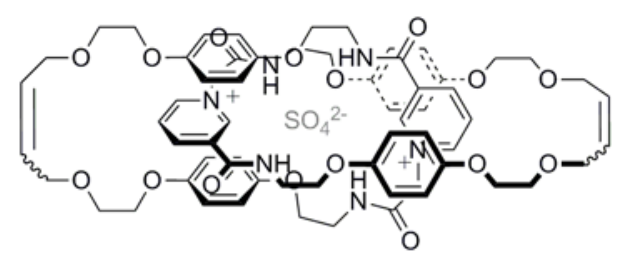

(b)

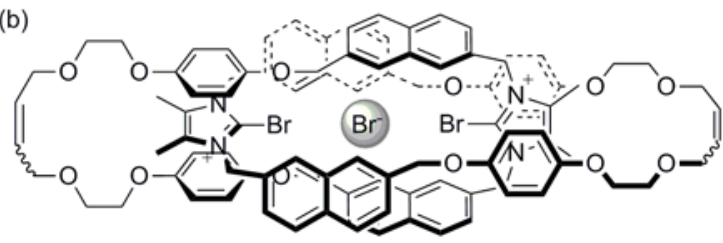

Figure 38. Structures of [2]catenanes prepared by double cyclization around sulfate and bromide templates.

The power of halide anion templation is elegantly demonstrated by the production of exotic structures including a "handcuff" catenane $^{[124]}$ and a "Janus" rotaxane ${ }^{[125]}$ (Figure 39). In both cases, the essential role of the chloride template was demonstrated by the failure to form the product when the hexafluorophosphate salts of the pyridinium precursors were used. 


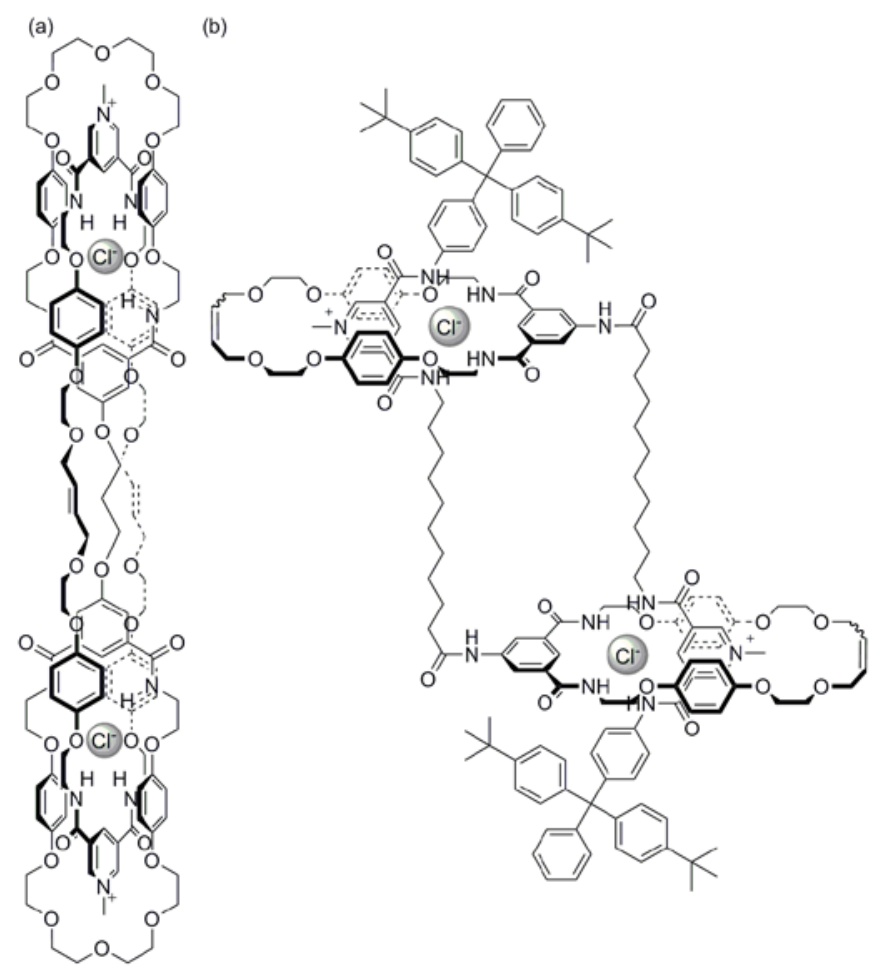

Figure 39. Chloride templated (a) "handcuff" catenane and (b) "Janus" rotaxane.

However, Grubbs' catalysts are expensive and intolerant of certain functionality (e.g. pyridyl). An alternative methodology has therefore been developed, where a bis-amine is reacted with a bisacid chloride in the presence of an axle or macrocycle to produce a rotaxane $^{[126]}$ or catenane ${ }^{[127]}$ (Figure 40 ). This method was exploited in the synthesis of a doubly charged rotaxane (produced by methylation of the pyridyl rotaxane in Figure 40), which was capable of selectively binding chloride in 65:35 [D $\left[\mathrm{D}_{6}\right.$ ]acetone$\mathrm{D}_{2} \mathrm{O} .^{[126 \mathrm{~b}]}$
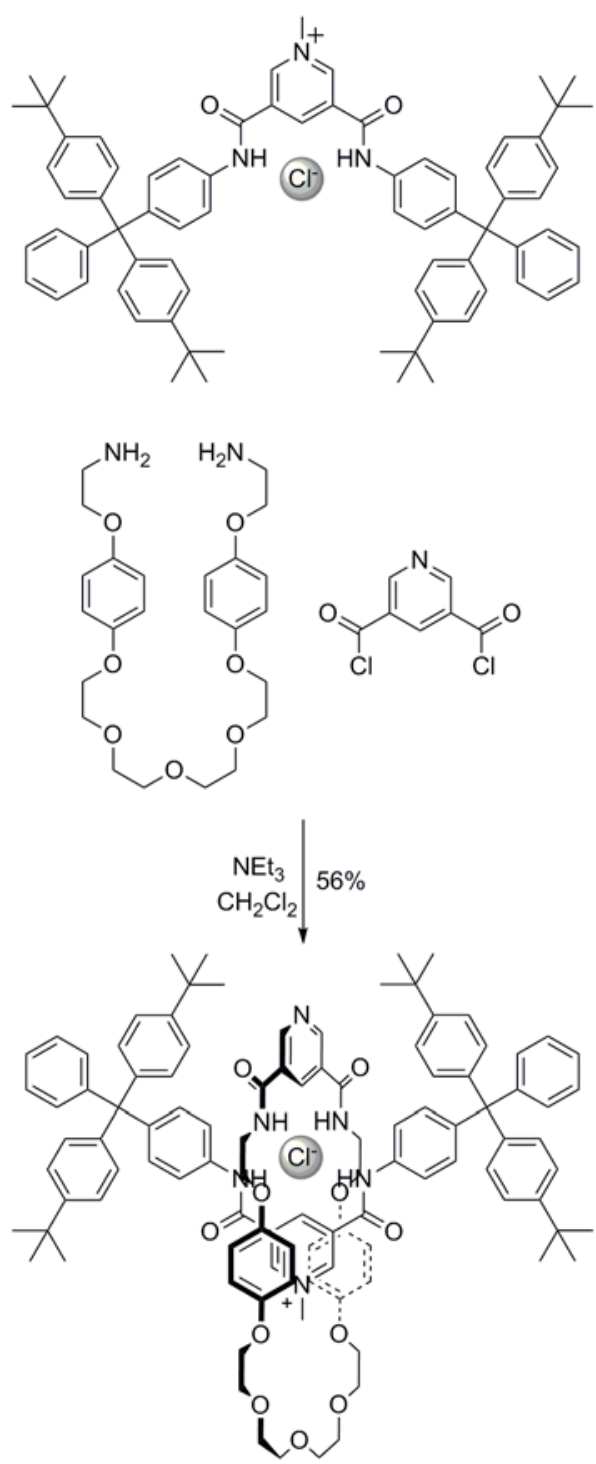

Figure 40. Beer's alternative bis-acid chloride/bis-amine "clipping" rotaxane synthesis.

A very recent development has been the use of the pyridine- $N$ oxide in place of methyl pyridinium to synthesize anion templated neutral rotaxanes (Figure 41). ${ }^{[128]}$ Here, the rotaxane was prepared by stoppering a pyridine- $N$-oxide axle precursor, threaded through a bis-isophthalamide macrocycle, using the CuAAC azide-alkyne cycloaddition "click" reaction. The presence of a chloride anion was still required for interlocked structure formation. Impressively, the isolated rotaxanes were capable of binding halides $\left(\mathrm{Cl}^{-}>\mathrm{Br}^{-}>\mathrm{I}^{-}\right)$in 45:45:10 $\mathrm{CDCl}_{3}-\mathrm{CD}_{3} \mathrm{OD}-\mathrm{D}_{2} \mathrm{O}$.

Another example of constructing interpenetrated and interlocked species by anion templation and neutral components comes from using indolocarbazole. For example, an indolocarbazole may thread through an isophthalamide macrocycle by either fluoride or sulfate templation, ${ }^{[129]}$ and catenanes have been prepared where two indolocarbazole coordinate around a chloride ion (Figure 42). ${ }^{[30]}$ 


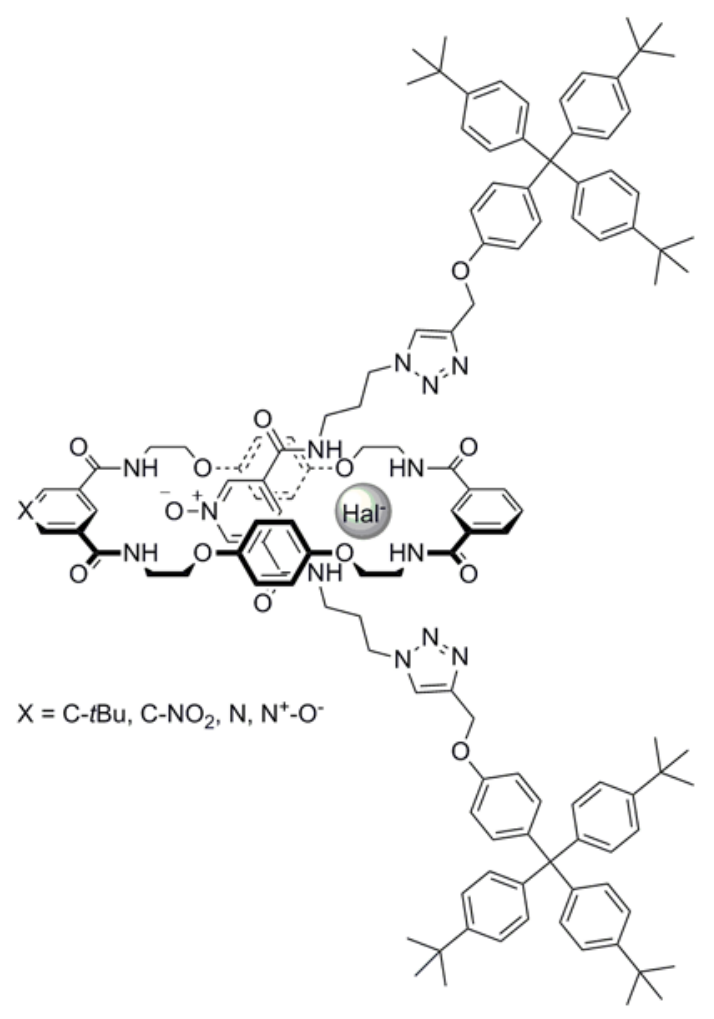

Figure 41. Beer's neutral pyridine- $N$-oxide rotaxane capable of binding halides in aqueous solvent.

(a)

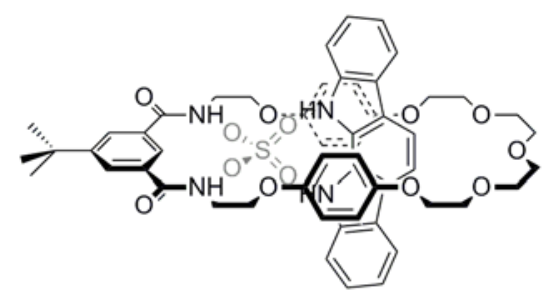

(b)

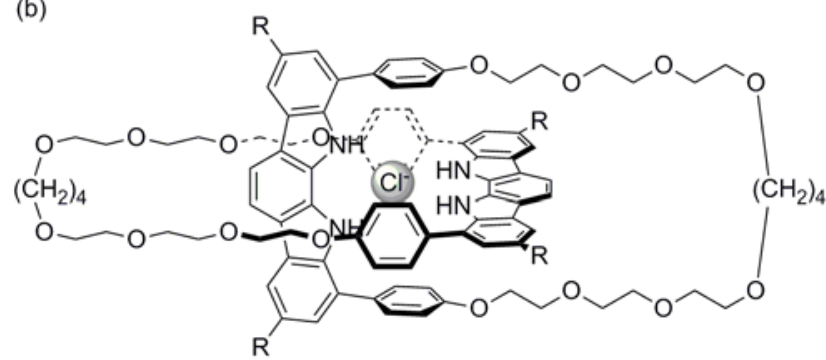

Figure 42. Indolocarbazole containing anion-templated (a) pseudorotaxane and (b) catenane.

To date, the anion templated synthesis of interlocked molecules has been dominated by the use of spherical halide (in particular chloride) templates. Beer has recently disclosed the preparation of a nitrate templated rotaxane (Figure 43).$^{[131]}$ By using an axle precursor containing both methyl pyridinium bis-amide and isophthalamide motifs, the polyatomic nitrate anion can template the formation of a pseudo-rotaxane with an isophthalamide macrocycle, which may be stoppered by the CuAAC “click” reaction. Evidence for the templating role of nitrate was provided by a reduced yields ( 0 - 15\% compared to $24 \%$ ) being observed when other anions (chloride, bicarbonate, dihydrogen phosphate and acetate) were used in place of nitrate in the reaction. The rotaxane was demonstrated to selectively recognize nitrate over other singly charged oxoanions (bicarbonate, dihydrogen phosphate and acetate) in 45:45:10 $\mathrm{CDCl}_{3}-\mathrm{CD}_{3} \mathrm{OD}-\mathrm{D}_{2} \mathrm{O}$.

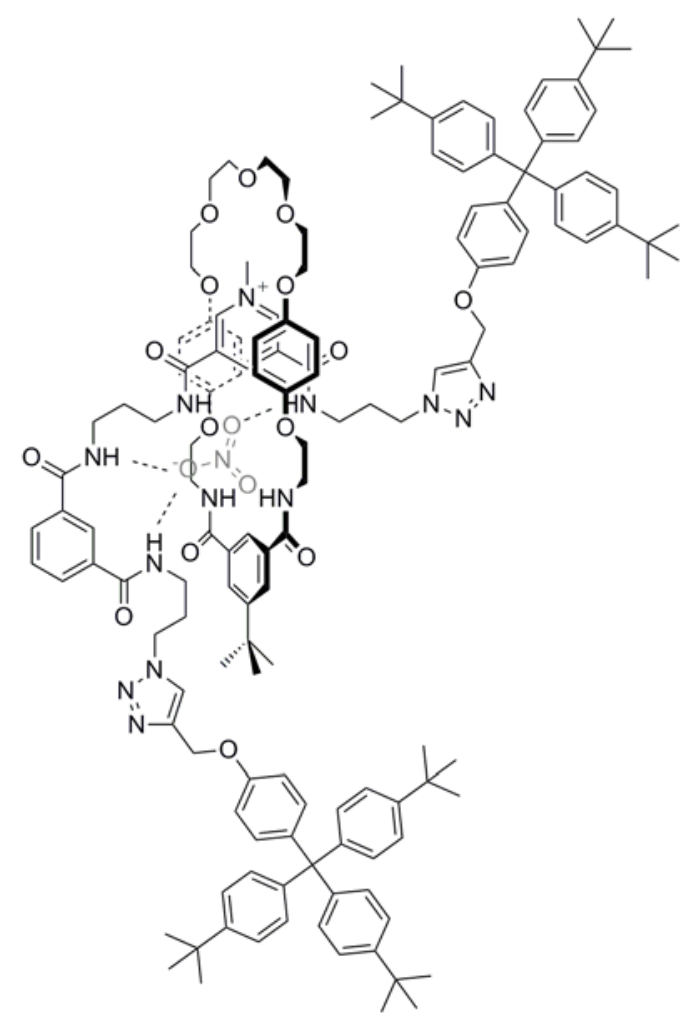

Figure 43. Beer's nitrate templated rotaxane.

\subsection{The Optimization and Discovery of Anion Templated Anion Receptors by Dynamic Combinatorial Chemistry (DCC)}

By its very nature, DCC appears to offer an excellent way of preparing receptors for specific guests such as anions. ${ }^{[132]}$ This is illustrated by refinements to the "molecular oysters" receptors of Kubik that have been developed in collaboration with Otto. ${ }^{[133]}$ In their first report, a molecule consisting of two identical cyclopeptide macrocycles connected by a single disulfide bond linker was introduced into a DCL containing a range of dithiol spacers (Figure 44a). Exchange of the sulfide bonds allowed for a variety of possible receptors to be generated. Upon the addition of iodide or sulfate (as their potassium salts) to the DCL, specific receptors were favoured and amplified (Figure 44a). ${ }^{[133 a]}$ Upon isolation of these receptors, the strongest binding affinities were observed with the receptor depicted in Figure 44b, with association constants of $\log K_{\mathrm{a}}\left(\mathrm{I}^{-}\right)=$ 4.75 and $\log K_{\mathrm{a}}\left(\mathrm{SO}_{4}{ }^{2-}\right)=6.83$ measured in 2:1 $\mathrm{CH}_{3} \mathrm{CN}-\mathrm{H}_{2} \mathrm{O}$, which were an order of magnitude greater than for the bis-amide linked receptor discussed in Section 2.1.2 above. In a second communication, use of an alternative library allowed for the optimization of a receptor with two linkers between the macrocycles. In this case, one of the amplified receptors was able to bind sulfate with a $\log K_{\mathrm{a}}=8.67\left(\right.$ in $\left.2: 1 \mathrm{CH}_{3} \mathrm{CN}-\mathrm{H}_{2} \mathrm{O}\right){ }^{[133 \mathrm{~b}]}$ 
(a)

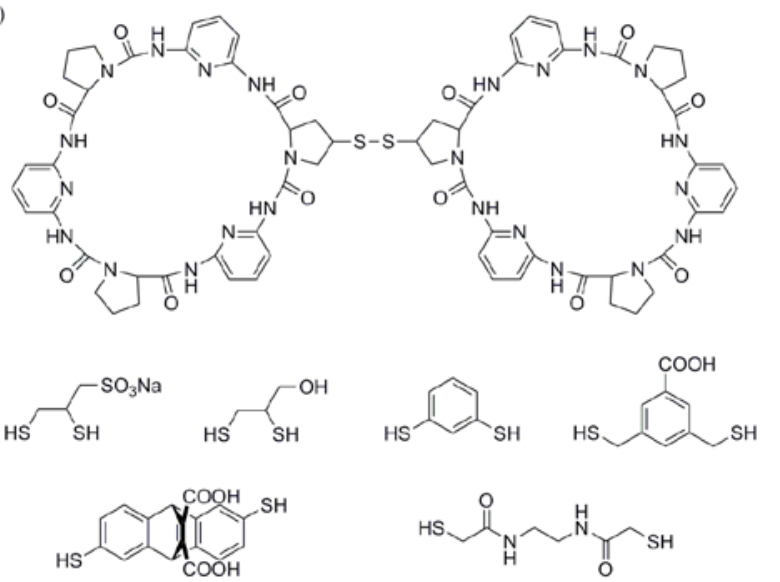

(b)

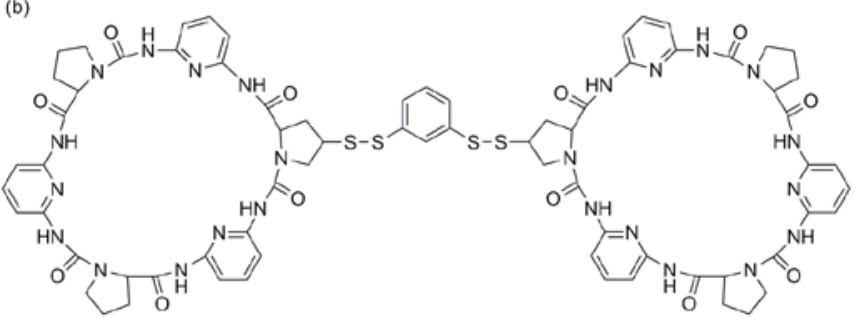

Figure 44. Kubik and Otto's DCC "molecular oysters": (a) the components of the DCL and (b) the structure of the receptor with a single linker possessing highest association constants for iodide and sulfate.

Beeren and Sanders have since taken the use of DCC one stage further by creating and then investigating novel anion receptors. ${ }^{[134]}$ A library was constructed containing a disubstituted ferrocene scaffold (specifically a bis-hydrazide), with isophthalaldehyde and 4-methylbenzylhydrazide. The addition of $\mathrm{TBAH}_{2} \mathrm{PO}_{4}$ to the DCL led to the magnification of a linear receptor that in fact binds two $\mathrm{H}_{2} \mathrm{PO}_{4}{ }^{-}$anions (Figure 45). ${ }^{[135]}$

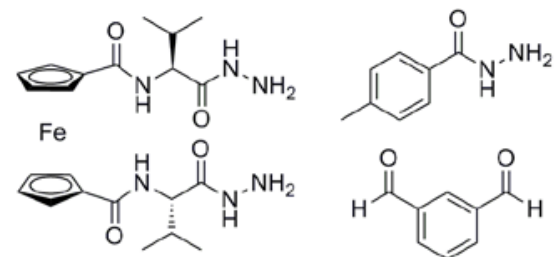

$$
\mathrm{TBAH}_{2} \mathrm{PO}_{4} \downarrow \begin{gathered}
\text { 1-naphthoic acid } \\
96: 4 \mathrm{CHCl}_{3} / \mathrm{CH}_{3} \mathrm{OH}
\end{gathered}
$$

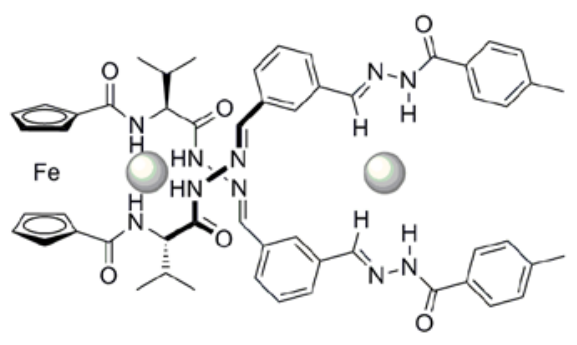

$=\mathrm{H}_{2} \mathrm{PO}_{4}^{-}$

\section{Progress in Anion Sensing}

The importance of anions in biology and their environmental impact has meant that ways to discriminatory detect and report, i.e. sense, the presence of an anionic species have been intensely investigated. Indeed, this area of anionic supramolecular chemistry saw significant early advances being made, as covered by Beer and Gale in 2001. ${ }^{[16]}$ Here, we focus on some of the key developments since that date.

Molecular sensors for anions may be classified by the macroscopic response that is produced upon binding the anion: electrochemical or optical. Optical anion sensors may be further classified as either fluorescent or colorimetric. While fluorescent sensors may be exceptionally sensitive, colorimetric sensors allow for the possibility of detection by the human eye.

\subsection{Reporter-Spacer-Receptor Anion Sensors}

A popular approach to construct an anion sensor is to link a binding site to a suitable redox-active or optical reporter group, which may be termed the reporter-spacer-receptor approach (Figure 46).
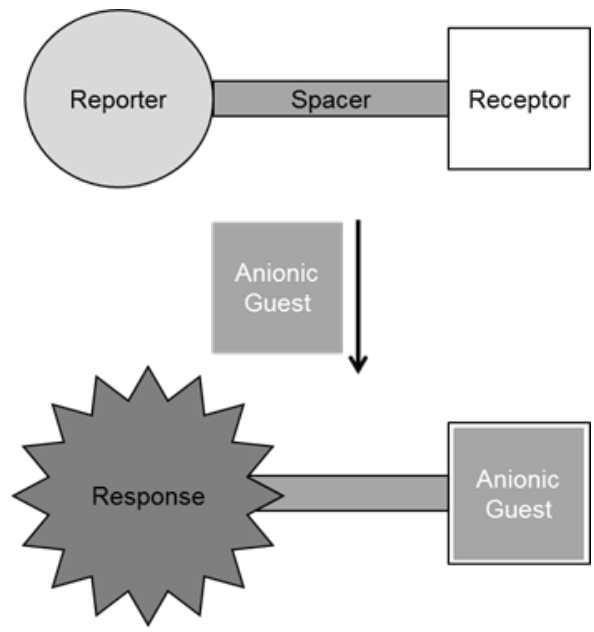

Figure 46. Schematic of sensing the binding of an anionic guest by the reporter-spacer-receptor approach.

\subsubsection{Electrochemical anion sensors}

A range of sensors capable of the electrochemical detection of anions have been constructed incorporating the redox-active ferrocene moiety. ${ }^{[136]}$ Anion recognition leads to a cathodic shift of the ferrocene/ferrocenium $\left(\mathrm{Fc} / \mathrm{Fc}^{+}\right)$redox couple, as measured by cyclic voltammetry. While the earliest examples of ferrocene anion sensors were typically based on secondary amides, ${ }^{[137]}$ the metallocene has subsequently been incorporated into a larger number of sensors where the anion is bound by a variety of hydrogen bonding groups. ${ }^{[138]}$ An impressive recent example is the ferrocene urea receptor depicted in Figure 47 which is able to electrochemically discriminate between enantiomers of chiral carboxylate anions in acetonitrile. ${ }^{[139]}$

Figure 45. Beeren and Sanders' linear receptor for dihydrogen phosphate. 


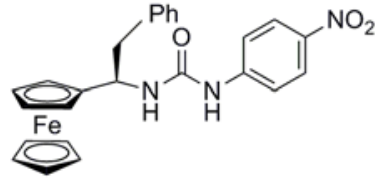

Figure 47. Tucker's chiral ferrocene urea sensor capable of electrochemically discriminating between enantiomers of a chiral carboxylate anion.

Since the Millennium, a number of alternative redox-active moieties have also been investigated as reporting groups in electrochemical anion sensors (Figure 48). For example, Fabbrizzi and co-workers demonstrated that cathodic shifts of the $\mathrm{Co}^{\mathrm{II}} / \mathrm{Co}^{\mathrm{III}}$ bipyridyl redox couple are observed in aqueous acetonitrile electrolyte solutions upon the binding of anions by the convergent array of imidazolium groups in a cage-like receptor (Figure 48a). ${ }^{[140]}$ Meanwhile, Beer has shown that the dithiocarbamate macrocycle depicted in Figure 48b, exhibits a cathodic shift in the $\mathrm{Cu}^{\mathrm{II}} / \mathrm{Cu}^{\mathrm{III}}$ redox couple upon the addition of dihydrogenphosphate. ${ }^{[141]}$ Nonmetallic electrochemical anion sensors have also been synthesized, for example the redox-active TTF has been fused to a halide binding calixpyrrole, which allows for the electrochemical sensing of halide anions in acetonitrile (Figure 48c). ${ }^{[142]}$ (a)

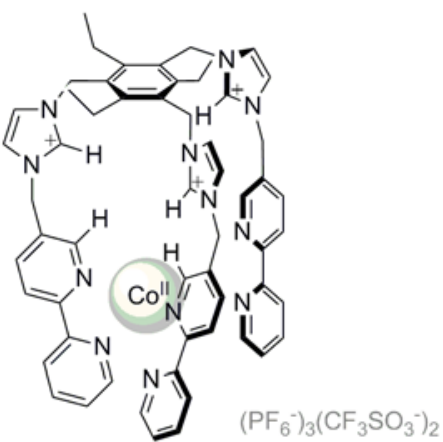

(c)

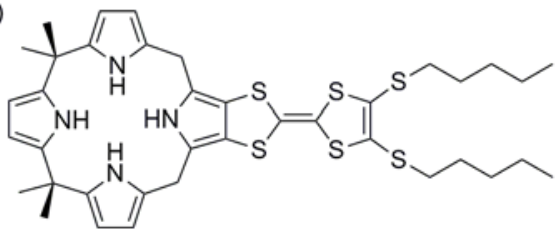

Figure 48. Electrochemical anion sensors: (a) Fabbrizzi's Co" trisimidazolium cage, (b) Beer's Cu" dithiocarbamate macrocycles and (c) Jeppesen's and Becher's TTF calixpyrrole.

\subsubsection{Optical anion sensors}

Many fluorescent anion sensors have been constructed using the reporter-spacer-receptor approach described above, with a variety of chemical functionality being used as the signalling unit. Examples incorporating organic reporter groups such as anthracene ${ }^{[143]}$ and pyrene ${ }^{[144]}$, as well as the transition metal luminescent motif $\mathrm{Ru}^{\mathrm{II}}$ bipyridyl ${ }^{[145]}$ have continued to be utilized.

An addition to these signaling units has been the naphthalimide group. $^{[146]}$ The first naphthalimide containing anion sensor was described by Gunnlaugsson (Figure 49). ${ }^{[147]}$ The addition of acetate and dihydrogen phosphate to this receptor in DMSO leads to a quenching of fluorescence, due to enhanced PET from the electronrich thiourea to the naphthalimide.

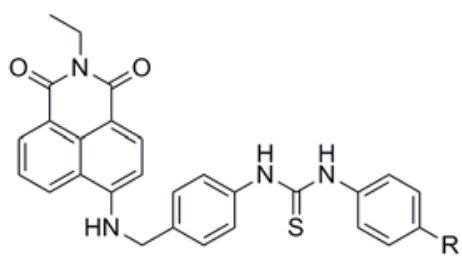

Figure 49. Gunnlaugsson's fluorescent napthalimide anion sensor.

Another organic chromophore investigated recently as a fluorescent signaling unit is 2, 6-bis(arylethynyl)pyridine. ${ }^{[148]}$ Johnson and Haley reported that the receptor in Figure 50 (once protonated) shows an "off to on" fluorescence response to added chloride in acetonitrile. Analogous compounds where the central pyridine is replaced by a benzene, have also been found to be fluorescently responsive to anions. ${ }^{[149]}$

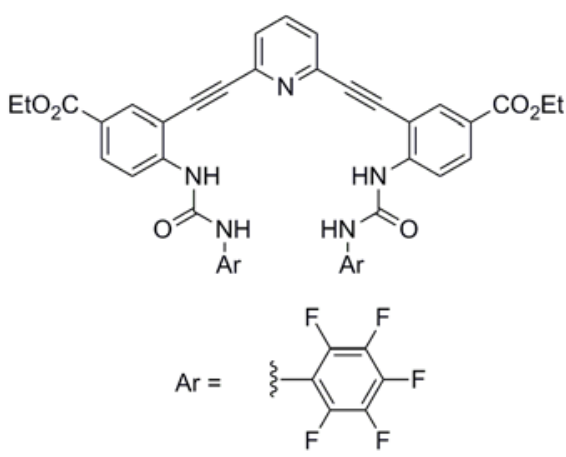

Figure 50. Johnson and Haley's 2, 6-bis(arylethynyl)pyridine fluorescent anion sensor.

A major aim of anion sensory research has been the development of systems capable of the detection of anionic species in biological media. Optical reporter groups have tended to be chosen to maximize sensitivity, while minimizing probe invasiness. In addition, direct metal-anion coordination allows for operation in highly competitive aqueous environment. Parker and co-workers have used sensitized $\mathrm{Ln}^{\mathrm{III}}$ complexes to sense anions both in vitro and in cellulo, with the sharp emission bands of $\mathrm{Eu}^{\mathrm{III}}$ (and $\mathrm{Tb}^{\mathrm{III}}$ ) cations allowing for ratiometric analysis thus avoiding any issues regarding the concentration of the complex. For example, the Eu complex in Figure 51a detects citrate in seminal fluid. ${ }^{[150]}$ The remarkable selectivity of the complex in response for citrate over the structurally similar lactate anion - both metabolites which may be found in human fluid media - is vital. As depleted levels of citrate are a symptom of prostate cancer, it has been argued this complex could be used in cancer screening. Another impressive example has been the study of bicarbonate concentrations in the mitochrondria of living cells, by use of a mixture of the Eu and Tb complexes of the same ligand (Figure 51b), that allows for the necessary ratiometric analysis. ${ }^{[151]}$ Modulation of the Eu emission (by coordination of bicarbonate) is varied by changing the levels of $\mathrm{CO}_{2}$ in the cell incubation atmosphere. 
(a)

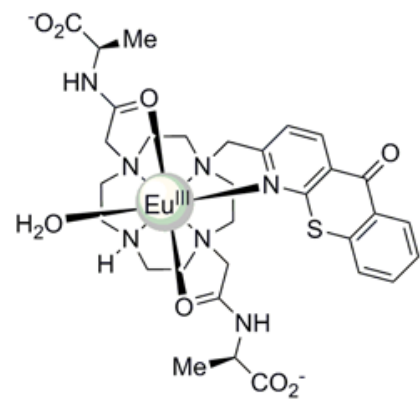

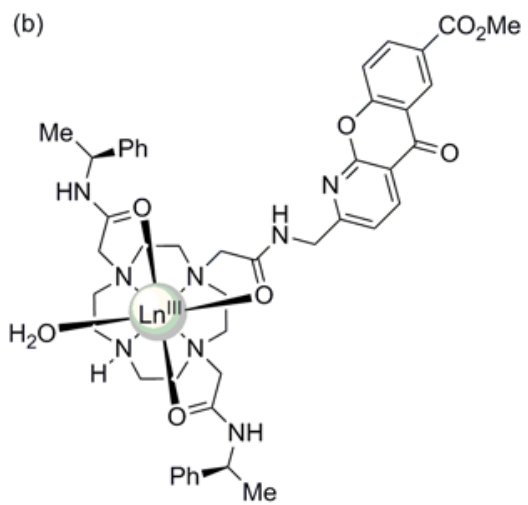

Figure 51. Lanthanide complexes used in the determination of (a) levels of citrate in seminal fluid and (b) mitchrondrial bicarbonate concentration

\subsubsection{Interlocked structures capable of selective anion sensing}

Beer and co-workers have taken their interlocked molecules capable of selective anion recognition and shown that by the appendage and incorporation of reporter groups it is possible to create rotaxanes and catenanes capable of selective anion sensory responses.

For example, a [2]rotaxane $\mathrm{e}^{[152]}$ and a [2]catenane $\mathrm{e}^{[153]}$ have been prepared by chloride anion templation, appended with a ferrocene unit. Their hexafluorophosphate salts demonstrate selective electrochemical anion sensing for chloride in acetonitrile-based electrolyte (Figure 52). Specifically, the maximum cathodic shift in the $\mathrm{Fc} / \mathrm{Fc}^{+}$redox couple was observed upon the addition of one equivalent of the halide anion. With oxoanions, further cathodic shift perturbations were observed upon the addition of excess anion. This observation was rationalized by considering that only chloride is capable of penetrating the interlocked cavity, whereas the polyatomic oxoanions associate at the cavity's periphery. (a)

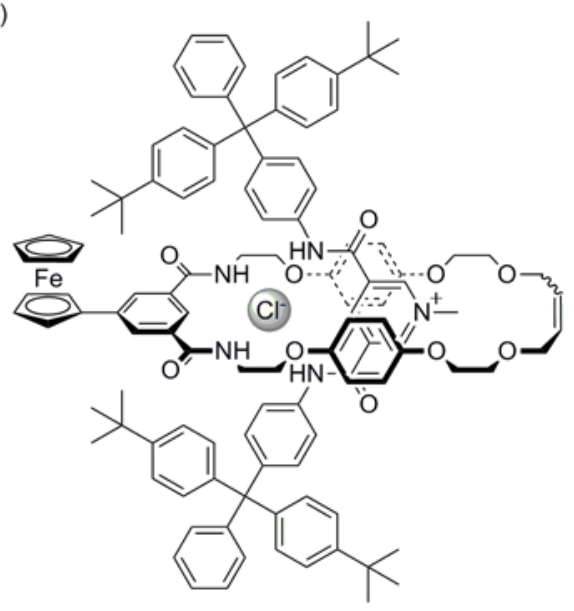

(b)

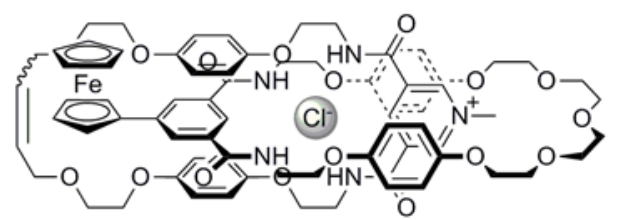

Figure 52. Beer's ferrocene-appended (a) rotaxane and (b) catenane that can selectively sense chloride anions bound within the interlocked cavity.

Luminescent rotaxanes incorporating a 4, 4'-bis-amide-2, 2'bipyridyl macrocycle to allow for complexation of $\mathrm{Re}^{\mathrm{I}}$ and $\mathrm{Ru}^{\mathrm{II}}$ have also been reported (Figure 53). ${ }^{[154]}$ Addition of chloride and dihydrogenphosphate to samples of the metallated rotaxanes dissolved in aqueous acetone (containing up to $30 \% \mathrm{H}_{2} \mathrm{O}$ ) led to enhancement of MLCT luminescence. The trend in calculated association constants - chloride being bound more strongly than dihydrogenphosphate - was in agreement with that obtained from ${ }^{1} \mathrm{H}$ NMR titrations.

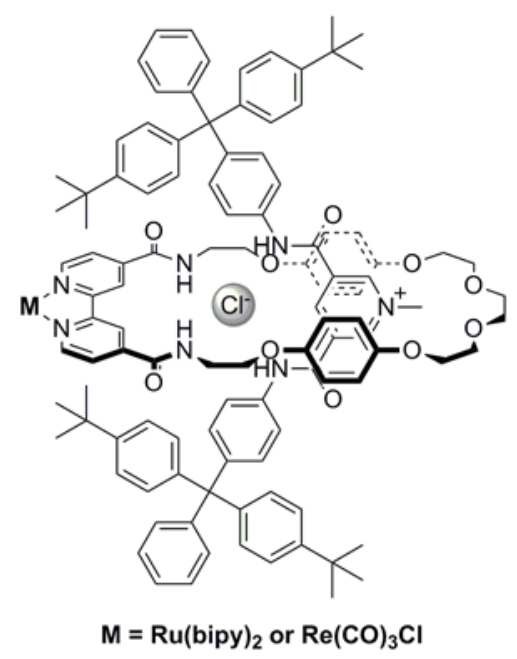

Figure 53. Rotaxane capable of selectively sensing chloride by modulation of transition metal bipyridyl luminescence.

In collaboration with Faulkner, Beer has also reported a lanthanide appended rotaxane that responds to changing chloride 
concentration (Figure 54). ${ }^{[155]}$ Luminescence behaviour is modulated by binding of chloride first to the ninth coordination site of the $\mathrm{Eu}^{\mathrm{III}}$ cation, which leads to quenching of the lanthanide emission. This is subsequently restored upon binding of the second equivalent of chloride within the rotaxane cavity.

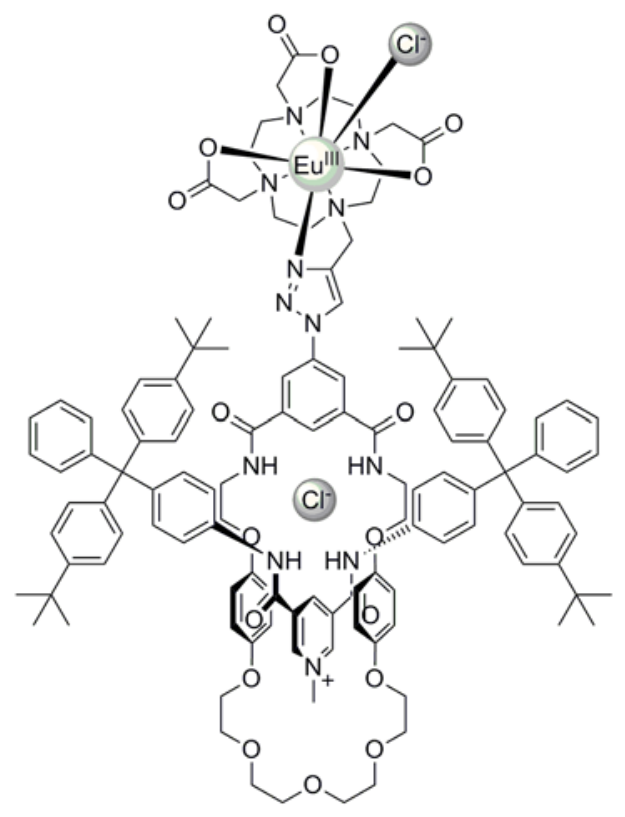

Figure 54. Rotaxane capable of selectively sensing chloride by modulation of Eu'II' cation luminescence.

The ability of higher order interlocked structures to provide alternative modes of sensory selectivity is demonstrated by ferrocene $\mathrm{e}^{[156]}$ and naphthalene $\mathrm{e}^{[157]}$ functionalized [3]rotaxanes (Figure 55). The $\mathrm{Fc} / \mathrm{Fc}^{+}$redox couple of the ferrocene rotaxane (Figure 55a) undergoes a cathodic shift upon the addition of up to two equivalents of chloride, consistent with binding of the halide anion within the two interlocked cavities. The addition of sulfate to the free host led to complex, but different, electrochemical behaviour; ${ }^{1} \mathrm{H}$ NMR titrations indicated that the neutral rotaxane binds the dianion in a 1:1 stoichiometry. For the naphthalene rotaxane (Figure 55b), the addition of chloride, bromide and acetate simply led to a modest enhancement of naphthalene emission. In the case of sulfate, a dramatic quenching was initially observed before restoration and enhancement. This result is attributed to the polyatomic sulfate dianion first coordinating between the two pyridinium units (in a 1:1 binding mode) close to the naphthalene, and then coordinating to each pyridinium separately (in a 2:1 binding mode) and being hence further away from the fluorescent moiety.

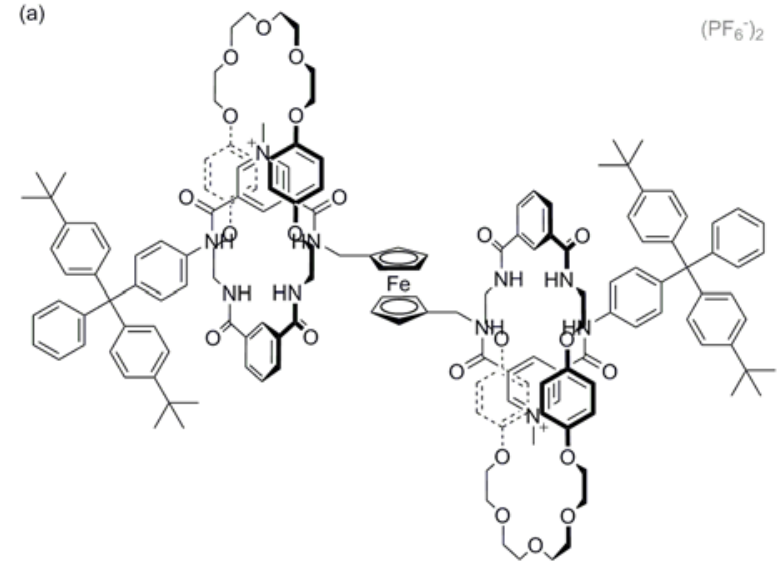

(b)

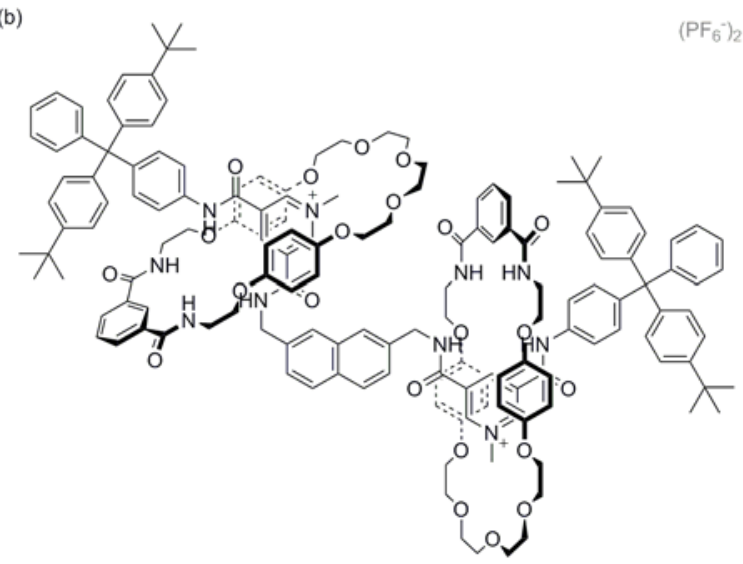

Figure 55. Beer's [3]rotaxanes which can selectively sense anions (a) electrochemically and (b) by fluorescence.

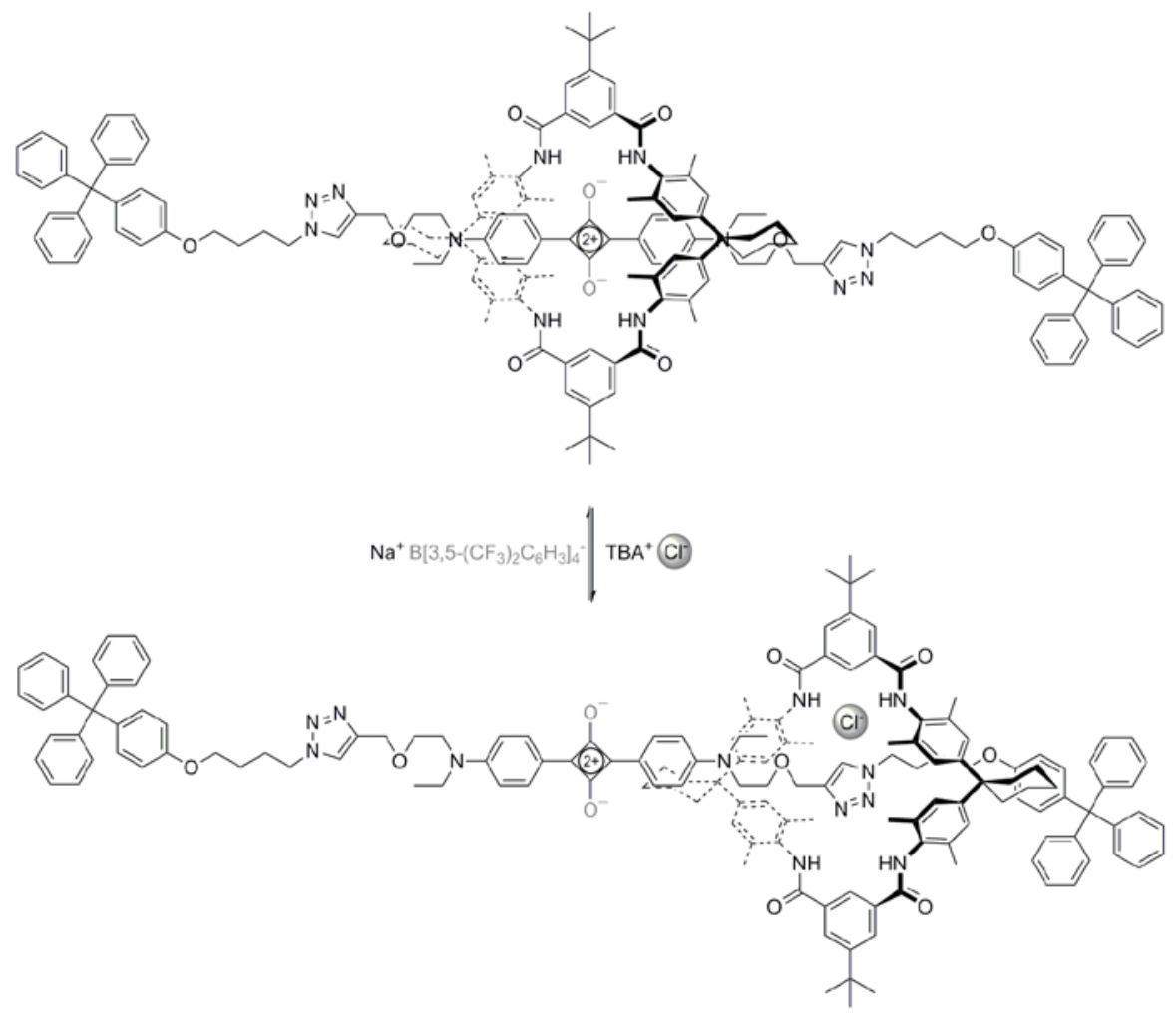

Figure 56. B. D. Smith's squaraine [2]rotaxane shuttle which senses chloride. 
B. D. Smith et al have reported upon the use of squaraine rotaxane shuttles as reversible optical chloride anion sensors (Figure 56). In the first report, ${ }^{[158]}$ they demonstrated that upon the addition of chloride, the tetralactam macrocycle of the rotaxane was displaced, leading to a three-fold increase in the deep-red fluorescence emission from the squaraine dye. Removal of the chloride, led to a complete reversal of this process. Prototype dipsticks (by adsorption of the rotaxane onto reverse-phase silica) were prepared, which were able to detect chloride in aqueous solution. Very recently, an improved shuttle has been reported. ${ }^{[159]}$ Not only containing a more stable dihydroxyl substituted dye, the rotaxane was able to sense anions ratiometrically due to anion binding modulating emission wavelength, rather than changing emission intensity.

\subsection{Indicator-Displacement Assays for Anions}

An alternative design for optical anion sensors is the use of indicator-displacement assays (IDA). Here, an indicator is bound weakly by the receptor, so that upon addition of guest it is displaced, giving either a colorimetric or fluorescent response (Figure 57). One of the principal advantages of this approach is the possibility of using different indicators with the same receptor. ${ }^{[160]}$

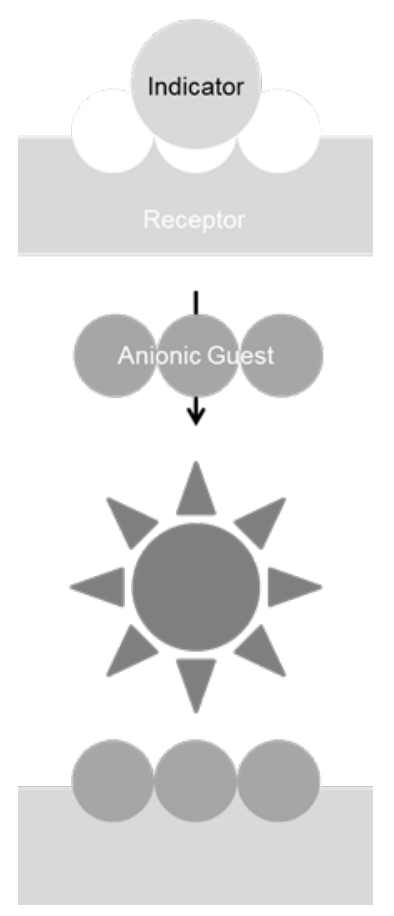

Figure 57. Schematic of sensing the binding of an anionic guest by indicator-displacement assay approach.

The pioneering work on indicator-displacement assays for anions was reported by Anslyn just before the Millennium. For example, a 1, 3, 5-trisubstituted-2, 4, 6-triethylbenzene scaffold containing three guanidinium groups was shown to selectively sense the levels of citrate in commercially available soft drinks by using 5carboxyfluorescein as an indicator (Figure 58). ${ }^{[161]}$ The same group has also reported a poly-guanidinium appended scaffold that fluorescently sensed inositol-triphosphate in methanol ${ }^{[162]}$ and an assay that colorimetrically sensed heparin. ${ }^{[163]}$
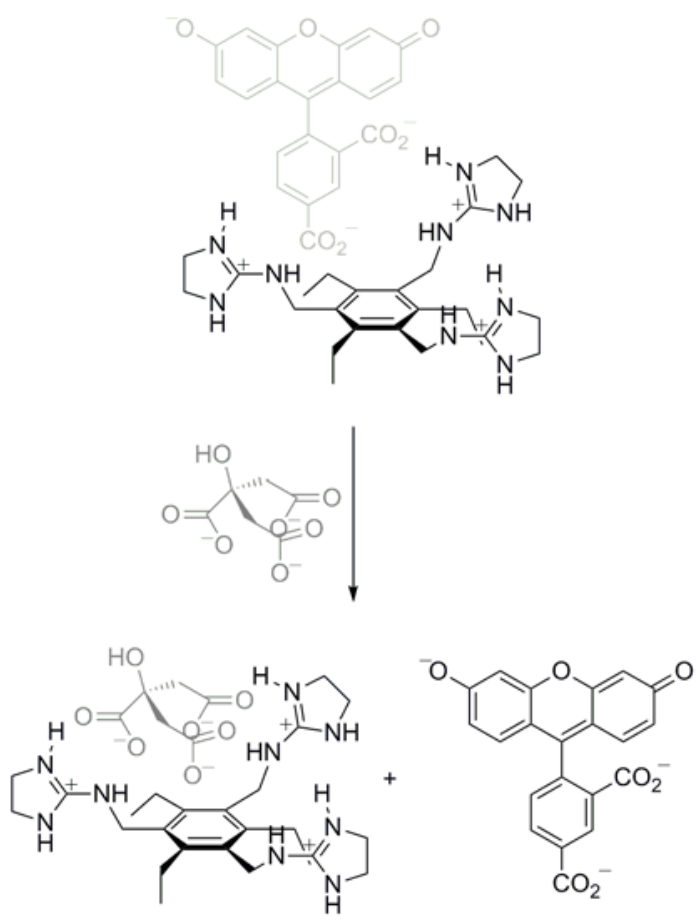

Figure 58. Anslyn's demonstration of IDAs by sensing citrate in aqueous solvent media.

The use of metallic complexes allows for the facile generation of assays that may operate in aqueous solvent media. Fabbrizzi reported upon a di-copper cage that could selectively detect (by fluorescence) bicarbonate in water, by displacement of a coumarine indicator (Figure 59). ${ }^{[164]}$

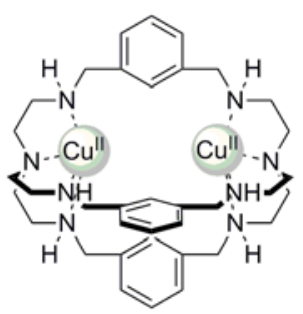<smiles>O=C(O)C1Cc2cc3c4c(c2OC1=O)CCCN4CCC3</smiles>

Figure 59. Fabrizzi's di-copper cage (and coumarine indicator) that can selectively detect bicarbonate.

\subsection{Anion Chemodosimeters}

Chemodosimeters are examples of a third class of anion sensor, which typically provide a colorimetric response (Figure 60). The anion may either form a covalent bond to the receptor, thus causing, for example, a change in the colour of the molecule or alternatively, the anion might catalyze a chemical transformation of the receptor molecule. Considering the irreversible change in the constitution of the "receptor", it is arguable whether chemodosimeters are genuinely supramolecular in nature. For completeness, we provide select examples here to give a flavour of the field. 


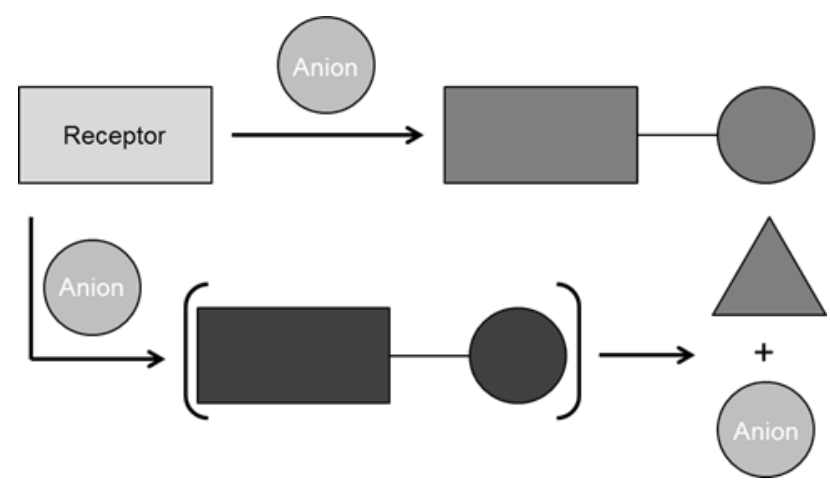

Figure 60 . Schematic of sensing the presence of anions by chemodosimeters.

Two reports of anion chemodosimeters from the laboratories of Martínez-Máñez are presented in Figure 61. In the first, the cyclization of a yellow pent-2-en-1,5-dione to the magenta pyrylium, allowed for discrimination between the olefinic isomers maleate and fumarate, as the cis-isomer maleate is able to form strong hydrogen bonds to the enol group (significantly enhancing the electron density on the oxygen atom), allowing for accelerated cyclization (Figure 61a). ${ }^{[165]}$ In a second paper, the pyrylium product has been shown to undergo a ring-opening, ring-closing to form a thiopyrylium upon the addition of the sulfide anion, which is marked with a change in colour from magenta to blue (Figure 61b) Impressive selectivity over a wide range of anions was reported. ${ }^{[166]}$

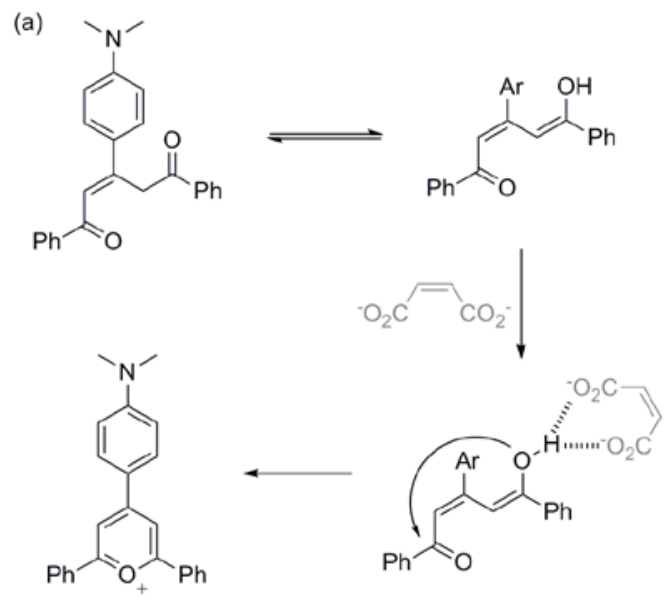

(b)

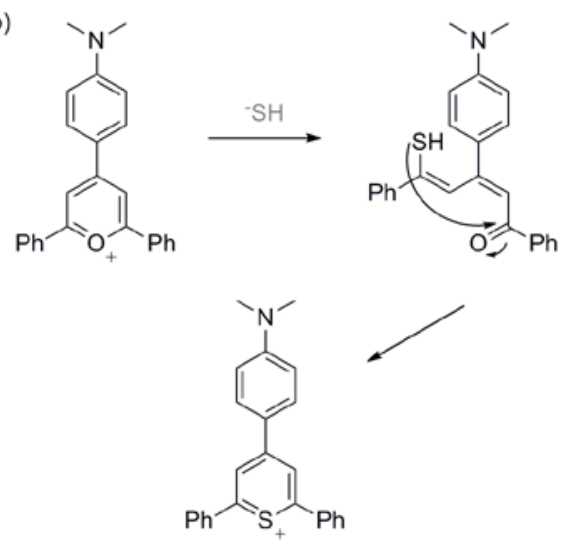

Figure 61. Examples of chemodosimeters that sense (a) maleate and (b) hydrogen sulfide anions.
The cyanide anion is a very common target for detection by chemodosimeters, as its high nucleophilicity, allows for the design of receptors that will selectively react with this particular anion. For example, Sessler and co-workers reported a colorimetric sensor for cyanide based on a benzil analogue (Figure 62). In 70:30 MeOH$\mathrm{H}_{2} \mathrm{O}$, solutions of the chemodosimeter are yellow, but upon addition of low concentrations of cyanide, the solution turns colourless, with high selectivity across a range of anions tested. ${ }^{[167]}$

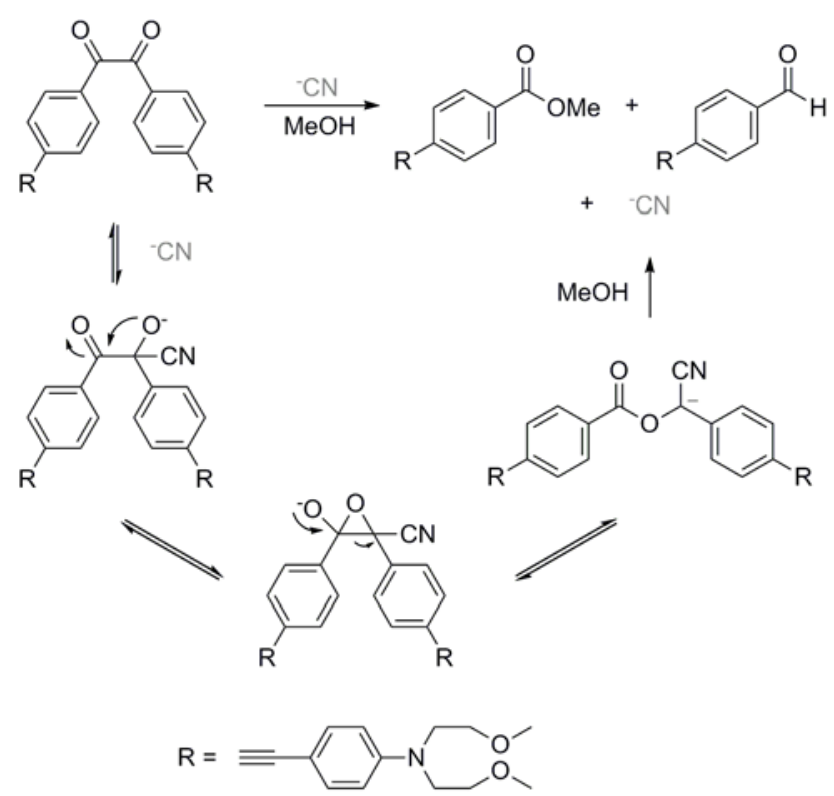

Figure 62. Sessler's benzil chemodosimeter which selectively senses cyanide.

Hudnall and Gabbaï have prepared an ammonium borane which is also highly selective for cyanide (Figure 63).$^{[168]}$ In the highly competitive 60:40 $\mathrm{H}_{2} \mathrm{O}$-DMSO solvent system, cyanide is bound with a $K_{\mathrm{a}}=3.9 \times 10^{8} \mathrm{M}^{-1}$, while a wide range of halides (including fluoride) and oxoanions exhibit no binding by monitoring the $\mathrm{UV}$-vis absorbance of the receptor. In a further experiment it was found that in 90:10 $\mathrm{H}_{2} \mathrm{O}-\mathrm{MeOH}$ the fluorescence of a $5 \mu \mathrm{M}$ sample of receptor is quenched by 1 equivalent of cyanide.

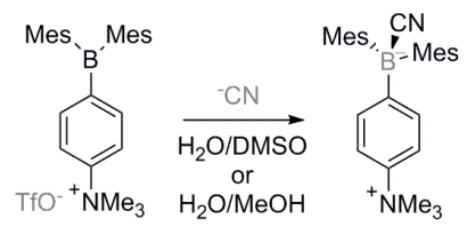

Figure 63. A cationic ammonium borane which is highly selective for the binding and sensing of cyanide.

Fluoride is another nucleophilic anion that is commonly sensed by chemodosimetric methods. In particular, a vast number of receptors have been prepared which exploit the formation of B-F ${ }^{[169]}$ and Si-F bonds (Figure 64). For example, the bis-boron naphthalene compound is capable of binding fluoride in a bidentate fashion with an exceptionally high association constant of $5 \times 10^{9} \mathrm{M}^{-1}$ in THF, with a change in colour from yellow to colourless. ${ }^{[170]}$ Addition of two equivalents of fluoride to the ferrocene bis-boronate, under aerobic conditions, leads to a colour change of orange to pale green, 
due to the fluoride inducing in situ oxidation of ferrocene to ferrocenium. ${ }^{[171]}$ In the case of the trianthrylsilane, an enhancement in fluorescence occurs due to alteration of the through-space interactions between the three anthracenes upon binding of fluoride (in THF) to the central silicon atom. ${ }^{[172]}$

(a)<smiles>CB(C)c1cccc2cccc(B3c4ccccc4Sc4ccccc43)c12</smiles>

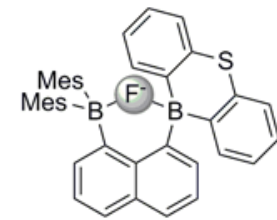

(b)

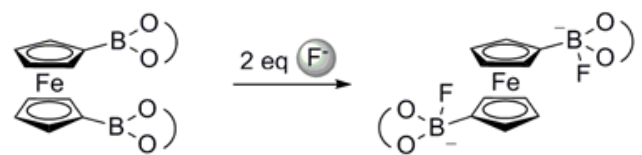

(c)

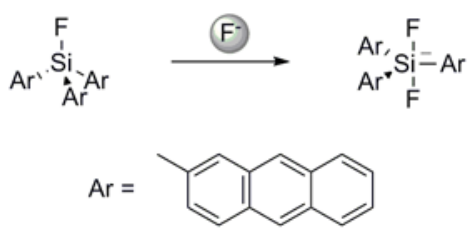

Figure 64. Chemodosimeters detecting fluoride: (a) Gabbaî's bisboron naphthalene; (b) Aldridge's bis-boronate ferrocene molecules and (c) Yamaguchi's trianthrylfluorosilane.

\subsection{Surface Attached Anion Sensors}

Research into anion sensors has traditionally focused on the design and synthesis of solution-based receptors, equipped with appropriate reporter groups. However, receptors attached to surfaces as self-assembled monolayers (SAMs) can exhibit a number of advantages over their solution phase analogues. ${ }^{[173]}$ First, the receptor is typically more preorganized on a surface which may lead to an amplification of sensory response. Second, there is the possibility of recycling a surface-attached sensor, and third, by immobilizing a receptor to a surface, it is possible to use a receptor which may be insoluble in water in aqueous conditions.

\subsubsection{Surface attached anion sensors using reporter groups}

The redox-active ferrocene motif has been used in a number of surface-confined anion sensors. The first example was demonstrated by Astruc and co-workers, where a simple amidoferrocenyl alkylthiolate was adsorbed onto a gold electrode surface, and a large cathodic shift of the $\mathrm{Fc} / \mathrm{Fc}^{+}$redox couple was observed upon the addition of dihydrogen phosphate. ${ }^{[174]}$ The same group has also attached amidoferrocenyl alkanethiols to gold nanoparticles, by constructing mixed monolayers of the ferrocene containing thiol and dodecanethiol. ${ }^{[175]}$ Beer and co-workers have since demonstrated that immobilization of ferrocene containing anion receptors to gold surfaces leads to amplification in the electrochemical response (Figure 65a \& b). ${ }^{[176]}$ For example, the ferrocene bis-amide SAM (Figure 65a) exhibits a $-100 \mathrm{mV}$ cathodic shift in the $\mathrm{Fc} / \mathrm{Fc}^{+}$redox couple upon addition of chloride, compared to a $-40 \mathrm{mV}$ cathodic shift for the receptor dissolved in the electrolyte solution (2:1 $\left.\mathrm{CH}_{2} \mathrm{Cl}_{2}-\mathrm{CH}_{3} \mathrm{CN}\right) .{ }^{\text {[176a] }}$ The redox couple of the ferrocene urea functionalized calixarene (Figure 65b) undergoes a similar enhancement in cathodic shift $(-115 \mathrm{mV}$ on the surface $\mathrm{vs}-60 \mathrm{mV}$ in solution, 1:1 $\left.\mathrm{CH}_{2} \mathrm{Cl}_{2}-\mathrm{CH}_{3} \mathrm{CN}\right){ }^{[176 b]}$ (a)

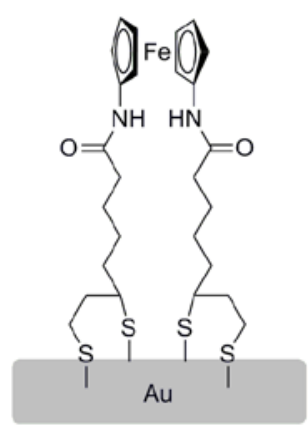

(b)

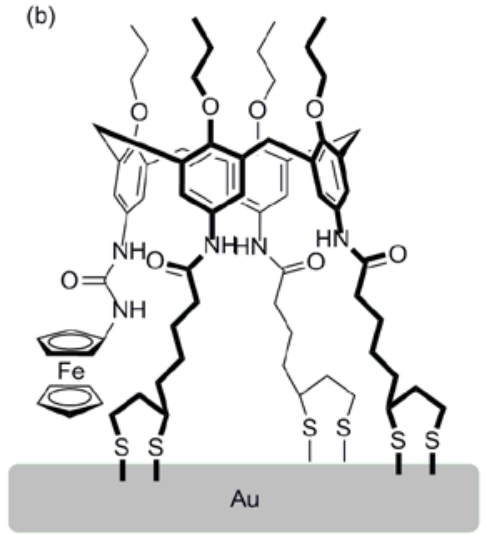

Figure 65. Electrochemical anion sensing SAMs absorbed on to gold, based on (a) ferrocene bis-amide and (b) ferrocene urea calixarene receptors.

Jeppesen et al have reported upon a TTF-calixpyrrole chloride sensor adsorbed onto a gold surface (Figure 66). ${ }^{[177]}$ In this case, the chloride-induced cathodic shift of the first oxidation wave of the TTF group in dichloromethane was significantly less than that of the solution-based analogue. This was attributed by the authors to the surface-confined receptor being sterically inhibited from undergoing rearrangement from its ground state 1,3-alternate conformation to the cone conformation that calix[4]pyrroles adopt when binding chloride anions in solution.

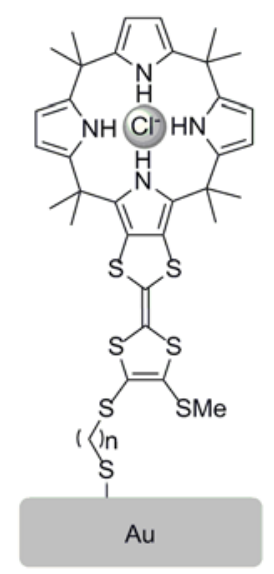

Figure 66. Jeppesen's calixpyrrole/TTF sensor capable of electrochemically detecting chloride.

Sophisticated redox-active rotaxane SAM chloride anion sensors have been prepared by Beer and Davis. ${ }^{[178,179]}$ In the first reported system, a ferrocene-appended macrocycle was confined to a surface as part of a rotaxane by use of a thioctic acid appended pentaphenylferrocene stoppered axle (Figure 67). ${ }^{[178]}$ Upon removal of the chloride template, the rotaxane was able to sense chloride in electrolytic acetonitrile solutions by a cathodic shift in the $\mathrm{Fc} / \mathrm{Fc}^{+}$ redox wave. Excellent selectivity in sensing was observed: chloride 
being sensed in the presence of 100 -fold excess of dihydrogen phosphate.

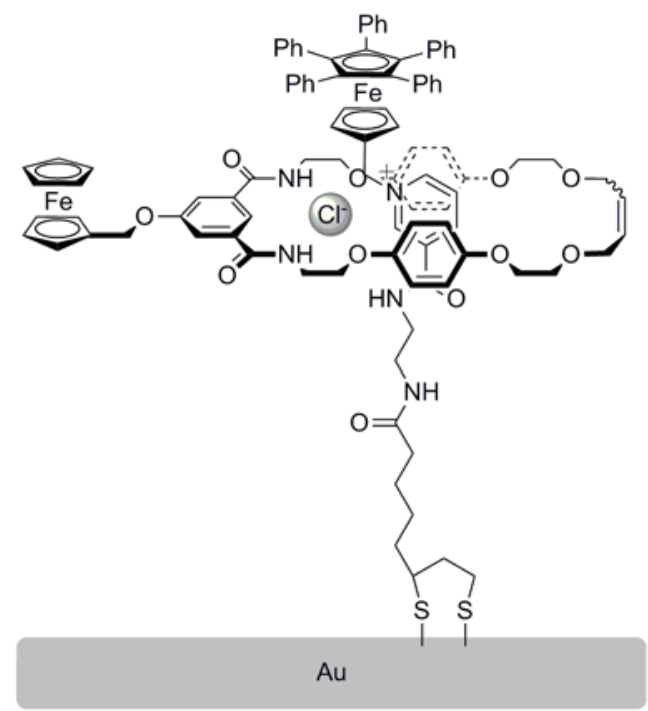

Figure 67. Surface-confined rotaxane capable of selectively sensing chloride by a cathodic shift in $\mathrm{Fc}_{\mathrm{Fc}}{ }^{+}$redox wave.

Very recently, an osmium bipyridyl macrocycle has been incorporated as part of a rotaxane SAM (Figure 68). ${ }^{[179]}$ As before, removal of the chloride template allows for electrochemical sensing of chloride in electrolytic acetonitrile solutions, this time by a cathodic shift in the $\mathrm{Os}^{\mathrm{II}} / \mathrm{Os}^{\mathrm{III}}$ bipyridyl redox wave.

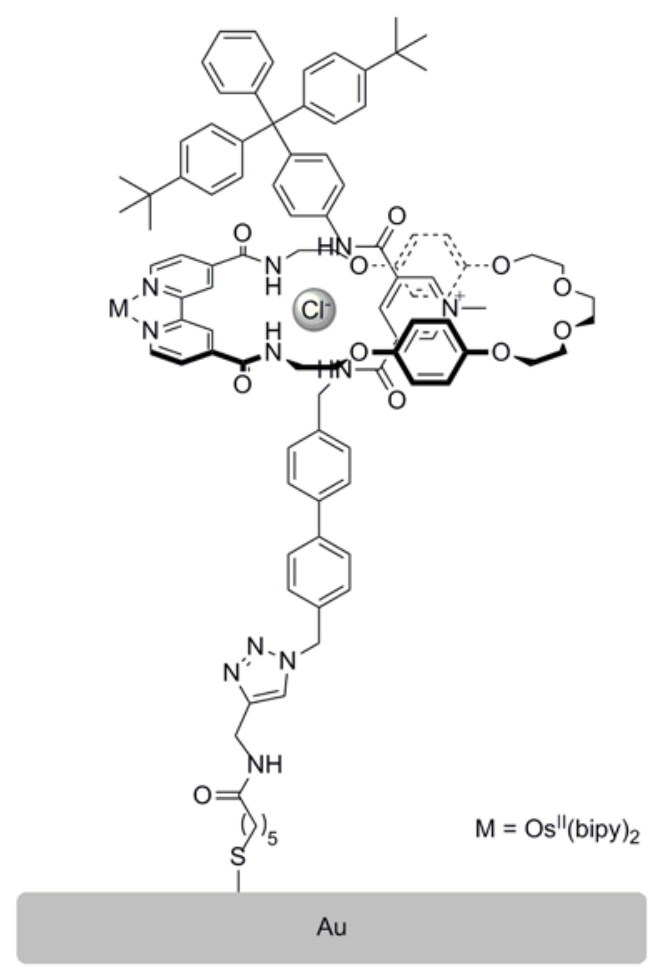

Figure 68. Surface-confined rotaxane capable of sensing chloride by a cathodic shift in the Os"/Os" bipyridyl redox wave.
Beer and Davis have also reported upon an optical surface attached anion sensor, consisting of $\mathrm{Zn}^{\text {II }}$ metalloporphyrins assembled onto gold nanoparticles (Figure 69). ${ }^{[180]}$ These were able to bind chloride and dihydrogenphosphate in dichloromethane and DMSO, as measured by UV-vis titration experiments, with higher affinities than when the metalloporphyrins were free in solution.

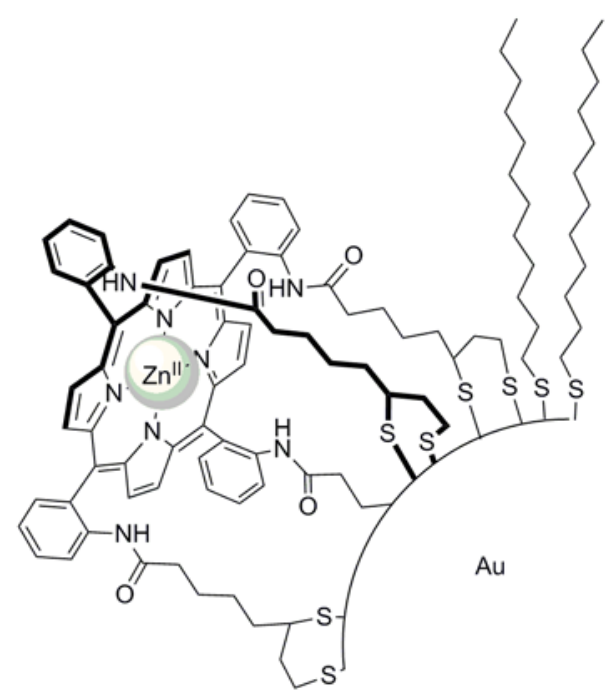

Figure 69. Beer and Davis' zinc metalloporphyrin nanoparticle sensor capable of optical anion detection.

Gunnlaugsson and co-workers have prepared lanthanide complexes on gold nanoparticles for luminescent sensing of phosphate anions in aqueous solution (Figure 70). ${ }^{[181]}$ Sensing of coordinating anions such as carboxylates and phosphates occurs by the switching off of $\mathrm{Eu}^{\text {III }}$ emission, by displacement of the $\beta$-diketone ligand, which acts as an "antenna" for the $\mathrm{Ln}^{\mathrm{III}}$ ion. Phosphate containing molecules such as AMP, ADP, ATP, cyclic $\mathrm{AMP}$, or NADP were found to quench luminescence to a greater degree over other anions. However, complete quenching was only observed with flavin monophosphate.

Crego-Calama and co-workers produced fluorescent anion sensors by decorating quartz slides with fluorophores and hydrogen bond donating groups (Figure 71). ${ }^{[182]}$ Amino functionality was first introduced onto a glass slide, which was then reacted to append the fluorophore and supporting hydrogen bonding unit. Impressively, the combination illustrated here was able to selectively sense, in acetonitrile, $10^{-5} \mathrm{M}^{-1}$ acetate in the presence of $10^{-4} \mathrm{M}^{-1}$ nitrate and $10^{-3} \mathrm{M}^{-1}$ hydrogensulfate. 


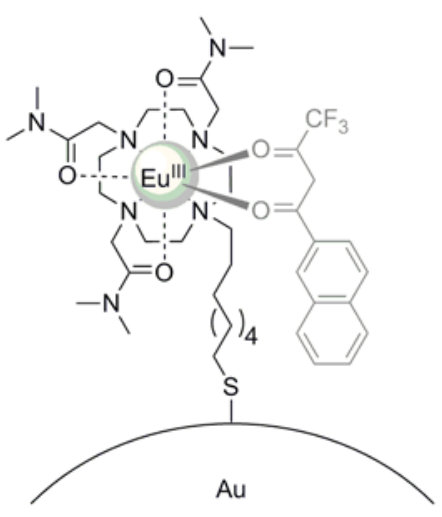

fluorescent
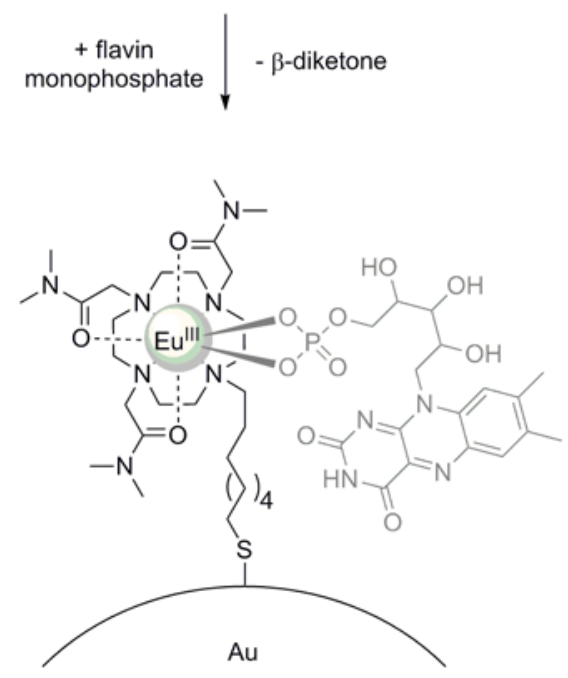

fluorescence quenched

Figure 70. Gunnlaugsson's luminescent lanthanide nanoparticle sensor optically detecting flavin monophosphate.

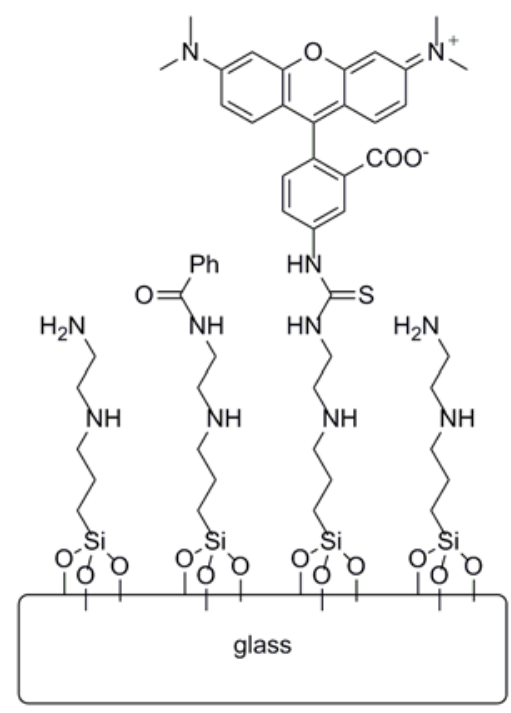

Figure 71. Structure of Crego-Calama's fluorescent anion sensor constructed on quartz selective in response to acetate.

\subsubsection{Surface attached anion sensors using electrochemical impedance spectroscopy}

Electrochemical impedance spectroscopy (EIS) is a technique which allows for the fabrication of a well-established (anion) binding motif onto a suitable surface without need to include a reporter group. The specific quantity measured in an experiment is the charge transfer resistance $\left(R_{\mathrm{ct}}\right)$ of a monolayer, which is carried out in the presence of a suitable redox-active couple, which may be a redox-active metal complex or organic molecule. If an anionic guest is bound, a build-up of negative charge occurs in the monolayer, which (e.g.) repels a negatively charged redox probe, this being detected as an increase in $R_{\mathrm{ct}}$.

For example, Echegoyen and co-workers reported upon a trisamide cyclotriveratrylene, attached to gold electrodes, that could signal the binding of acetate in aqueous solution by EIS (Figure 72). ${ }^{[183]}$ When $\left[\mathrm{Fe}(\mathrm{CN})_{6}\right]^{3-/ 4-}$ was used as the redox probe, a dramatic increase in $R_{\mathrm{ct}}$ was observed upon addition of acetate, whereas a decrease was observed when $\left[\mathrm{Ru}\left(\mathrm{NH}_{3}\right)_{6}\right]^{3+/ 2+}$ was used. These SAMs proved to be selective for acetate, with the less basic halides not being detected. In a similar system, based on a calix[6]crown-4 scaffold, selectivity for fluoride was found. ${ }^{[184]}$ In both these systems the surface confined sensor mirrored the anion binding properties of solution-phase analogues.

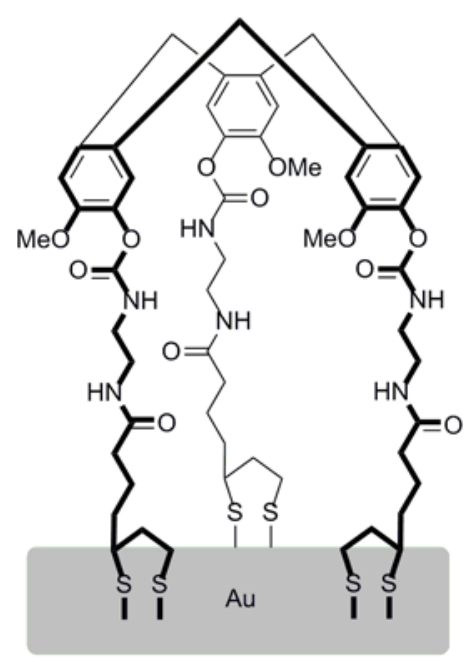

Figure 72. A cyclotriveratrylene SAM which allow for the detection of anions by EIS.

\subsection{Detection of Multiple Anions: Sensor Arrays and Pattern Recognition}

Many simple anion sensors are promiscuous, being capable of responding to a range of anions, and so will only be useful as a sensor for a particular anionic species in isolation. Typical "realworld” environmental and biological samples will not conform to this limitation. Even if a sensor is able to operate in the presence of other anions, it may be of interest to sense more than one (perhaps even all) of the anions in a sample.

A supramolecular chemistry approach to overcome these issues is to employ a sensor array. ${ }^{[185]}$ This has been demonstrated by Anzenbacher et al using eight hydrogen bond donating colorimetric sensors (six calixpyrroles, one $\mathrm{N}$-confused calixpyrrole and one 
anthraquinone, Figure 73) embedded in a polyurethane hydrogel that enabled the differentiation of ten inorganic anions. ${ }^{[186]}$ The eight sensors were carefully chosen on the basis of their anion association constants determined in organic solvents (the hydrogel desolvates the anions present in the aqueous sample, thus allowing the neutral receptors to function). The colorimetric responses of the array to anions were recorded using an electronic scanner, which facilitated the necessary computational calculations. An application was demonstrated by analysing several commercial toothpaste brands, which could be differentiated by the quantity of fluoride and other anions present. In the same year, Anzenbacher and co-workers also described a sensor array for detecting phosphate anions in human serum, using eight different (tripodal hydrogen bond donating) sensor molecules. ${ }^{[187]}$

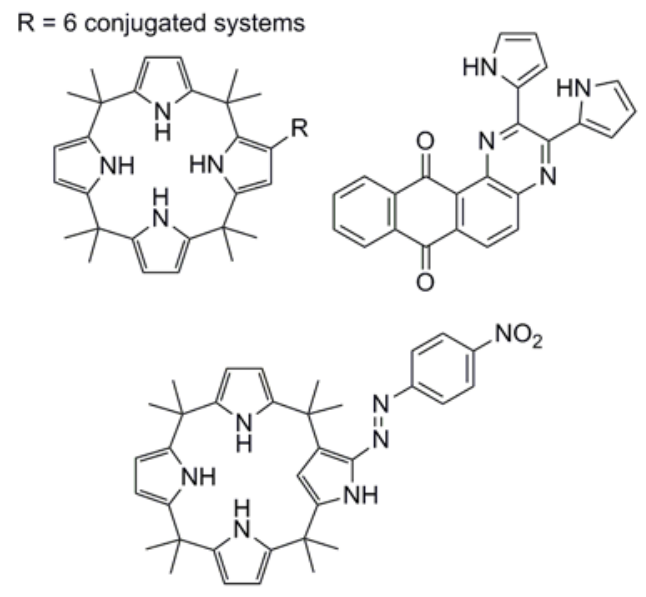

Figure 73. Structures of colorimetric anion sensors used by Anzenbacher to construct a sensor array able to differentiate brands of toothpaste by anionic composition.

A notable recent example of a ratiometric indicatordisplacement assay array capable of colorimetrically distinguishing between ten anions in water has been reported by Feng and Guan. ${ }^{[188]}$ The principle behind each IDA used is that a colorimetric indicator chelates a metal cation. Exposure to an anion may lead to the cation being removed from the indicator-cation complex. This event then produces a colorimetric response from the uncomplexed indicator. Nine chelating indicators and eight metal cations were used to construct the $3 \times 6$ array, which could analyse anions in "real-world" samples, e.g. drinking water or discharged waste streams.

\section{Anion Transportation}

\subsection{Introduction}

The investigation of synthetic anion transportation is inspired by the knowledge that a number of diseases are caused by the misregulation of anionic species across the phospholipid bilayers of cell membranes. The most well-known of these is the genetic disorder cystic fibrosis (CF), caused by the dysfunction of the CFTR anion channel in epithelial cell membranes, which impairs the flux of chloride and bicarbonate anions. ${ }^{[1]}$ In addition, it is known that prodigiosins, a family of small naturally occurring molecules capable of anion binding, possess a range of biological activity including antibiotic, immunosuppressive and antitumour behaviour. $^{[189]}$

In recent times, most anion transportation studies have used unilamellar vesicles composed of a lipid or a mixture of lipid and cholesterol to simulate the phospholipid bilayers of cell membranes. Anion efflux, as affected by added transporter molecules, may be monitored by use of (a) ion selective electrodes (ISEs); (b) encapsulated fluorescent dyes capable of detecting changes in $\mathrm{pH}$ or anion concentration and (c) NMR spectroscopy. However, real cells have been and are increasingly being used, in conjunction with whole cell patch clamp or Ussing chamber techniques. For accessible discussions of these experimental methodologies we refer interested readers to specialist reviews. ${ }^{[190]}$

Ion transport may be classified by the direction of travel of the ionic species. A uniport mechanism is where a single type of ion is transported with no other processes occurring at the same time. This process is therefore accompanied with the build-up of an electrostatic potential across the membrane. Antiport involves the transport of a species in one direction with the transport of a second species in the opposite direction. In the case of two anions this will avoid the accumulation of an electrostatic potential. The same effect may be achieve by symport (or co-transport), where two species, specifically a cation and an anion are transported in the same direction. Strictly this is ion-pair transportation, but we will cover examples for completeness in this section of the review.

Here we choose to discuss anion transportation research based primarily on whether the transporter is either (a) a mobile carrier (molecules that bind and "chaperone" the ion(s) across the bilayer) or $(b)$ an anion channel (where molecules are large enough alone, or by aggregation, to span a bilayer).

\subsection{Mobile Anion Carriers - "Anionophores"}

The design of successful mobile anion carriers, which may be termed anionophores, typically arise from examples of anion receptors. ${ }^{[191]}$ While the ability to bind the anion guest is essential, another important property to be considered is the lipophilicity of the carrier, as anion transport will be occurring across a lipophilic medium.

In one of the most established anionophore research programmes, A. P. Davis and co-workers have reported upon the use of derivatives of cholic acid, which possess both hydrogen bond donating urea groups and a lipophilic steroid skeleton that can shield a complexed anion (Figure 74) ${ }^{[192]}$ In their first studies (in collaboration with B. D. Smith), chloride anion efflux was monitored by use of an ISE and ${ }^{35} \mathrm{Cl}$ NMR spectroscopy. ${ }^{[193]}$ The strongest binders of chloride were found to be the best transporters of the anion across unilamellar vesicles. In the same report, they used an Ussing chamber to demonstrate that chloride transport was possible across live epithelium, as detected by the creation of a potential difference across the cellular membrane. 


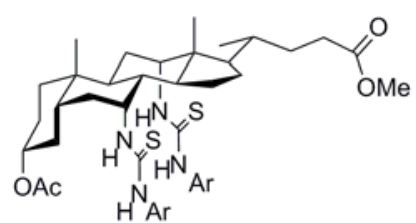

Figure 74. A. P. Davis' first cholic acid derived chloride transporter.

A greater range of studies have been subsequently taken, typically incorporating the transporter within synthetic vesicles, and using the fluorescent dye lucigenin, to monitor influx of chloride. Interesting results from these investigations include the presence of a positive charge having a deleterious effect on transport, ${ }^{[194]}$ while a cyclic "cholaphane" (Figure 75a) was shown to be a more active transporter. ${ }^{[195]}$ While a modestly stronger anion binder, the authors attribute the greater transport activity of the cholaphane to the increased shielding of the anion from solvent. More recently, the same group has reported upon simplifying the structure from a steroid scaffold to a trans-decalin, while retaining high levels of transport of activity (Figure 75b). ${ }^{[196]}$ Potentially pharmacologically useful features of this trans-decalin structure are lower lipophilicity (more likely to be deliverable through aqueous environments in vivo) and reduced molecular weight (more "drug-like"). (a)

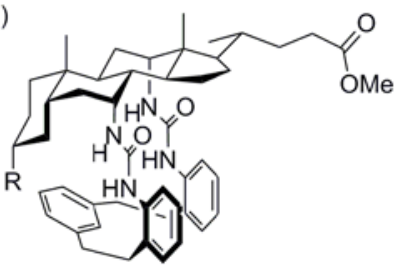

(b)

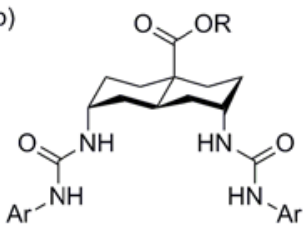

Figure 75. A. P. Davis' (a) "cholaphane" and (b) trans-decalin based anionophore.

There is a considerable body of work describing molecules capable of acting as symportic transporters of the $\mathrm{H}^{+} / \mathrm{Cl}^{-}$ion pair. For example, Sessler et al, studied the efflux of chloride across synthetic membranes by synthetic prodigiosins and dipyrromethenes using an ISE (Figure 76a). ${ }^{[197]} \mathrm{A} \mathrm{pH}$ dependency, consistent with $\mathrm{HCl}$ symport was observed. The groups of Gale and B. D. Smith have investigated a number of simple prodigiosin mimics, including examples containing pyrrole ${ }^{[198]}$ or 2, 6-pyridinedicarboxamide ${ }^{[199]}$, appended with a methylimidazole that could act as a site of protonation (Figure 76b). Chloride transport from vesicles was observed in the presence of a suitable $\mathrm{pH}$ gradient, with analogues lacking a protonable site being found to be transport inactive. (a)

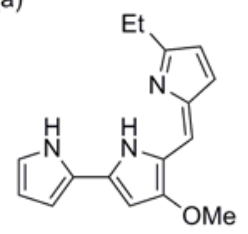

(b)<smiles>Cc1[nH]c(C(=O)NCc2cn(C)cn2)c(-c2ccccc2)c1-c1ccccc1</smiles>

Figure 76. Anionophores capable of $\mathrm{H}^{+} / \mathrm{Cl}^{-}$transport: (a) Sessler's synthetic prodigiosin and (b) Gale and B. D. Smith's imidazolepyrrole.
Systems incorporating the tris-(2-aminoethyl)amine (tren) functional group have also been studied, for the tertiary nitrogen may be protonated, while the facile incorporation of hydrogen bond donors (e.g. amides) allows for chloride complexation. For example, D. K. Smith reported upon tris-amide tren molecules able to transport $\mathrm{H}^{+} / \mathrm{Cl}^{-}{ }^{[200]}$ while J. T. Davis described a bis-catechol tren able to do so (Figure 77). ${ }^{[201]}$ In the latter case, the presence and specific substitution pattern of the catechol appeared to be crucial, for neither the tetramethylated phenol analogue, nor the 3, 4-isomer, were able to transport anions. (a)<smiles>[R][R3]#[R]</smiles>

(b)

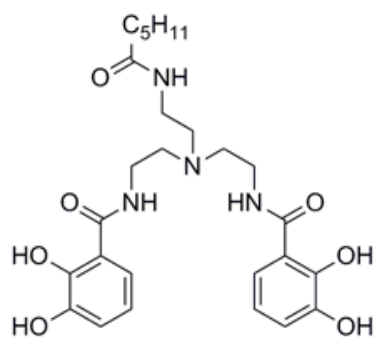

Figure 77. Tren-based anionophores capable of $\mathrm{H}^{+} / \mathrm{Cl}^{-}$transport: (a) D. K. Smith's tris-amide and (b) J. T. Davis' bis-catechol.

Attention has also been paid to the transportation of the bicarbonate anion across bilayers, with a key seminal report on this topic being made by J. T. Davis, Gale and Quesada. ${ }^{[202]}$ Studying a selection of natural and synthetic anionophores by use of ISEs and ${ }^{13} \mathrm{C}$ NMR spectroscopy, they verified that $\mathrm{Cl}^{-} / \mathrm{HCO}_{3}{ }^{-}$antiport was possible across synthetic membranes. Notably, natural prodigiosins were found to be more effective transporters than the synthetic isophthalamides investigated. Quesada has since studied synthetic prodiginines, and shown that the anti-cancer drug candidate Obatoclax (Figure 78a), was a highly active anionophore able to facilitate chloride/bicarbonate antiport. It was also shown to acidify a GLC4 cell line, and hence have considerable cytotoxic character. ${ }^{[203]}$ Similar behaviour was observed in the related, but structurally simpler, tambjamine alkaloids (Figure 78b). ${ }^{[204]}$ Meanwhile, Gale and co-workers have reported that tripodal tristhioureas are capable of $\mathrm{Cl}^{-} / \mathrm{HCO}_{3}{ }^{-}$antiport across synthetic membranes (Figure 78c). Notably, the tris-urea analogues exhibit much lower (if any) transport ability. ${ }^{[205]}$ More recently, the same group has demonstrated that squaramides can facilitate antiport chloride anion transportation, including $\mathrm{Cl}^{-} / \mathrm{HCO}_{3}{ }^{-}$exchange (Figure 78d). In this report, the squaramides were found to be better transporters than analogous thioureas and ureas. ${ }^{[206]}$ 
<smiles>COc1cc(-c2cc3ccccc3[nH]2)[nH]c1/C=C1\N=C(C)C=C1C</smiles>

(b)

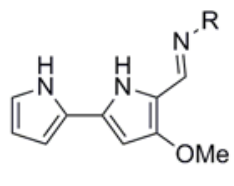

$\mathrm{R}=$ alkyl or aryl

(c)<smiles>[R]NC(=S)NCCN(CCNC(=S)N[R])CCNC(=S)N[R]</smiles>

(d)

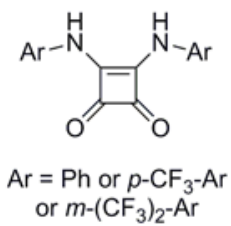

Figure 78. Anionophores capable of $\mathrm{Cl}^{-} / \mathrm{HCO}_{3}{ }^{-}$transport: (a) Obatoclax, (b) tambjamine alkaloids,(c) tripodal tris-thioureas and (d) squaramides.

This interest in the transportation of other biologically relevant anions is a developing research theme. Gale and co-workers have reported that ortho-phenylenediamine-based ureas are capable of the antiport transportation of maleate and fumarate (Figure 79a). ${ }^{[207]}$ The same group has also disclosed that thioureas can act as antiport transporters of lactate and pyruvate (Figures $79 b$ \& c). ${ }^{[208]}$ In this case, variation in transporter structure led to a change in selectivity in transportation efficiency; the simpler thiourea-indole (Figure 79b) transported pyruvate more effectively, while the inclusion of an amide (Figure 79c) led to a transporter with greater efficiency for lactate - the authors proposed the presence of an additional hydrogen bond between receptor and lactate could explain this observation.

(a)

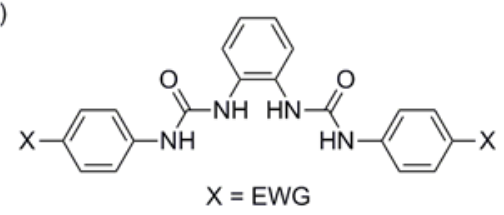

(b)<smiles>CCCCCCNC(=S)Nc1cccc2cc[nH]c12</smiles>

(c)

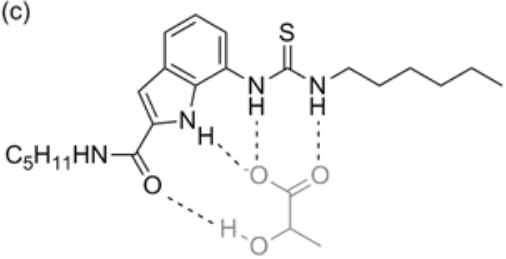

Figure 79. Anionophores for: (a) maleate and fumarate, (b) pyruvate and (c) lactate.

Sulfate is a highly hydrophilic anion (in part due to its double negative charge), and hence is hugely challenging to transport across

a lipophilic membrane. Gale, Jolliffe and Plavec have very recently demonstrated direct evidence of achieving sulfate transportation with tris-(thio)ureas based on tren or cyclopeptide scaffolds, by use of ${ }^{33} \mathrm{~S}$ NMR spectroscopy. ${ }^{[209]}$ Specifically, ${ }^{33}$ S-labelled sulfate, in conjunction with paramagnetic $\mathrm{Mn}^{2+}$ and $\mathrm{Fe}^{3+}$ cations, allowed for the discrimination of intra- and extravesicular sulfate. Using this technique, it was shown that the cyclopeptide cage in Figure 80, could facilitate not only $\mathrm{Cl}^{-} / \mathrm{SO}_{4}{ }^{2-}$ and $\mathrm{HCO}_{3}{ }^{-} / \mathrm{SO}_{4}{ }^{2-}$ antiport, but $\mathrm{Mn}^{2+} / \mathrm{SO}_{4}{ }^{2-}$ symport as well.

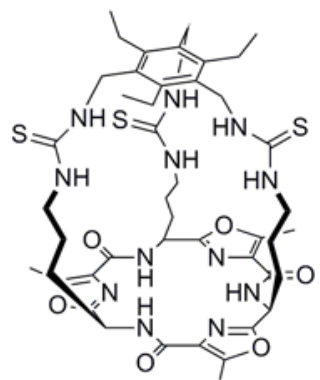

Figure 80. Tris-thiourea cyclopeptide cage capable of facilitating transmembrane sulfate transportation.

Hydrogen bonding has been all but ubiquitous in the anionophores described to date. However, calix[4]arenes that can bind and transport anions by anion- $\pi$ (Figure 81a) or halogen bonding (Figure 81b) interactions have been prepared by Matile and co-workers. ${ }^{[10]}$ In a more recent communication, the ability of simple, commercially available halogenated compounds to transport anions, utilizing halogen bonding, has been reported by the same group (Figure 81c). ${ }^{[211]}$ (a)<smiles>Cc1cccc(C(C)(C)C)c1OCc1c(F)c(F)c(F)c(F)c1F</smiles>

(b)<smiles>Cc1cccc(C(C)C)c1OCc1cccc(I)c1</smiles>

(c)<smiles>Fc1c(F)c(F)c(I)c(F)c1F</smiles>

Figure 81. Anionophores that utilize (a) anion- $\pi$ and (b) \& (c) halogen bonding interactions.

\subsection{Anion Channels}

Considering that Nature employs channels to transport anions, it is unsurprising that there has been research into the development of synthetic analogues. Here we provide a few illustrative examples; for further discussions we refer interested readers to specialist reviews. ${ }^{[190]}$

Tomich and co-workers have been pursuing the preparation of chloride ion transporting channels for some considerable time. ${ }^{[212]}$ Basing their work on the natural spinal cord glycine receptor ion channel, 22-amino acid residue peptides have been synthesised, and found to be selective for chloride, as tested by the planar lipid bilayer method. Gokel and co-workers have reported upon the use of shorter amphiphilic heptapeptides, which form anion channels upon 
dimerizing in a bilayer (Figure 82). ${ }^{[213]}$ This group has been able to optimize features (e.g. the lipophilic $\mathrm{N}$ - and C- termini and the actual amino acid sequence) of the peptides to maximize chloride transport efficiency. ${ }^{[214]}$ Specific examples were also demonstrated (by Ussing chamber experiments) to effect anion transport in epithelial cells. $^{[215]}$

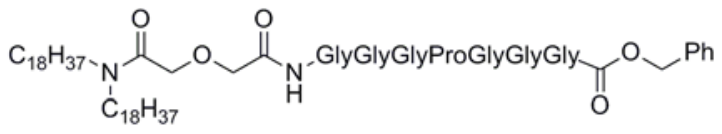

Figure 82. Structure of Gokel's prototype amphiphilic heptapeptide.

Relatively small molecules may act as anion channels. For example, J. T. Davis et al have used voltage-clamp experiments to demonstrate that a 1, 3-alternate tetrabutylamide calix[4]arene could assemble into channels for the transport of the $\mathrm{H}^{+} / \mathrm{Cl}^{-}$ion pair (Figure 83). ${ }^{[216]}$ Subsequently the same group have reported upon calix[4]arenes existing in partial cone $e^{[217]}$ and cone $e^{[218]}$ conformations that also form ion channels that permit the transfer of the same ion pair.

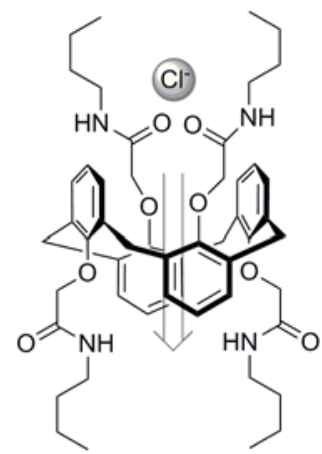

Figure 83. J. T. Davis' 1, 3-alternate tetrabutylamide calix[4]arene.

Matile and co-workers have been working upon anion- $\pi$ slides. ${ }^{[76]}$ In the archetypal example, rigid, membrane spanning, $p$ oligo-(p-phenylene)- $N, N$-napthalenediimide rods transport chloride across a bilayer by anion- $\pi$ interactions (Figure 84). ${ }^{[219]}$ More recently, perylenediimide analogues have been shown to facilitate anion transport as well. ${ }^{[220]}$

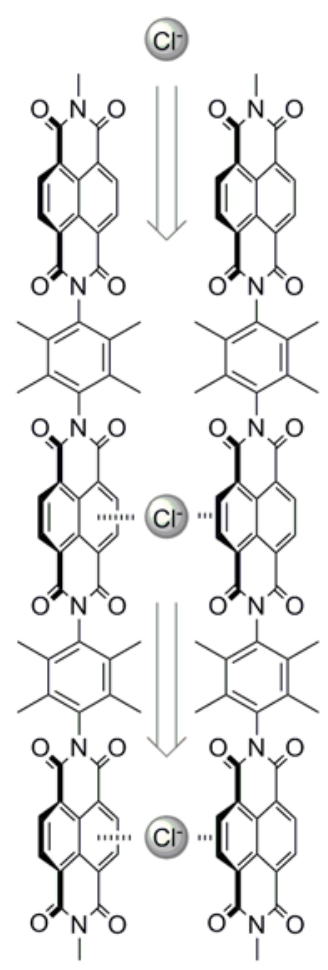

Figure 84. Matile's napthalenediimide anion- $\pi$ slide.

\section{Future Directions: Applications of Anion Supramolecular Chemistry}

Here attention is turned to examples of functional applications of anion supramolecular chemistry. Some of these research themes have already reached remarkably high levels of research output, whilst others, in comparison, are somewhat underexplored.

\subsection{Anions in Catalysis}

\subsubsection{Anion recognition in asymmetric organic catalysis using neutral hydrogen bond donors}

The use of hydrogen bond donating molecules as catalysts of asymmetric organic chemical transformations represents an elegant demonstration of how knowledge of anion recognition may be applied to a chemical application. This area has attracted huge amounts of research interest, and we emphasize that what follows merely represents a couple of highlights from a large number of examples which may be found from the literature. ${ }^{[221]}$

For example, Jacobsen et al reported upon a thiourea catalyzed enantioselective Pictet-Spengler cyclization (Figure 85)..$^{[222]}$ The proposed reaction mechanism has the chiral thiourea catalyst hydrogen bonding to the chloride counteranion of the charged electrophile, thus allowing chiral information to be transferred from the thiourea to the cyclizing molecule. Further reactions where chloride, ${ }^{[223]}$ and alternatively, bromide ${ }^{[224]}$ and fluoride ${ }^{[225]}$ anions are bound by chiral thiourea catalysts have been reported by the same group. 


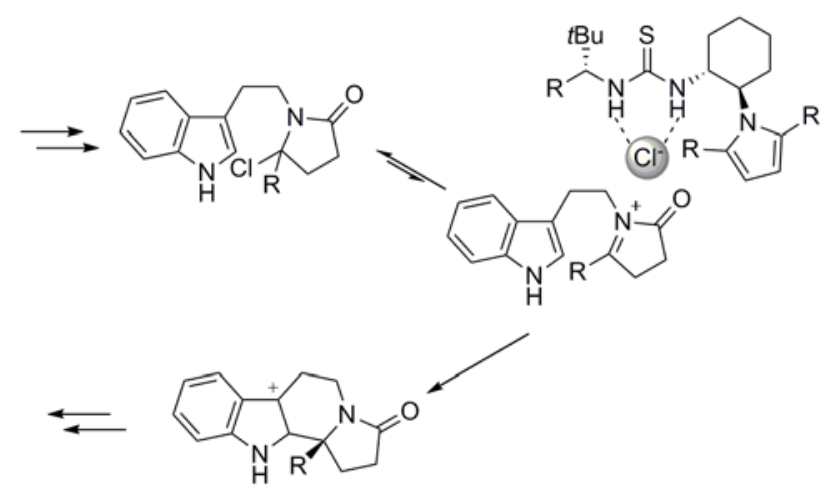

Figure 85. Key mechanistic steps in Jacobsen's thiourea catalyzed Pictet-Spengler cyclization, with a mediating chloride anion.

In a recent study Ooi and co-workers have disclosed that chiral 1, 2, 3-triazoliums can act as cationic organocatalysts in the asymmetric alkylation of oxindoles (Figure 86). Optimization of catalyst structure and solvent allowed for almost quantitative yields and enantiomeric excesses of up to $97 \%$. ${ }^{[226]}$

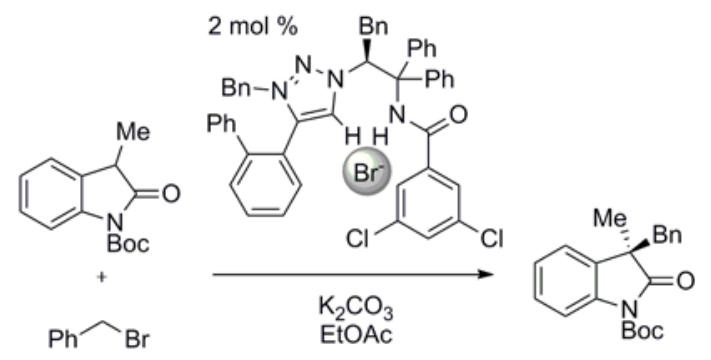

Figure 86. Ooi's asymmetric alkylation of oxindoles, catalyzed by a chiral 1, 2, 3-triazolium organocatalyst.

\subsubsection{Chiral anion catalysis in organic chemistry}

Another highly investigated research theme utilizing anions in catalytic reactions has been the deployment of chiral anions in achieving stereoselective organic transformations. ${ }^{[227]}$ In the majority of cases these have been axially chiral binaphthylphosphate anions. For example, Mayer and List reported upon the transfer hydrogenation of $\alpha, \beta$-unsaturated aldehydes using dihydropyridine and $20 \mathrm{~mol} \%$ of an ammonium binaphthylphosphate salt, with enantiomer excesses $>98 \%$ being observed (Figure 87 ). ${ }^{[228]}$ Xiao and co-workers have subsequently demonstrated that an Ir $^{\text {III }}$ catalysed imine hydrogenation could similarly operate at high levels of enantioselectivity by use of binaphthylphosphates as counter ions to the cationic $\operatorname{Ir}^{\mathrm{III}}$ organometallic fragment. ${ }^{[229]}$

Toste et al have also described the use of a chiral binaphthylphosphate anion, to mediate the asymmetric ring opening of meso-aziridinium and episulfonium ions (Figure 88). ${ }^{[230]}$ The positively charged 3-membered rings that are formed in the first stages of the reaction associate with the chiral anion, thus directing the attack of the incoming nucleophilic alcohol, with enantiomeric excesses $>90 \%$.

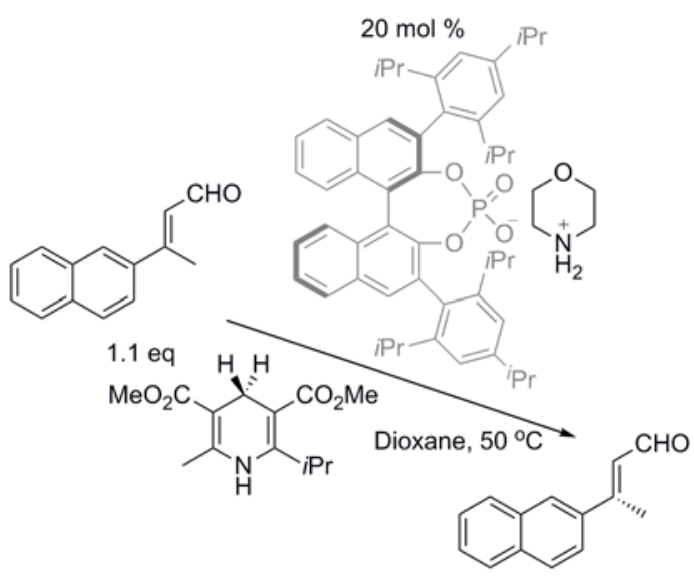

Figure 87. Mayer and List's enantioselective transfer hydrogenation of unsaturated aldehyedes, utilizing a chiral binaphthylphosphate anion.

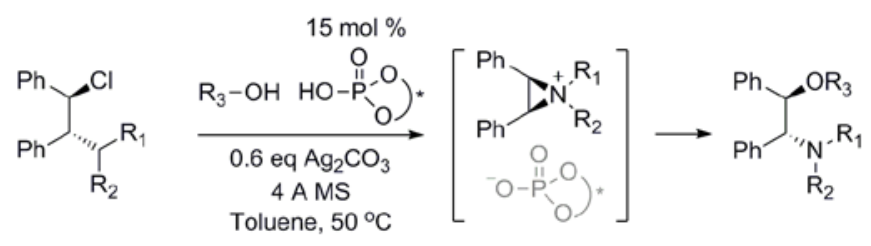

Figure 88. Mechanism of Toste's chiral anion mediated asymmetric ring opening of meso-aziridinium ions.

In contrast, Liao and List's report on the enantioselective epoxidation of alkenes with a $\mathrm{Mn}^{\text {III }}$ salen complex involves coordination of the chiral anion with the catalytic reagent, rather than the reaction substrate (Figure 89). ${ }^{[231]}$ After thorough screening almost quantitative yields and enantiomeric excesses of up to $96 \%$ were achieved.

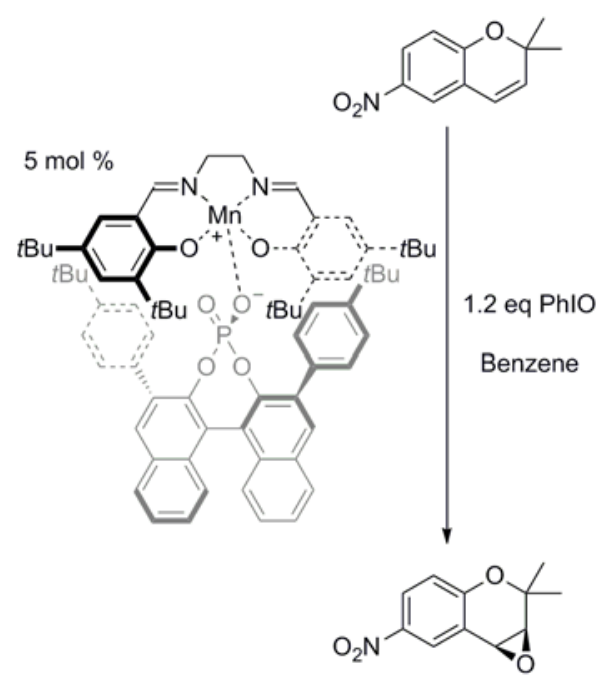

Figure 89. Liao and List's enantioselective epoxidation of alkenes with a $\mathrm{Mn}^{\text {III }}$ salen-chiral phosphate complex.

In a notable departure, Reek and co-workers have investigated the use of chiral carboxylate anions as co-factors in enantioselective catalysis. ${ }^{[232]}$ Specifically, they studied a bis-phosphine Rh complex 
that contained a bis-amidodiindolylmethane hydrogen bond donor array in the ligand structure. Addition of a chiral carboxylate allows for formation a chiral complex (in dichloromethane), that induces enantioselective hydrogenation (Figure 90).

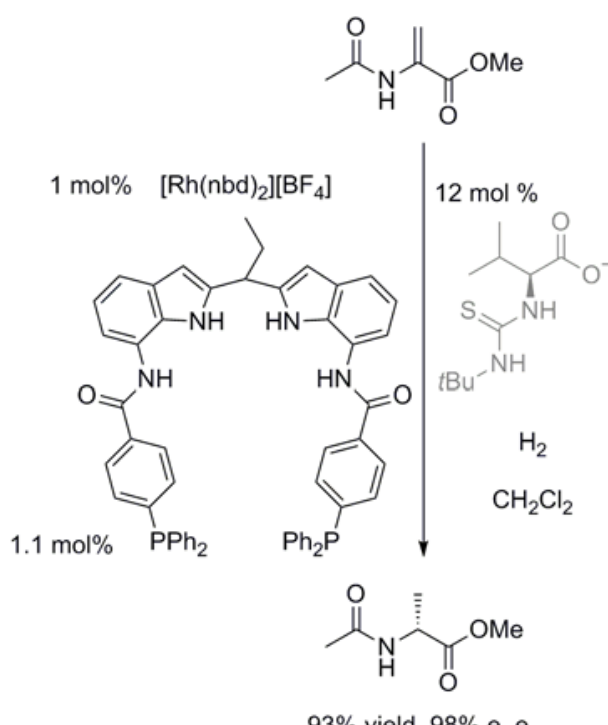

Figure 90. Reek's asymmetric hydrogenation using a chiral co-factor.

\subsubsection{Anion templation in the synthesis of catalytic nanoparticles}

Bimetallic core@shell nanoparticles, consisting of a "shell" coating a "core", possess unique catalytic properties. Beer and coworkers have used anion coordination as a novel synthetic methodology to prepare Au@Pd and Pt@Pd core@shell nanoparticles. ${ }^{[233]}$ First, core nanoparticles are prepared using stabilizing ligands containing hydrogen bond donating amides. Then the shell metal is introduced, in an oxidized form, as part of an anionic $\left[\mathrm{MCl}_{4}\right]^{\mathrm{n}-}$ complex which is bound by the hydrogen bond donating amides (Figure 91). To complete the synthesis, the metal is reduced, yielding the core@shell nanoparticles. The Au@Pd nanoparticles synthesized by this method were shown to be highly efficient in catalysing the industrially useful conversion of chloronitrobenzene to chloroaniline.

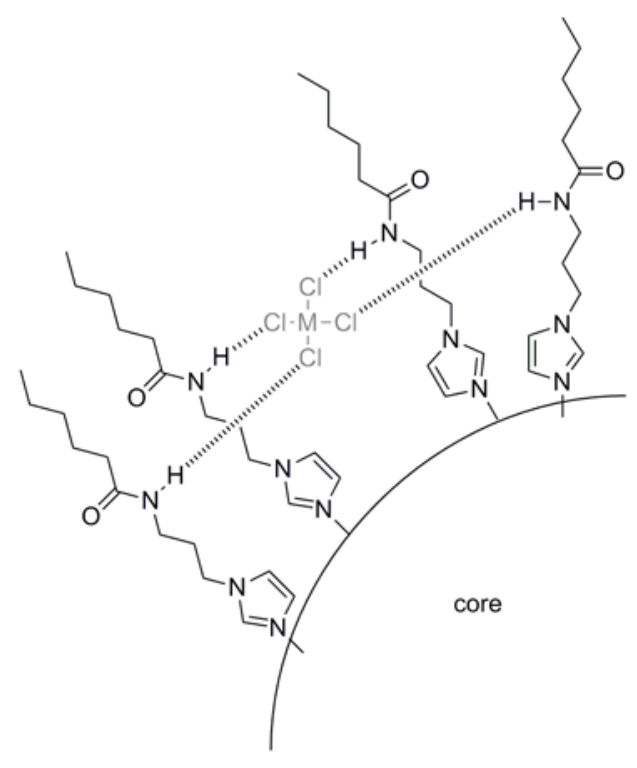

Figure 91. Beer's method of synthesizing core@shell nanoparticles via complexation of the shell metal as an anionic complex by functionalized core nanoparticles.

\subsection{Anionic Extraction}

As stated in the Introduction, a key motivation for investigating anion recognition is the capture and removal of certain anionic pollutants from the natural environment often resulting from anthropogenic activities. An excellent demonstration of anionic extraction is provided by Custelcean and co-workers, who have been able to separate sulfate from simulated nuclear waste. Key challenges they faced included the strong hydration of the dianion, the presence of various competing anions and extreme alkalinity $(\mathrm{pH}>14)$. However, a remarkably simple tren-tris-urea (see Figure 92a) can extract sulfate from simulated nuclear waste by crystallisation. ${ }^{[234]}$ One equivalent of sulfate anion is bound by hydrogen bonds from two tren-tris-urea ligand molecules that encapsulate their oxoanion guest (as evidenced by crystallographic structure determination), with sodium ions acting as the necessary counter-cations.

Similar tren-tris-urea molecules have also been employed by Tasker and Schröder in the extraction and transport of the $\left[\mathrm{PtCl}_{6}\right]^{2-}$ anion (Figure 92b). ${ }^{[235]}$ The industrial isolation of Pt cannot utilize inner-sphere coordination complexes due to the very slow ligand exchange kinetics of the $\mathrm{Pt}^{\mathrm{IV}}$ cation, and so outer-sphere coordination complexation is required to form neutral anion-ligand systems. As for Custelcean's sulfate system, one equivalent of $\left[\mathrm{PtCl}_{6}\right]^{2-}$ anion is bound by two tren ligands, but the tren ligands are protonated and crystallographical structure determination indicates that only two of the tren "arms" participate in hydrogen bonding with any given anion. The authors were able to demonstrate that this system was able to recover $\mathrm{Pt}^{\mathrm{IV}}$ from acidic chloride feed solutions. 
(a)<smiles>O=C(NCCN(CCNC(=O)Nc1cccnc1)CCNC(=O)Nc1cccnc1)Nc1cccnc1</smiles>

(b)<smiles>COc1ccc(NC(=O)NCCN(CCNC(=O)Nc2ccc(OC)cc2)CCNC(=O)Nc2ccc(OC)cc2)cc1</smiles>

Figure 92. Structures of tren-tris-ureas used by (a) Custelcean to extract sulfate from simulated nuclear waste and (b) Tasker and Schröder to extract and transport $\left[\mathrm{PtCl}_{6}\right]^{2-}$.

\subsection{Anion Responsive Materials and Molecules}

The generation of systems which respond by a change in property that is beyond a perturbation leading simply to an optical or electrochemical sensory response is a key area of investigation in supramolecular chemistry today. With their wide variety of geometries, anions offer possibilities which can complement those offered by other classes of chemical or physical stimuli. While significant progress has been made in developing anion responsive materials and molecules, this area of research is still in its infancy and has much potential for future development.

\subsubsection{Anion responsive gels and liquid crystals}

A gel is a semi-solid colloidal system, consisting of a fibrous solid network and a solvent that is retained within this solid "structure". A gel will remain in the vessel it is residing upon inversion of the vessel, however, upon heating it may pass through a phase transition, equivalent to the melting of a solid, at a temperature denoted $T_{\text {gel }}$. Molecules containing neutral hydrogen bond donors and acceptors, for example ureas, may form gels provided the solvent is not too competitive to prevent hydrogen bonding. Anions may be added that compete as hydrogen bond acceptors, hence disrupting the network and lowering $T_{\text {gel }}{ }^{[236]}$

For example, Steed and co-workers have reported a set of bisureas ( $\mathrm{n}=2,4,6,8$ in Figure 93) that act as gelators in chloroform. $^{[237]}$ Addition of strongly binding anions - such as acetate - reduces gel strength, and in one case $(n=2)$ disrupts gel formation completely. Importantly, a practical use of this phenomenon has been found in the growth of crystals of pharmaceutical molecules. ${ }^{[238]}$ Historically, this application has used hydrogels, which typically require harsh conditions to disrupt the gel phase which may dissolve the crystals being obtained. By using bisureas gelators, similar in structure to those shown in Figure 93, addition of acetate triggers the destruction of the gel, allowing for easy isolation of the desired crystal.<smiles>CC(NC(=O)NC(C)C(C)NC(=O)NC(C)c1ccccc1)C(=O)NC(C)c1ccccc1</smiles>

Figure 93. Structure of Steed's bis-urea gelators illustrating the hydrogen bonding between individual molecules.

Anion-triggered hydrogelators have also been reported. For example, Mocerino and Ogden described a proline functionalized calix[4]arene (Figure 94a) which formed hydrogels in the presence of specific anions; the effect the anion had on gel stability being attributed to the Hofmeister series. ${ }^{[239]}$. Zhang and co-workers demonstrated that protonated melamine will form gels in water with oxoanions such as nitrate, phosphate, sulfate and ATP (Figure 94b). ${ }^{[240]}$ In both cases gelation can be switched off by increasing $\mathrm{pH}$ which leads to deprotonation of the gelator and loss of the positive charge required to interact with the anion in the competitive aqueous solvent.

(a)

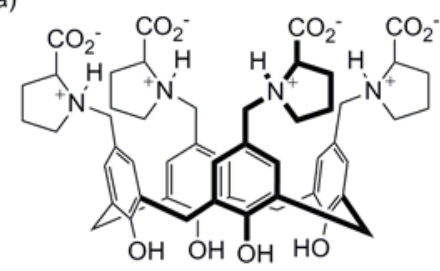

(b)<smiles>Nc1nc(N)nc(N)n1</smiles>

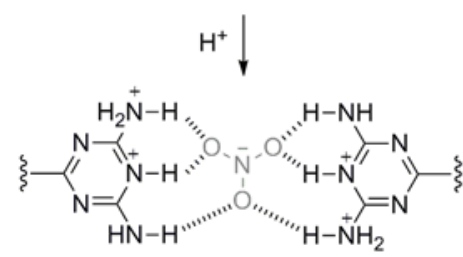

Figure 94. Anion-triggered hydrogelators: (a) structure of proline functionalized calix[4]arene and (b) proposed hydrogen bonding interactions of anion-templated gel structure of melamine and nitrate. 
Anions have also been used to affect the supramolecular structures of liquid crystals. Kim and co-workers incorporated a guanidinium motif onto the apex of a liquid crystalline molecule to allow for interaction of an anion with the molecule (Figure 95). ${ }^{[241]}$ The resulting cation forms supramolecular structures dependent upon the nature of the counter-anion: hexagonal columnar when nitrate or tetrafluoroborate, rectangular columnar with $\mathrm{HCCCO}_{2}^{-}$, while a cubic mesophase is observed with chloride. Notably the deprotonated guanidine is not a liquid crystal but does form a gel phase in dodecane.<smiles>[X]/C(N)=[W]\Nc1cc(OCCC)c(OCCC)c(OCCC)c1</smiles>

Figure 95. Kim's guanidinium functionalized liquid crystalline molecule, which exhibits different supramolecular structures depending on counter-anion.

\subsubsection{Anion responsive complexes and molecules}

The effect of anions on the structures and conformational behaviours of single chemical species has also been documented. For example, Yam and co-workers have reported the anion assisted trans-cis isomerization of a $\mathrm{Pd}^{\mathrm{II}}$ phosphine complex (Figure 96). ${ }^{[242]}$ Both phosphine ligands contain an acetanilide functionality, which can form a convergent hydrogen bonding cleft to an appropriate anion, only when cis to one another. Hence, in chloroform, the addition of chloride or triflate results in trans-cis isomerization, which may be reversed by the addition of DMSO.

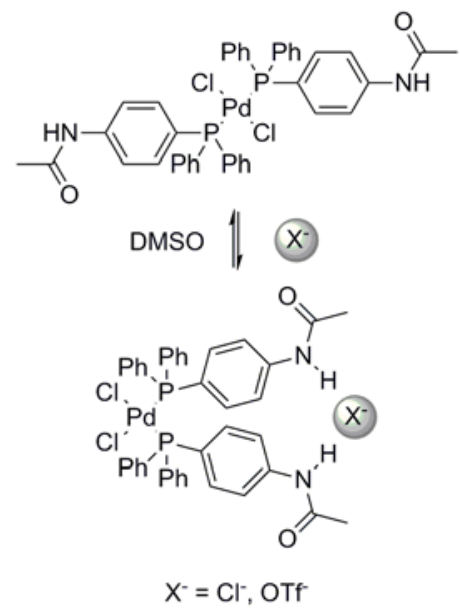

Figure 96. Yam's anion assisted trans-cis isomerization of a Pd" phosphine complex.

Hamilton has documented the ability of halide anions to control the conformation of hydrogen-bonded diphenylacetylenes. ${ }^{[243]}$ In chloroform, the free diphenylacetylene in Figure 97 exists mainly ( $9: 1)$ in the conformation where the ester carbonyl can hydrogen bond to one of the $\mathrm{N}-\mathrm{H}$ groups of the acidic urea functionality. A halide anion will bind in preference to the urea, so upon the addition of chloride, the phenylacetylene rotates, to allow for the ester $\mathrm{C}=\mathrm{O}$ to hydrogen bond to the amide $\mathrm{N}-\mathrm{H}$ instead.

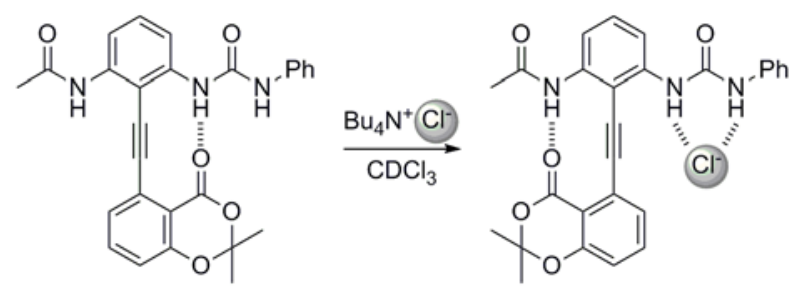

Figure 97. Hamilton's halide anion controlled hydrogen-bonded diphenylacetylene.

A principal incentive for the preparation of interlocked architectures is the potential for such molecules to exhibit relative motion of their constituent parts. In recent times, it has been shown that this may be achieved by use of anionic stimuli. For example, Beer et al have reported upon a pH switchable catenane (Figure 98). ${ }^{[24]}$ Synthesised by chloride anion templation and then exchanged to the hexafluorophosphate salt, the catenane contains a phenol which may be deprotonated to generate a phenoxide moiety. The catenane undergoes ring rotation so that the phenolate anion is bound by the pyridinium isophthalamide motif. Re-protonation reverses the process, driven by favourable aromatic donor-acceptor interactions of the electron poor pyridinium ring with the electron rich hydroquinones. A pH switchable phenol containing rotaxane shuttle has also been reported by Keaveney and Leigh. ${ }^{[245]}$
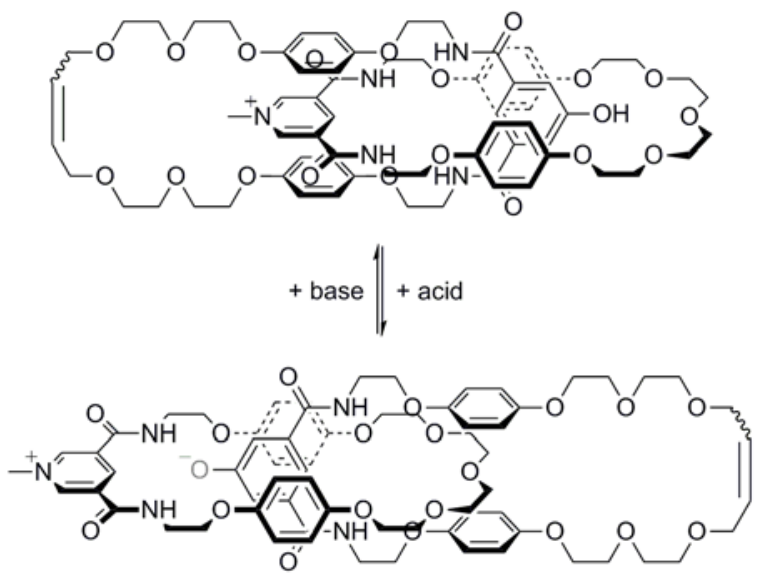

Figure 98. Beer's pH switchable phenol/phenoxide catenane.

Alternatively, the switching of the counter-anion of a positively charged interlocked molecule may induce molecular motion. For instance, Leigh et al synthesised the chloride salt of a rotaxane (Figure 99), where the macrocyclic component initially resides over a pyridinium ring in the axle, due to electrostatic attraction between the positively charged pyridinium ring and a negatively charged chloride ion coordinated to a $\mathrm{Pd}^{\mathrm{II}}$ cation bound by the macrocycle. ${ }^{[246]}$ Exchange of chloride for the non-coordinating hexafluorophosphate, leaves the $\mathrm{Pd}^{\mathrm{II}}$ cation coordinatively unsaturated and induces shuttling to the Lewis basic nitrogen of the triazole. Re-introduction of chloride returns the macrocycle to its original position. Other rotaxane shuttles, switchable by $\mathrm{Cl}^{-} / \mathrm{PF}_{6}{ }^{-}$ metathesis, have also been reported by the groups of Beer ${ }^{[247]}$ and Chiu. ${ }^{[248]}$ 


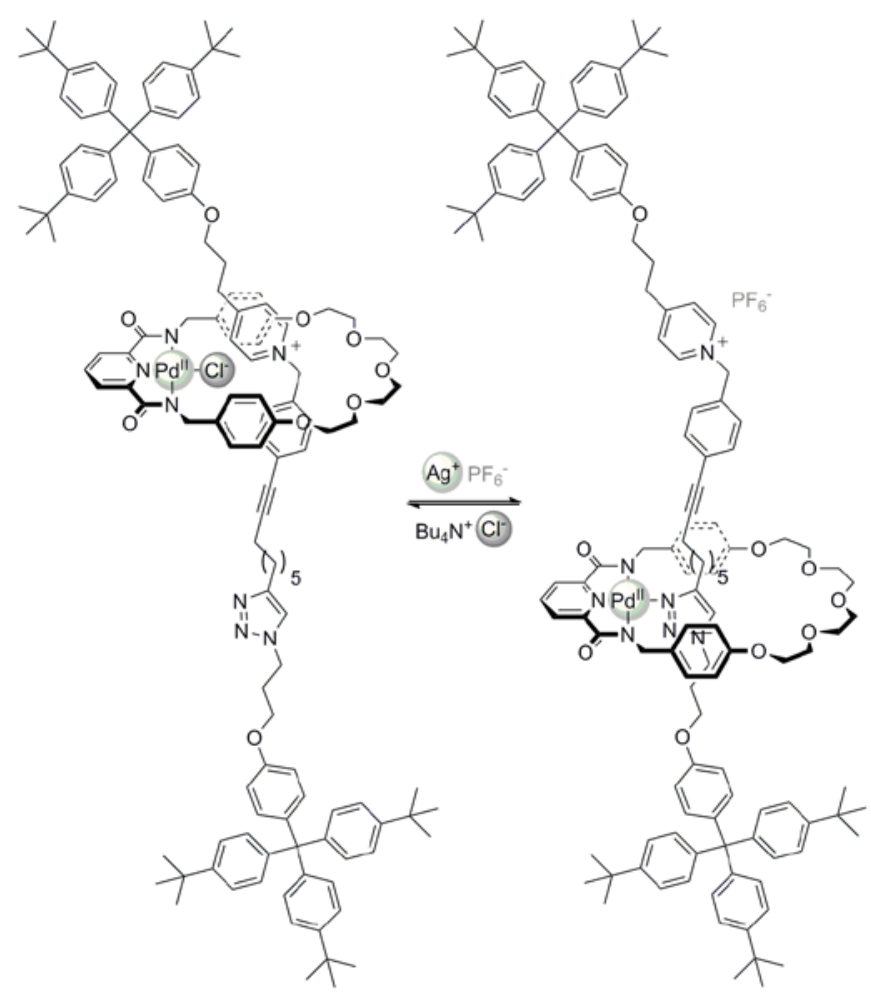

Figure 99. Leigh's molecular shuttle driven by $\mathrm{Cl}^{2} / \mathrm{PF}_{6}{ }^{-}$metathesis.

A neutral rotaxane, switchable by the addition and removal of acetate, has been reported by Chiu and co-workers (Figure 100). ${ }^{[249]}$ In $1: 1 \mathrm{CDCl}_{3}-\mathrm{CD}_{3} \mathrm{CN}$, the axle of the rotaxane resides with the urea $\mathrm{C}=\mathrm{O}$ hydrogen bonding to the 2,6-pyridyl-bis-amide of the macrocycle. In the presence of acetate, the urea N-Hs hydrogen bond to the anion, forcing the macrocycle to move and hydrogen bond to the ester $\mathrm{C}=\mathrm{O}$ instead.
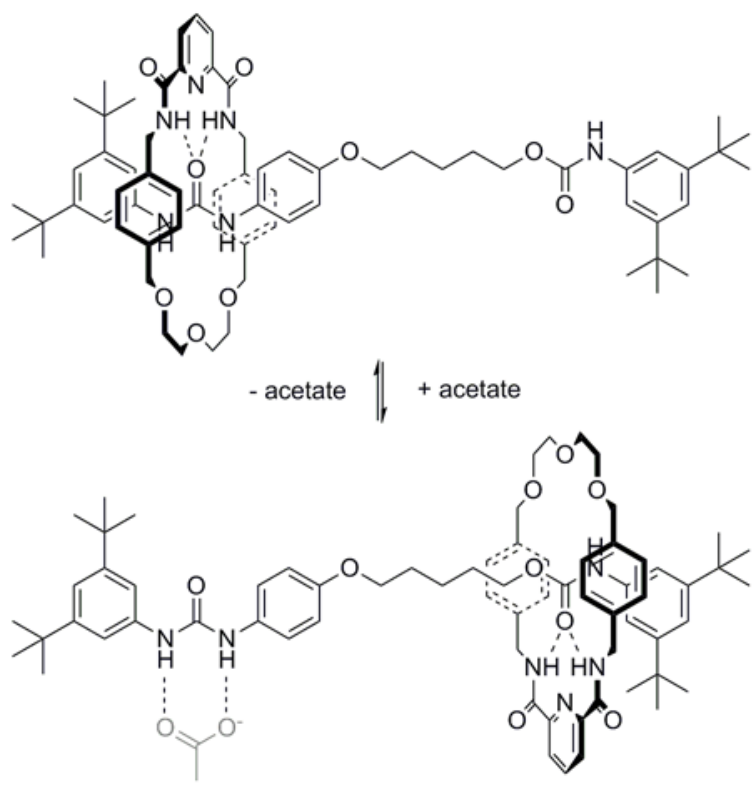

Figure 100. Chiu's acetate-driven molecular shuttle.

We note that appropriately designed switchable interlocked molecules have been shown to act as anion sensors. Examples of rotaxane shuttles that provide an optical sensory response to chloride have been reported recently by $\mathrm{B}$. D. Smith (vide supra $)^{[158,159]}$ and Beer. ${ }^{[250]}$

\subsubsection{Anion responsive transition metallo-organic cages}

While metal templated organic cages that can act as anion receptors are known, ${ }^{[251]}$ examples that are responsive to anionic stimuli, either by reconstitution of the cage or by disturbing an equilibrium of isomers have only been reported very recently.

Nitschke and co-workers have described that the reaction of $p$ toluidine, 6, 6'-diformyl-3, 3'-bipyridine and $\mathrm{Co}(\mathrm{OTf})_{2}$ produces a $\left[\mathrm{Co}_{4} \mathrm{~L}_{6}\right]^{8+}$ tetrahedron, where each ligand $\mathrm{L}$ is a bis-imine bipyridyl (Figure 101). ${ }^{[252]}$ The addition of $\mathrm{LiClO}_{4}$ leads to a structural reconstitution, to create a barrel-like $\left[\mathrm{Co}_{10} \mathrm{~L}_{15}\right]^{20+}$ pentagonal prism, which binds chloride within its structure, with an affinity $K>$ $6 \times 10^{5} \mathrm{M}^{-1}$. The same group has also reported on an alternative system, where 4, 4'-diaminobiphenyl, 2-formylpyridine and a $\mathrm{Fe}^{\mathrm{II}}$ salt are allowed to react. $\mathrm{A}\left[\mathrm{Fe}_{4} \mathrm{~L}_{6}\right]^{8+}$ tetrahedral cage results, which exists as a system of interconverting diastereomers in solution. The addition of anionic guests leads to new combinations of diastereomers, which are able to rotate their bonds to adapt to the particular anion added. ${ }^{\text {[253] }}$

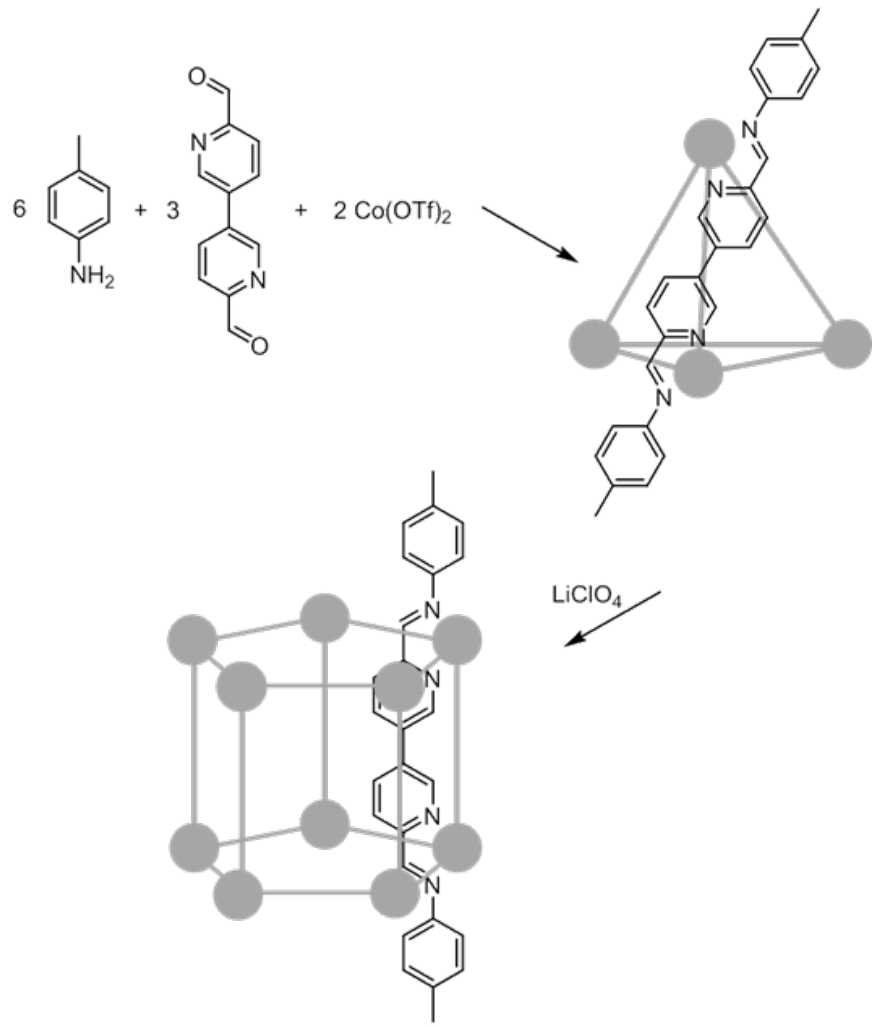

Figure 101. Nitschke's $\left[\mathrm{Co}_{4} \mathrm{~L}_{6}\right]^{8+}$ tetrahedron and $\left[\mathrm{Co}_{10} \mathrm{~L}_{15}\right]^{20+}$ pentagonal prism.

Chofotides and Dunbar have studied the conversion of $\mathrm{Fe}^{\mathrm{II}}$ bispyridyl tetrazine metallo-cages with $\pi$-acidic cavities by exchange of the anion encapsulated within the self-assembled structure (Figure 102). ${ }^{[254]}$ They first established that a 3, 6-bis(2-pyridyl)1, 2, 4, 5-tetrazine (bptz) ligand forms a molecular square $\left[\mathrm{Fe}_{4}(\mathrm{bptz})_{4}\left(\mathrm{CH}_{3} \mathrm{CN}\right)_{8}\right]\left(\mathrm{BF}_{4}\right)_{8}$ with the $\mathrm{BF}_{4}{ }^{-}$anion and a pentagon $\left[\mathrm{Fe}_{5}(\mathrm{bptz})_{5}\left(\mathrm{CH}_{3} \mathrm{CN}\right)_{10}\right]\left(\mathrm{SbF}_{6}\right)_{10}$ with the $\mathrm{SbF}_{6}{ }^{-}$anion. X-ray 
crystallography indicated that a $\mathrm{BF}_{4}{ }^{-}$and (two) $\mathrm{SbF}_{6}{ }^{-}$ions reside within the cavities of the respective self-assembled structures. It was then demonstrated that it was possible convert a $\mathrm{SbF}_{6}{ }^{-}$templated pentagon to a square, by use of a 25 -fold excess $\mathrm{BF}_{4}{ }^{-}$in refluxing acetonitrile. The failure to achieve this conversion under less stringent conditions (a 15-fold excess of $\mathrm{BF}_{4}^{-}$, stirring at room temperature), suggests that the pentagonal $\mathrm{SbF}_{6}{ }^{-}$capsule is much more stable than the square $\mathrm{BF}_{4}{ }^{-}$structure.

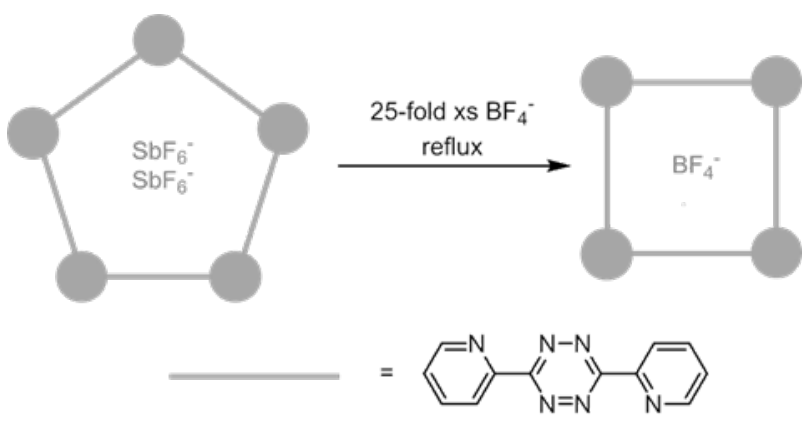

Figure 102. Chofotides and Dunbar's study of conversion of a $\mathrm{SbF}_{6}$ templated pentagonal cage to $\mathrm{aBF}_{4}{ }^{-}$templated molecular square.

Clever et al have reported upon the elegant formation of an interpenetrated coordination cage upon $\mathrm{BF}_{4}{ }^{-} / \mathrm{Cl}^{-}$metathesis (Figure 103). ${ }^{[255]}$ By use of a dibenzosuberone bis-monodentate pyridyl ligand derivatised with a bulky aryl substituent, formation of a thermodynamically stable monomeric $\left[\mathrm{Pd}_{2} \mathrm{~L}_{4}\right]\left(\mathrm{BF}_{4}\right)_{4}$ cage occurs in acetonitrile upon reacting the ligand with $\left[\mathrm{Pd}\left(\mathrm{CH}_{3} \mathrm{CN}\right)_{4}\right]\left[\mathrm{BF}_{4}\right]$. Addition of the much smaller chloride anion permits dimerization, resulting in an interpenetrated $\left[\mathrm{Cl} @ \mathrm{Pd}_{4} \mathrm{~L}_{8}\right]\left(\mathrm{BF}_{4}\right)_{7}$ double cage. The enlarged outer pockets of this double cage show a preference for the binding of large anions such as $\mathrm{ReO}_{4}{ }^{-}$.

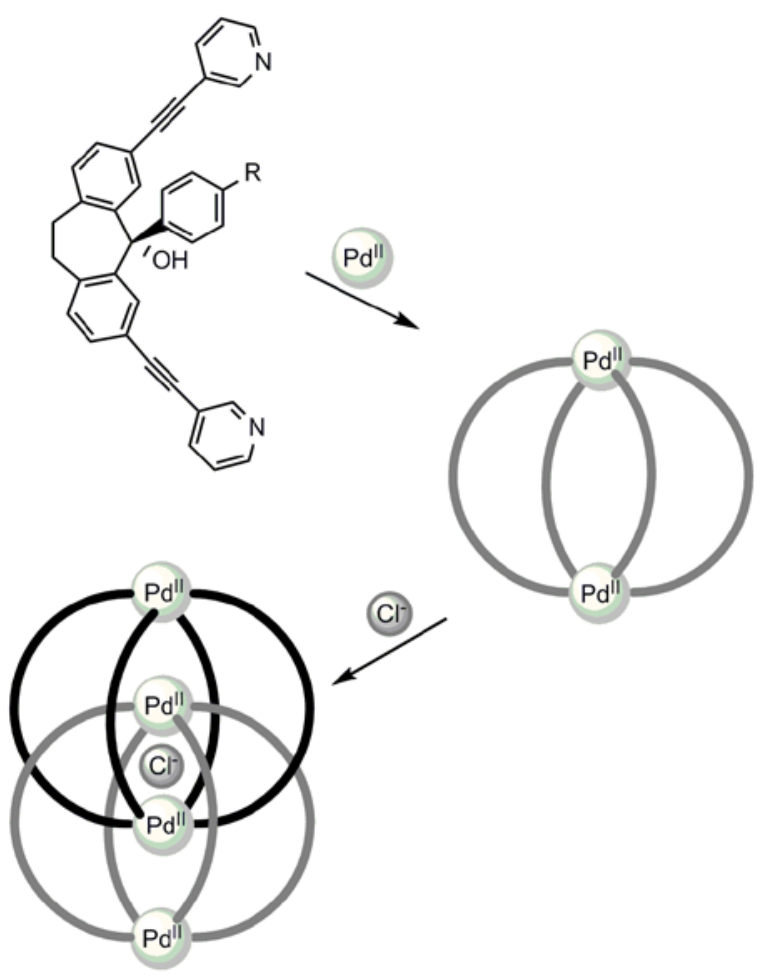

Figure 103. Clever's monomeric cage that can form an interpenetrated dimer upon $\mathrm{BF}_{4} / \mathrm{Cl}^{-}$metathesis.

\section{Conclusion and Outlook}

In the last ten years or so, since the last review, ${ }^{[16]}$ a vast wealth of anion supramolecular research has been undertaken. Alongside continued interest in anion binding and sensing, the fields of anion templation and transportation have flourished. Pleasingly, lessons learnt have been applied to applications such as catalysis, ion extraction and responsive materials and molecules.

So, what may be achieved in the next ten, twenty or even fifty years? We foresee exploitation and numerous applications of the "new" anion supramolecular interactions - anion- $\pi$ and especially halogen bonding. There will undoubtedly be progress in the recognition of anions in aqueous solvent media, noting that the in cellulo sensing of anions is still very much in its infancy. We anticipate that anion transportation research will lead to treatments for diseases arising from anion misregulation. Perhaps most ambitiously, anionic species may act as stimuli in highly sophisticated responsive nanotechnological devices and materials, mimicking systems to be found in Nature. Hence, anion supramolecular chemistry will continue to be an exciting, innovative and productive field of scientific research for many years to come.

We thank the many group members and collaborators who have contributed to the research carried out in the laboratories of P. D. B. in Oxford. P. D. B. wishes to acknowledge funding from the EPSRC, the European Research Council (Advanced Grant), the European Union for Marie Curie Fellowships, the Clarendon Fund and the Royal Commission for the Exhibition of 1851. N. H. E. wishes to thank the EPSRC for the funding of his doctoral studentship at Oxford, and Lancaster University for their current on-going financial support.

Received: ((will be filled in by the editorial staff))

Published online on ((will be filled in by the editorial staff))

[1] S. M. Rowe, S. Miller, E. J. Sorscher, New. Engl. J. Med. 2005, 352, 1992-2001.

[2] F. Delange, Thyroid 1994, 4, 107-128.

[3] M. Cametti, K. Rissanen, Chem. Commun. 2009, 2809-2829.

[4] S. G. Chang, D. Littlejohn, K. Y. Hu, Science 1987, 237, 756-758.

[5] B. Moss, Chem. Ind. - London 1996, 407-411.

[6] K. Yoshihara, Top. Curr. Chem. 1996, 176, 17-35.

[7] P. K. Dasgupta, J. V. Dyke, A. B. Kirk, W. A. Jackson, Environ. Sci. Technol. 2006, 40, 6608-6614.

[8] A. H. Smith, E. O. Lingas, M. Rahman, Bull. World Health Organ. 2000, 78, 1093-1103.

[9] C. H. Park, H. E. Simmons, J. Am. Chem. Soc. 1968, 90, 2431-2432.

[10] D. F. Shriver, M. J. Biallas, J. Am. Chem. Soc. 1967, 89, 1078-1081.

[11] C. J. Pedersen, Angew. Chem. 1988, 100, 1053-1059; Angew. Chem. Int. Ed. Engl.1988, 27, 1021-1027.

[12] J.-M. Lehn, Angew. Chem. 1988, 100, 91-116; Angew. Chem. Int. Ed. Engl.1988, 27, 89-112.

[13] D. J. Cram, Angew. Chem. 1988, 100, 1041-1052; Angew. Chem. Int Ed. Engl.1988, 27, 1009-1020. 
[14] M. W. Hosseini, J.-M. Lehn, J. Am. Chem. Soc. 1982, 104, 35253527.

[15] F. P. Schmidtchen, Chem . Ber. - Recl. 1981, 114, 597-607.

[16] P. D. Beer, P. A. Gale, Angew. Chem. 2001, 113, 502-532; Angew. Chem. Int. Ed. 2001, 40, 486-516.

[17] In 2001, ion pair recognition was marked out as an area of future advance in anion supramolecular chemistry. In the interests of space, we do not discuss developments in this particular field here. For current accounts of progress in ion pair recognition, see: a) A. J. McConnell, P. D. Beer, Angew. Chem. 2012, 124, 5138-5148; Angew. Chem. Int. Ed. 2012, 51, 5052-5061; b) S. K. Kim, J. L. Sessler, Chem. Soc. Rev. 2010, 39, 3784-3809.

[18] Seminal examples: a) R. A. Pascal, J. Spergel, D. Vanengen, Tetrahedron Lett. 1986, 27, 4099-4102; b) T. R. Kelly, M. H. Kim, J. Am. Chem. Soc. 1994, 116, 7072-7080. For reviews see: c) A. F. Li, J. H. Wang, F. Wang, Y. B. Jiang, Chem. Soc. Rev. 2010, 39, 37293745; d) V. Amendola, L. Fabbrizzi, L. Mosca, Chem. Soc. Rev. 2010, 39, 3889-3915.

[19] Seminal examples: a) S. Valiyayeettil, J. F. J. Engbersen, W. Verboom, D. N. Reinhoudt, Angew. Chem. 1993, 105, 942-944; Angew. Chem. Int. Ed. Engl.1993, 32, 900-901; b) A. P. Bisson, V. M. Lynch, M. K. C. Monahan, E. V. Anslyn, Angew. Chem. 1997, 109, 2435-2437; Angew. Chem. Int. Ed. 1997, 36, 2340-2342; c) K. Kavallieratos, S. R. deGala, D. J. Austin, R. H. Crabtree, J. Am. Chem. Soc. 1997, 119, 2325-2326. For a review on early work see: d) C. R. Bondy, S. J. Loeb, Coord. Chem. Rev. 2003, 240, 77-99.

[20] P. A. Gale, J. L. Sessler, V. Kral, V. Lynch, J. Am. Chem. Soc. 1996, 118, 5140-5141.

[21] a) P. Blondeau, M. Segura, R. Perez-Fernandez, J. de Mendoza, Chem. Soc. Rev. 2007, 36, 198-210; b) C. Schmuck, Coord. Chem. Rev. 2006, 250, 3053-3067.

[22] a) J. Yoon, S. K. Kim, N. J. Singh, K. S. Kim, Chem. Soc. Rev. 2006, 35, 355-360; b) Z. Xu, S. K. Kim, J. Yoon, Chem. Soc. Rev. 2010, 39, 1457-1466.

[23] N. L. Kilah, P. D. Beer, Top. Heterocyclic Chem. 2010, 24, 301-340.

[24] S. Arimori, M. G. Davidson, T. M. Fyles, T. G. Hibbert, T. D. James, G. I. Kociok-Kohn, Chem. Commun. 2004, 1640-1641.

[25] A. R. Bassindale, M. Pourny, P. G. Taylor, M. B. Hursthouse and M. E. Light, Angew. Chem. 2003, 115, 3612-3614; Angew.Chem. Int. Ed. 2003, 42, 3488-3490.

[26] H. Y. Zhao, F. P. Gabbai, Nat. Chem. 2010, 2, 984-990.

[27] Gale has published detailed annual updates on developments in anion receptor chemistry, the most recent of which are: a) P. A. Gale, N. Busschaert, C. J. E. Haynes, L. E. Karagiannidis, I. L. Kirby, Chem. Soc. Rev. 2014, 43, 205-241; b) M. Wenzel, J. R. Hiscock, P. A. Gale, Chem. Soc. Rev. 2012, 41, 480-520; c) P. A. Gale, Chem. Soc. Rev. 2010, 39, 3746-3771. The following relevant books have also been published: d) K. Bowman-James, A. Bianchi, E. García-España, Anion Coordination Chemistry, Wiley-VCH, Weinheim, 2011; e) J. L. Sessler, P. A. Gale, W.-S. Cho, Anion Receptor Chemistry, RSC, Cambridge, 2006.

[28] R. Prohens, S. Tomàs, J. Morey, P. M. Deyà, P. Ballester, A. Costa, Tetrahedron Lett. 1998, 39, 1063-1066.

[29] a) A. Frontera, J. Morey, A. Oliver, M. N. Piña, D. Quiñonero, A. Costa, P. Ballester, P. M. Deyà, E. V. Anslyn, J. Org. Chem. 2006, 71, 7185-7195; b) G. Ambrosi, M. Formica, V. Fusi, L. Giorgi, A. Guerri, M. Micheloni, P. Paoli, R. Pontellini, P. Rossi, Chem. - Eur. J. 2007, 13, 702-712, c) V. Ramalingam, M. E. Domaradzki, S. Jang, R. S. Muthyala, Org. Lett. 2008, 10, 3315-3318.

[30] D. Quiñonero, R. Prohens, C. Garau, A. Frontera, P. Ballester, A. Costa, P. M. Deyà, Chem. Phys. Lett. 2002, 351, 115-120.
[31] V. Amendola, G. Bergamaschi, M. Boiocchi, L. Fabbrizzi, M. Milani, Chem. - Eur. J. 2010, 16, 4368-4380.

[32] J. J. He, F. A. Quiocho, Science 1991, 251, 1479-1481.

[33] P. A. Gale, Chem. Commun. 2008, 4525-4540.

[34] G. W. Bates, P. A. Gale, M. E. Light, Chem. Commun. 2007, 21212123.

[35] M. J. Chmielewski, M. Charon, J. Jurczak, Org. Lett. 2004, 6, 35013504.

[36] D. Curiel, A. Cowley, P. D. Beer, Chem. Commun. 2005, 236-238.

[37] N.-K. Kim, K.-J. Chang, D. Moon, M. S. Lah, K.-S. Jeong, Chem. Commun. 2007, 3401-3403.

[38] J.-m. Suk, D. A. Kim, K.-S. Jeong, Org. Lett. 2012, 14, 5018-5021.

[39] Z.-M. Shi, S.-G. Chen, Z. Zhao, X.-K. Jiang, Z.-T. Li, Org. Biomol. Chem. 2011, 9, 8122-8129.

[40] J.-M. Lehn, E. Sonveaux, A. K. Willard, J. Am. Chem. Soc. 1978, 100, 4914-4916.

[41] S. O. Kang, J. M. Llinares, V. W. Day, K. Bowman-James, Chem. Soc. Rev. 2010, 39, 3980-4003.

[42] a) S. O. Kang, J. M. Llinares, D. Powell, D. VanderVelde, K. Bowman-James, J. Am. Chem. Soc. 2003, 125, 10152-10153; b) S. O. Kang, D. VanderVelde, D. Powell, K. Bowman-James, J. Am. Chem. Soc. 2004, 126, 12272-12273.

[43] a) T. Guchhait, G. Mani, C. Schulzke, A. Anoop, Inorg. Chem. 2012, 51, 11635-11644; b) D. Jana, G. Mani, C. Schulzke, Inorg. Chem. 2013, 52, 6427-6439.

[44] R. Alberto, G. Bergamaschi, H. Braband, T. Fox, V. Amendola, Angew. Chem. 2012, 124, 9910-9914; Angew. Chem. Int. Ed. 2012, 51, 9772-9776.

[45] D. K. Smith, Org. Biomol. Chem. 2003, 1, 3874-3877.

[46] K. J. Winstanley, A. M. Sayer, D. K. Smith, Org. Biomol. Chem. 2006, 4, 1760-1767.

[47] K. J. Winstanley, D. K. Smith, J. Org. Chem. 2007, 72, 2803-2815.

[48] a) V. V. Rostovtsev, L. G. Green, V. V. Fokin, K. B. Sharpless, Angew. Chem. 2002, 114, 2708-2711; Angew. Chem. Int. Ed. 2002, 41, 2596-2599; b) C. W. Tornøe, C. Christensen, M. Meldal, J. Org. Chem. 2002, 67, 3057-3064.

[49] a) Y. J. Li, A. H. Flood, Angew. Chem. 2008, 120, 2689-2692; Angew. Chem. Int. Ed. 2008, 47, 2649-2652; b) Y. J. Li, A. H. Flood, J. Am. Chem. Soc. 2008, 130, 12111-12122.

[50] Y. J. Li, M. Pink, J. A. Karty, A. H. Flood, J. Am. Chem. Soc. 2008, 130, 17293-17295.

[51] H. Juwarker, J. M. Lenhardt, D. M. Pham, S. L. Craig, Angew. Chem. 2008, 120, 3800-3803; Angew. Chem. Int. Ed. 2008, 47, 3740-3743.

[52] R. M. Meudtner, S. Hecht, Angew. Chem. 2008, 120, 5004-5008; Angew. Chem. Int. Ed. 2008, 47, 4926-4930.

[53] S. Lee, C.-H. Chen, A. H. Flood, Nat. Chem. 2013, 5, 704-710.

[54] a) J. Svec, M. Necas, V. Sindelar, Angew. Chem. 2010, 122, 24282431; Angew. Chem. Int. Ed. 2010, 49, 2378-2381; b) V. Havel, J. Svec, M. Wimmerova, M. Dusek, M. Pojarova, V. Sindelar, Org. Lett. 2011, 13, 4000-4003.

[55] S. Kubik, R. Goddard, R. Kirchner, D. Nolting, J. Seidel, Angew. Chem. 2001, 113, 2722-2725; Angew. Chem. Int. Ed. 2001, 40, 26482651.

[56] S. Kubik, R. Goddard, Proc. Natl. Acad. Sci. USA 2002, 99, 51275132. 
[57] S. Kubik, R. Kirchner, D. Nolting, J. Seidel, J. Am. Chem. Soc. 2002, 124, 12752-12760.

[58] Z. Rodriguez-Docampo, S. I. Pascu, S. Kubik, S. Otto, J. Am. Chem. Soc. 2006, 128, 11206-11210.

[59] J.-m. Suk, K.-S. Jeong, J. Am. Chem. Soc. 2008, 130, 11868-11869.

[60] a) I. E. D. Vega, S. Camiolo, P. A. Gale, M. B. Hursthouse, M. E. Light, Chem. Commun. 2003, 1686-1687; b) I. E. D. Vega, P. A. Gale, M. B. Hursthouse, M. E. Light, Org. Biomol. Chem. 2004, 2, 29352941.

[61] C. Caltagirone, J. R. Hiscock, M. B. Hursthouse, M. E. Light, P. A. Gale, Chem. - Eur. J. 2008, 14, 10236-10243.

[62] S. Kubik, Chem. Soc. Rev. 2010, 39, 3648-3663.

[63] V. Amendola, D. Esteban-Gómez, L. Fabbrizzi, M. Licchelli, Acc. Chem. Res. 2006, 39, 343-353.

[64] P. A. Gale, Acc. Chem. Res. 2006, 39, 465-475.

[65] T. Gunnlaugsson, M. Glynn, G. M. Tocci, P. E. Kruger, F. M. Pfeffer, Coord. Chem. Rev. 2006, 250, 3094-3117.

[66] M. Boiocchi, L. Del Boca, D. E. Gómez, L. Fabbrizzi, M. Licchelli, E. Monzani, J. Am. Chem. Soc. 2004, 126, 16507-16514.

[67] S. Camiolo, P. A. Gale, M. B. Hursthouse, M. E. Light, A. J. Shi, Chem. Commun. 2002, 758-759.

[68] L. S. Evans, P. A. Gale, M. E. Light, R. Quesada, Chem. Commun. 2006, 965-967.

[69] P. A. Gale, J. R. Hiscock, S. J. Moore, C. Caltagirone, M. B. Hursthouse, M. E. Light, Chem. - Asian. J. 2010, 5, 555-561.

[70] A. Frontera, P. Gamez, M. Mascal, T. J. Mooibroek, J. Reedijk, Angew. Chem. 2011, 123, 9736-9756; Angew. Chem. Int. Ed. 2011, 50, 9564-9583.

[71] For some examples of anion- $\pi$ interactions characterized exclusively in the solid state see: a) M. Mascal, I. Yakovlev, E. B. Nikitin, J. C. Fettinger, Angew. Chem. 2007, 119, 8938-8940; Angew. Chem. Int. Ed. 2007, 46, 8782-8784; b) M. Albrecht, M. Müller, O. Mergel, K. Rissanen, A. Valkonen, Chem. - Eur. J. 2010, 16, 5062-5069.

[72] O. B. Berryman, F. Hof, M. J. Hynes, D. W. Johnson, Chem. Commun. 2006, 506-508.

[73] O. B. Berryman, A. C. Sather, B. P. Hay, J. S. Meisner, D. W. Johnson, J. Am. Chem. Soc. 2008, 130, 10895-10897.

[74] D.-X. Wang, Q.-Y. Zheng, Q.-Q. Wang, M.-X. Wang, Angew. Chem. 2008, 120, 7595-7598; Angew. Chem. Int. Ed. 2008, 47, 7485-7488.

[75] S.T. Schneebeli, M. Frasconi, Z. Liu, Y. Wu, D. M. Gardner, N. L. Strutt, C. Cheng, R. Carmieli, M. R. Wasielewski, J. F. Stoddart, Angew. Chem. 2013, 125, 13338-13342; Angew. Chem. Int. Ed. 2013, 52, 13100-13104.

[76] J. Mareda, S. Matile, Chem. - Eur. J. 2009, 15, 28-37.

[77] a) G. Cavallo, P. Metrangolo, T. Pilati, G. Resnati, M. Sansotera, G. Terraneo, Chem. Soc. Rev. 2010, 39, 3772-3783; b) T. M. Beale, M. G. Chudzinski, M. G. Sarwar, M. S. Taylor, Chem. Soc. Rev. 2013, 42, 1667-1680.

[78] N. L. Kilah, M. D. Wise, P. D. Beer, Cryst. Growth. Des. 2011, 11, 4565-4571.

[79] M. G. Sarwar, B. Dragisic, S. Sagoo, M. S. Taylor, Angew. Chem. 2010, 122, 1718-1721; Angew. Chem. Int. Ed. 2010, 49, 1674-1677.

[80] A. Caballero, N. G. White, P. D. Beer, Angew. Chem. 2011, 123, 1885-1888; Angew. Chem. Int. Ed. 2011, 50, 1845-1848.

[81] F. Zapata, A. Caballero, N. G. White, T. D. W. Claridge, P. J. Costa, V. Félix, P. D. Beer, J. Am. Chem. Soc. 2012, 134, 11533-11541.
[82] M. Cametti, K. Raatikainen, P. Metrangolo, T. Pilati, G. Terraneo, G Resnati, Org. Biomol. Chem. 2012, 10, 1329-1333.

[83] S. M. Walter, F. Kniep, L. Rout, F. P. Schmidtchen, E. Herdtweck, S. M. Huber, J. Am. Chem. Soc. 2012, 134, 8507-8512.

[84] M. G. Chudzinski, C. A. McClary, M. S. Taylor, J. Am. Chem. Soc. 2011, 133, 10559-10567.

[85] R. Vilar, D. M. P. Mingos, A. J. P. White, D. J. Williams, Angew. Chem. 1998, 110, 1323-1326; Angew. Chem. Int. Ed. 1998, 37, 12581261.

[86] a) B. Hasenknopf, J.-M. Lehn, B. O. Kneisel, G. Baum, D. Fenske, Angew. Chem. 1996, 108, 1987-1990; Angew. Chem. Int. Ed. Engl.1996, 35, 1838-1840; b) B. Hasenknopf, J.-M. Lehn, N. Boumediene, A. Dupont-Gervais, A. Van Dorsselaer, B. Kneisel, D. Fenske, J. Am. Chem. Soc. 1997, 119, 10956-10962.

[87] X. Yang, C. B. Knobler, M. F. Hawthorne, Angew. Chem. 1991, 103, 1519-1521; Angew. Chem. Int. Ed. Engl. 1991, 30, 1507-1508.

[88] R. Vilar, Struct. Bond. 2008, 129, 175-206.

[89] P. T. Corbett, J. Leclaire, L. Vial, K. R. West, J.-L. Wietor, J. K. M. Sanders, S. Otto, Chem. Rev. 2006, 106, 3652-3711.

[90] C. Jia, B. Wu, S. Li, Z. Yang, Q. Zhao, J. Liang, Q.-S. Li, X.-J. Yang, Chem. Commun. 2010, 5376-5378.

[91] B. Schulze, C. Friebe, M. D. Hager, W. Günther, U. Köhn, B. O. Jahn, H. Görls, U. S. Schubert, Org. Lett. 2010, 12, 2710-2713.

[92] A. L. Cresswell, M.-O. M. Piepenbrock, J. W. Steed, Chem. Commun. 2010, 46, 2787-2789.

[93] M. Arunachalam, P. Ghosh, Chem. Commun. 2009, 5389-5391.

[94] A related hexapodal ligand that forms a dimeric assembly around the $\left[\mathrm{F}_{4}\left(\mathrm{H}_{2} \mathrm{O}\right)_{10}\right]^{4-}$ anion has also been reported: $\mathrm{M}$. Arunachalam, P. Ghosh, Chem. Commun. 2011, 6269-6271.

[95] S. K. Dey, G. Das, Dalton Trans. 2011, 40, 12048-12051.

[96] C. Jia, S. Li, X. Huang, Q. Zhao, Q.-S. Li, X.-J. Yang, Angew. Chem. 2011, 123, 506-510; Angew. Chem. Int. Ed. 2011, 50, 486-490.

[97] B. Akhuli, I. Ravikumar, P. Ghosh, Chem. Sci. 2012, 3, 1522-1530.

[98] S. Ramos, E. Alcalde, G. Doddi, P. Mencarelli, L. Pérez-Garcia, J. Org. Chem. 2002, 67, 8463-8468.

[99] D. Meshcheryakov, V. Böhmer, M. Bolte, W. Hubscher-Bruder, F. Arnaud-Neu, H. Herschbach, A. Van Dorsselaer, I. Thondorf, W. Mögelin, Angew. Chem. 2006, 118, 1679-1682; Angew. Chem. Int. Ed. 2006, 45, 1648-1652.

[100] a) E. A. Katayev, G. D. Pantos, M. D. Reshetova, V. N. Khrustalev, V. M. Lynch, Y. A. Ustynyuk, J. L. Sessler, Angew. Chem. 2005, 117, 7552-7556; Angew. Chem. Int. Ed. 2005, 44, 7386-7390; b) E. A. Katayev, J. L. Sessler, V. N. Khrustalev, Y. A. Ustynyuk, J. Org. Chem. 2007, 72, 7244-7252.

[101] a) M. Bru, I. Alfonso, M. I. Burguete, S. V. Luis, Angew. Chem. 2006, 118, 6301-6305; Angew. Chem. Int. Ed. 2006, 45, 6155-6159; b) I. Alfonso, M. Bolte, M. Bru, M. I. Burguete, S. V. Luis, J. Rubio, J. Am. Chem. Soc. 2008, 130, 6137-6144; c) M. Bru, I. Alfonso, M. Bolte, M. I. Burguete, S. V. Luis, Chem. Commun. 2011, 47, 283-285; d) A. Moure, S. V. Luis, I. Alfonso, Chem. - Eur. J. 2012, 18, 54965500 .

[102] J. S. Fleming, K. L. V. Mann, C.-A. Carraz, E. Psillakis, J. C. Jeffery, J. A. McCleverty, M. D. Ward, Angew. Chem. 1998, 110, 1315-1318; Angew. Chem. Int. Ed. 1998, 37, 1279-1281.

[103] R. L. Paul, Z. R. Bell, J. C. Jeffery, J. A. McCleverty, M. D. Ward, Proc. Natl. Acad. Sci. USA 2002, 99, 4883-4888.

[104] S. P. Argent, T. Riis-Johannessen, J. C. Jeffery, L. P. Harding, M. D. Ward, Chem. Commun. 2005, 4647-4649. 
[105] R. Custelcean, J. Bosano, P. V. Bonnesen, V. Kertesz, B. P. Hay, Angew. Chem. 2009, 121, 4085-4089; Angew. Chem. Int. Ed. 2009, 48, 4025-4029.

[106] S. Yi, V. Brega, B. Captain, A. E. Kaifer, Chem. Commun. 2012, 48, 10295-10297.

[107] P. J. Steel, C. J. Sumby, Chem. Commun. 2002, 322-323.

[108] X. Wang, J. Huang, S. Xiang, Y. Liu, J. Zhang, A. Eichhöffer, D. Fenske, S. Bai, C.-Y. Su, Chem. Commun. 2011, 47, 3849-3851.

[109] C. O. Dietrich-Buchecker, J.-P. Sauvage, Chem. Rev. 1987, 87, 795810.

[110] D. Philp, J. F. Stoddart, Angew. Chem. 1996, 108, 1242-1286; Angew. Chem. Int. Ed. Engl. 1996, 35, 1155-1196.

[111] a) G. M. Hübner, J. Gläser, C. Seel, F. Vögtle, Angew. Chem. 1999, 111, 395-398; Angew. Chem. Int. Ed. 1999, 38, 383-386; b) C. Reuter, W. Wienand, G. M. Hübner, C. Seel, F. Vögtle, Chem. - Eur. J. 1999, 5, 2692-2697.

[112] a) P. Ghosh, O. Mermagen, C. A. Schalley, Chem. Commun. 2002, 2628-2629; b) C. A. Schalley, G. Silva, C. F. Nising, P. Linnartz, Helv. Chim. Acta 2002, 85, 1578-1596.

[113] M. D. Lankshear, P. D. Beer, Acc. Chem. Res. 2007, 40, 657-668.

[114] J. A. Wisner, P. D. Beer, M. G. B. Drew, M. R. Sambrook, J. Am. Chem. Soc. 2002, 124, 12469-12476.

[115] M. R. Sambrook, P. D. Beer, J. A. Wisner, R. L. Paul, A. R. Cowley, J. Am. Chem. Soc. 2004, 126, 15364-15365.

[116] N. G. White, P. D. Beer, Org. Biomol. Chem. 2013, 11, 1326-1333.

[117] N. G. White, P. D. Beer, Chem. Commun. 2012, 48, 8499-8501.

[118] G. T. Spence, C. J. Serpell, J. Sardinha, P. J. Costa, V. Félix, P. D. Beer, Chem. - Eur. J. 2011, 17, 12955-12966.

[119] K. M. Mullen, J. Mercurio, C. J. Serpell, P. D. Beer, Angew. Chem. 2009, 121, 4875-4878; Angew. Chem. Int. Ed. 2009, 48, 4781-4784.

[120] N. L. Kilah, M. D. Wise, C. J. Serpell, A. L. Thompson, N. G. White, K. E. Christensen, P. D. Beer, J. Am. Chem. Soc. 2010, 132, 1189311895.

[121] a) K.-Y. Ng, A. R. Cowley, P. D. Beer, Chem. Commun. 2006, 36763678; b) N. H. Evans, E. S. H. Allinson, M. D. Lankshear, K.-Y. Ng, A. R. Cowley, C. J. Serpell, S. M. Santos, P. J. Costa, V. Félix, P. D. Beer, RSC Adv. 2011, 1, 995-1003.

[122] B. Q. Huang, S. M. Santos, V. Félix, P. D. Beer, Chem. Commun. 2008, 4610-4612.

[123] A. Caballero, F. Zapata, N. G. White, P. J. Costa, V. Félix, P. D. Beer, Angew. Chem. 2012, 124, 1912-1916; Angew. Chem. Int. Ed. 2012, 51, 1876-1880.

[124] N. H. Evans, C. J. Serpell, P. D. Beer, Angew. Chem. 2011, 123, 2555 2558; Angew. Chem. Int. Ed. 2011, 50, 2507-2510.

[125] N. H. Evans, P. D. Beer, Chem. - Eur. J. 2011, 17, 10541-10545.

[126] a) L. M. Hancock, P. D. Beer, Chem. - Eur. J. 2009, 15, 42-44; bL. M. Hancock, L. C. Gilday, S. Carvalho, P. J. Costa, V. Félix, C. J. Serpell, N. L. Kilah, P. D. Beer, Chem. - Eur. J. 2010, 16, 1308213094.

[127] L. M. Hancock, L. C. Gilday, N. L. Kilah, C. J. Serpell, P. D. Beer, Chem. Commun. 2011, 47, 1725-1727.

[128] J. M. Mercurio, F. Tyrrell, J. Cookson, P. D. Beer, Chem. Commun. 2013, 49, 10793-10795.

[129] M. J. Chmielewski, L. Y. Zhao, A. Brown, D. Curiel, M. R. Sambrook, A. L. Thompson, S. M. Santos, V. Félix, J. J. Davis, P. D. Beer, Chem. Commun. 2008, 3154-3156.
[130] a) M. K. Chae, J.-m. Suk, K.-S. Jeong, Tetrahedron Lett. 2010, 51, 4240-4242; b)Y. J. Zhao, Y. L. Li, Y. J. Li, H. Y. Zheng, X. D. Yin, H. B. Liu, Chem. Commun. 2010, 46, 5698-5700.

[131] M. J. Langton, L. C. Duckworth, P. D. Beer, Chem. Commun. 2013, 49, 8608-8610.

[132] In a DCL the total free energy is minimized which means that the receptor with the highest affinity for an added guest is not necessarily the molecule amplified. For example, see: P. T. Corbett, J. K. M. Sanders, S. Otto, J. Am. Chem. Soc. 2005, 127, 9390-9392.

[133] a) S. Otto, S. Kubik, J. Am. Chem. Soc. 2003, 125, 7804-7805; b) Z. Rodriguez-Docampo, E. Eugenieva-Ilieva, C. Reyheller, A. M. Belenguer, S. Kubik, S. Otto, Chem. Commun. 2011, 47, 9798-9800.

[134] S. R. Beeren, J. K. M. Sanders, J. Am. Chem. Soc. 2011, 133, 38043807.

[135] In a subsequent report (S. R. Beeren, J. K. M. Sanders, Chem. Sci. 2011, 2, 1560-1567) 4-methylbenzylaldehyde was removed from the library, and in this case a range of macrocycles were generated. However, this library was found to be static, and not under thermodynamic control.

[136] S. R. Bayly, P. D. Beer, G. Z. Chen, in Ferrocenes: Ligands, Materials and Biomolecules (Ed.: P. Štěpnička), Wiley, UK, 2008, pp. 281-318.

[137] P. D. Beer, A. R. Graydon, A. O. M. Johnson, D. K. Smith, Inorg. Chem. 1997, 36, 2112-2118.

[138] a) M. D. Pratt, P. D. Beer, Polyhedron 2003, 22, 649-653; b) H.-T. Niu, Z. M. Yin, D. D. Su, D. Niu, Y. B. Ao, J. Q. He, J.-P. Cheng, Tetrahedron 2008, 64, 6300-6306; c) T. Romero, A. Caballero, A. Tárraga, P. Molina, Org. Lett. 2009, 11, 3466-3469.

[139] Y. Willener, K. A. Joly, C. J. Moody, J. H. R. Tucker, J. Org. Chem. 2008, 73, 1225-1233.

[140] V. Amendola, M. Boiocchi, B. Colasson, L. Fabbrizzi, E. Monzani, M. J. Douton-Rodriguez, C. Spadini, Inorg. Chem. 2008, 47, 48084816.

[141] P. D. Beer, N. Berry, M. G. B. Drew, O. D. Fox, M. E. Padilla-Tosta, S. Patell, Chem. Commun. 2001, 199-200.

[142] K. A. Nielsen, J. O. Jeppesen, E. Levillain, J. Becher, Angew. Chem. 2003, 115, 197-201; Angew. Chem. Int. Ed. 2003, 42, 187-191.

[143] a) T. Gunnlaugsson, A. P. Davis, G. M. Hussey, J. Tierney, M. Glynn, Org. Biomol. Chem. 2004, 2, 1856-1863; b) Y. K. Kim, H. N. Lee, N. J. Singh, H. J. Choi, J. Y. Xue, K. S. Kim, J. Yoon, M. H. Hyun, J. Org. Chem. 2008, 73, 301-304.

[144] a) B. Schazmann, N. Alhashimy, D. Diamond, J. Am. Chem. Soc 2006, 128, 8607-8614; b) Z. C. Xu, N. J. Singh, J. S. Lim, J. Pan,H. N. Kim, S. S. Park, K. S. Kim, J. Y. Yoon, J. Am. Chem. Soc., 2009, 131, 15528-15533; c) Y.-X. Xu, G.-T. Wang, X. Zhao, X.-K. Jiang, Z.-T. Li, J. Org. Chem., 2009, 74, 7267-7273.

[145] a) M. S. Vickers, K. S. Martindale, P. D. Beer, J. Mater. Chem. 2005, 15, 2784-2790; b) N. C. A. Baker, N. McGaughey, N. C. Fletcher, A V. Chernikov, P. N. Horton, M. B. Hursthouse, Dalton Trans. 2009, 965-972.

[146] R. M. Duke, E. B. Veale, F. M. Pfeffer, P. E. Kruger, T. Gunnlaugsson, Chem. Soc. Rev. 2010, 39, 3936-3953.

[147] T. Gunnlaugsson, P. E. Kruger, T. C. Lee, R. Parkesh, F. M. Pfeffer, G. M. Hussey, Tetrahedron Lett. 2003, 44, 6575-6578.

[148] J. M. Engle, C. N. Carroll, D. W. Johnson, M. M. Haley, Chem. Sci. 2012, 3, 1105-1110.

[149] B. W. Tresca, L. N. Zakharov, C. N. Carroll, D. W. Johnson, M. M. Haley, Chem. Commun. 2013, 49, 7240-7242.

[150] R. Pal, D. Parker, L. C. Costello, Org. Biomol. Chem. 2009, 7, 15251528. 
[151] D. G. Smith, G.-l. Law, B. S. Murray, R. Pal, D. Parker, K.-L. Wong, Chem. Commun. 2011, 47, 7347-7349.

[152] N. H. Evans, P. D. Beer, Org. Biomol. Chem. 2011, 9, 92-100.

[153] N. H. Evans, H. Rahman, A. V. Leontiev, N. D. Greenham, G. A. Orlowski, Q. Zeng, R. M. J. Jacobs, C. J. Serpell, N. L. Kilah, J. J. Davis, P. D. Beer, Chem. Sci. 2012, 3, 1080-1089.

[154] L. M. Hancock, E. Marchi, P. Ceroni, P. D. Beer, Chem. - Eur. J. 2012, 18, 11277-11283.

[155] C. Allain, P. D. Beer, S. Faulkner, M. W. Jones, A. M. Kenwright, N. L. Kilah, R. C. Knighton, T. J. Sørensen, M. Tropiano, Chem. Sci. 2013, 4, 489-493.

[156] N. H. Evans, C. J. Serpell, P. D. Beer, Chem. Commun. 2011, 47, 8775-8777.

[157] M. J. Langton, P. D. Beer, Chem. - Eur. J. 2012, 18, 14406-14412.

[158] J. J. Gassensmith, S. Matthys, J.-J. Lee, A. Wojcik, P. V. Kamat, B. D. Smith, Chem. - Eur. J. 2010, 16, 2916-2921.

[159] C. G. Collins, E. M. Peck, P. J. Kramer, B. D. Smith, Chem. Sci. 2013, 4, 2557-2563.

[160] B. T. Nguyen, E. V. Anslyn, Coord. Chem. Rev. 2006, 250, 31183127.

[161] A. Metzger, E. V. Anslyn, Angew. Chem. 1998, 110, 682-684; Angew. Chem. Int. Ed. 1998, 37, 649-652.

[162] K. Niikura, A. Metzger, E. V. Anslyn, J. Am. Chem. Soc. 1998, 120, 8533-8534.

[163] Z. L. Zhong, E. V. Anslyn, J. Am. Chem. Soc. 2002, 124, 9014-9015.

[164] L. Fabbrizzi, A. Leone, A. Taglietti, Angew. Chem. 2001, 113, 31563159; Angew. Chem. Int. Ed. 2001, 40, 3066-3069.

[165] F. Sancenón, R. Martínez-Máñez, M. A. Miranda, M.-J. Seguí, J. Soto, Angew. Chem. 2003, 115, 671-674; Angew. Chem. Int. Ed. 2003, 42, 647-650.

[166] D. Jiménez, R. Martínez-Máñez, F. Sancenón, J. V. Ros-Lis, A. Benito, J. Soto, J. Am. Chem. Soc. 2003, 125, 9000-9001.

[167] D.-G. Cho, J. H. Kim, J. L. Sessler, J. Am. Chem. Soc. 2008, 130, 12163-12167.

[168] T. W. Hudnall, F. P. Gabbaï, J. Am. Chem. Soc. 2007, 129, 1197811986.

[169] C. R. Wade, A. E. J. Broomsgrove, S. Aldridge, F. P. Gabbaï, Chem. Rev. 2010, 110, 3958-3984.

[170] S. Solé, F. P. Gabbaï, Chem. Commun. 2004, 1284-1285.

[171] S. Aldridge, C. Bresner, I. A. Fallis, S. J. Coles, M. B. Hursthouse, Chem. Commun. 2002, 740-741.

[172] S. Yamaguchi, S. Akiyama, K. Tamao, J. Am. Chem. Soc. 2000, 122, 6793-6794.

[173] a) S. Zhang, C. M. Cardona, L. Echegoyen, Chem. Commun. 2006, 4461-4473; b) N. H. Evans, H. Rahman, J. J. Davis, P. D. Beer, Anal. Bioanal. Chem. 2012, 402, 1739-1748.

[174] E. Alonso, A. Labande, L. Raehm, J.-M. Kern, D. Astruc, Cr. Acad. Sci. IIc 1999, 2, 209-213.

[175] a) A. Labande, J. Ruiz, D. Astruc, J. Am. Chem. Soc. 2002, 124, 1782 1789; b) M.-C. Daniel, J. Ruiz, S. Nlate, J.-C. Blais, D. Astruc, J. Am. Chem. Soc. 2003, 125, 2617-2628.

[176] a) P. D. Beer, J. J. Davis, D. A. Drillsma-Milgrom, F. Szemes, Chem. Commun. 2002, 1716-1717; b) D. P. Cormode, A. J. Evans, J. J. Davis, P. D. Beer, Dalton Trans. 2010, 39, 6532-6541.

[177] L. G. Jensen, K. A. Nielsen, T. Breton, J. L. Sessler, J. O. Jeppesen, E. Levillain, L. Sanguinet, Chem. - Eur. J. 2009, 15, 8128-8133.
[178] S. R. Bayly, T. M. Gray, M. J. Chmielewski, J. J. Davis, P. D. Beer, Chem. Commun. 2007, 2234-2236.

[179] J. Lehr, T. Lang, O. A. Blackburn, T. A. Barendt, S. Faulkner, J. J. Davis, P. D. Beer, Chem. - Eur. J. 2013, 19, 15898-15906.

[180] P. D. Beer, D. P. Cormode, J. J. Davis, Chem. Commun. 2004, 414415.

[181] J. Massue, S. J. Quinn, T. Gunnlaugsson, J. Am. Chem. Soc. 2008, 130, 6900-6901.

[182] L. Basabe-Desmonts, J. Beld, R. S. Zimmerman, J. Hernando, P. Mela, M. F. García Parajó, N. F. van Hulst, A. v. d. Berg, D. N. Reinhoudt, M. Crego-Calama, J. Am. Chem. Soc. 2004, 126, 72937299.

[183] S. Zhang, L. Echegoyen, J. Am. Chem. Soc. 2005, 127, 2006-2011.

[184] S. Zhang, A. Palkar, L. Echegoyen, Langmuir 2006, 22, 10732-10738.

[185] P. Anzenbacher, P. Lubal, P. Buček, M. A. Palacios, M. E. Kozelkova, Chem. Soc. Rev. 2010, 39, 3954-3979.

[186] M. A. Palacios, R. Nishiyabu, M. Marquez, P. Anzenbacher, J. Am. Chem. Soc. 2007, 129, 7538-7544.

[187] G. V. Zyryanov, M. A. Palacios, P. Anzenbacher, Angew. Chem. 2007, 119, 7995-7998; Angew. Chem. Int. Ed. 2007, 46, 7849-7852.

[188] L. Feng, H. Li, X. Li, L. Chen, Z. Shen, Y. F. Guan, Anal. Chim. Acta 2012, 743, 1-8.

[189] A. Fürstner, Angew. Chem. 2003, 115, 3706-3728; Angew. Chem. Int. Ed. 2003, 42, 3582-3603.

[190] a) A. P. Davis, D. N. Sheppard, B. D. Smith, Chem. Soc. Rev. 2007, 36, 348-357; b) J. T. Davis, O. Okunola, R. Quesada, Chem. Soc. Rev. 2010, 39, 3843-3862.

[191] P. A. Gale, Acc. Chem. Res. 2011, 44, 216-226.

[192] P. R. Brotherhood, A. P. Davis, Chem. Soc. Rev. 2010, 39, 3633-3647.

[193] A. V. Koulov, T. N. Lambert, R. Shukla, M. Jain, J. M. Boon, B. D. Smith, H. Y. Li, D. N. Sheppard, J.-B. Joos, J. P. Clare, A. P. Davis, Angew. Chem. 2003, 115, 5091-5083; Angew Chem. Int. Ed. 2003, 42, 4931-4933.

[194] B. A. McNally, A. V. Koulov, T. N. Lambert, B. D. Smith, J.-B. Joos, A. L. Sisson, J. P. Clare, V. Sgarlata, L. W. Judd, G. Magro, A. P. Davis, Chem. - Eur. J. 2008, 14, 9599-9606.

[195] L. W. Judd, A. P. Davis, Chem. Commun. 2010, 46, 2227-2229.

[196] S. Hussain, P. R. Brotherhood, L. W. Judd, A. P. Davis, J. Am. Chem. Soc. 2011, 133, 1614-1617.

[197] J. L. Sessler, L. R. Eller, W.-S. Cho, S. Nicolaou, A. Aguilar, J. T. Lee, V. M. Lynch, D. J. Magda, Angew. Chem. 2005, 117, 6143-6146; Angew. Chem. Int. Ed. 2005, 44, 5989-5992.

[198] P. A. Gale, M. E. Light, B. McNally, K. Navakhun, K. E. Sliwinski, B. D. Smith, Chem. Commun. 2005, 3773-3775.

[199] P. A. Gale, J. Garric, M. E. Light, B. A. McNally, B. D. Smith, Chem. Commun. 2007, 1736-1738.

[200] K. J. Winstanley, S. J. Allen, D. K. Smith, Chem. Commun. 2009, 4299-4301.

[201] S. K. Berezin, J. T. Davis, J. Am. Chem. Soc. 2009, 131, 2458-2459.

[202] J. T. Davis, P. A. Gale, O. A. Okunola, P. Prados, J. C. IglesiasSánchez, T. Torroba, R. Quesada, Nat. Chem. 2009, 1, 138-144.

[203] B. Díaz de Grenu, P. I. Hernández, M. Espona, D. Quiñonero, M. E. Light, T. Torroba, R. Pérez-Tomás, R. Quesada, Chem. - Eur. J. 2011, 17, 14074-14083.

[204] P. I. Hernández, D. Moreno, A. A. Javier, T. Torroba, R. PérezTomás, R. Quesada, Chem. Commun. 2012, 48, 1556-1558. 
[205] N. Busschaert, P. A. Gale, C. J. E. Haynes, M. E. Light, S. J. Moore, C. C. Tong, J. T. Davis and W. A. Harrell, Chem. Commun. 2010, 46, 6252-6254.

[206] N. Busschaert, I. L. Kirby, S. Young, S. J. Coles, P. N. Horton, M. E. Light and P. A. Gale, Angew. Chem. 2012, 124, 4502-4506; Angew. Chem. Int. Ed. 2012, 51, 4426-4430.

[207] S. J. Moore, C. J. E. Haynes, J. González, J. L. Sutton, S. J. Brooks, M. E. Light, J. Herniman, G. J. Langley, V. Soto-Cerrato, R. PérezTomás, I. Marques, P. J. Costa, V. Félix, P. A. Gale, Chem. Sci. 2013, 4, 103-117.

[208] C. J. E. Haynes, S. N. Berry, J. Garric, J. Herniman, J. R. Hiscock, I. L. Kirby, M. E. Light, G. Perkes, P. A. Gale, Chem. Commun. 2013, 49, 246-248.

[209] N. Busschaert, L. E. Karagiannidis, M. Wenzel, C. J. E. Haynes, N. J. Wells, P. G. Yound, D. Makuc, J. Plavec, K. A. Jolliffe, P. A. Gale, Chem. Sci. 2014, 5, 1118-1127.

[210] A. V. Jentzsch, D. Emery, J. Mareda, P. Metrangolo, G. Resnati, S. Matile, Angew. Chem. 2011, 123, 11879-11882; Angew. Chem. Int. Ed. 2011, 50, 11675-11678.

[211] A. V. Jentzsch, D. Emery, J. Mareda, S. K. Nayak, P. Metrangolo, G. Resnati, N. Sakai, S. Matile, Nat. Commun. 2012, 3, Art. No. 905.

[212] U. Bukovnik, J. Gao, G. A. Cook, L. P. Shank, M. B. Seabra, B. D. Schultz, T. Iwamoto, J. Chen, J. M. Tomich, BBA Biomembranes 2012, 1818, 1039-1048.

[213] P. H. Schlesinger, R. Ferdani, J. Liu, J. Pajewska, R. Pajewski, M. Saito, H. Shabany, G. W. Gokel, J. Am. Chem. Soc. 2002, 124, 18481849.

[214] a) N. Djedovič, R. Ferdani, E. Harder, J. Pajewska, R. Pajewski, M. E. Weber, P. H. Schlesinger, G. W. Gokel, New J. Chem. 2005, 29, 291305; b) R. Ferdani, R. Pajewski, N. Djedovič, J. Pajewska, P. H. Schlesinger, G. W. Gokel, New. J. Chem. 2005, 29, 673-680.

[215] R. Pajewski, R. Garcia-Medina, S. L. Brody, W. M. Leevy, P. H. Schlesinger, G. W. Gokel, Chem. Commun. 2006, 329-331.

[216] V. Sidorov, F. W. Kotch, G. Abdrakhmanova, R. Mizani, J. C. Fettinger, J. T. Davis, J. Am. Chem. Soc. 2002, 124, 2267-2278.

[217] J. L. Seganish, P. V. Santacroce, K. J. Salimian, J. C. Fettinger, P. Zavalij, J. T. Davis, Angew. Chem. 2006, 118, 3412-3416; Angew. Chem. Int. Ed. 2006, 45, 3334-3338.

[218] O. A. Okunola, J. L. Seganish, K. J. Salimian, P. Y. Zavalij, J. T. Davis, Tetrahedron 2007, 63, 10743-10750.

[219] V. Gorteau, G. Bollot, J. Mareda, A. Perez-Velasco, S. Matile, J. Am. Chem. Soc. 2006, 128, 14788-14789.

[220] A. Perez-Velasco, V. Gorteau, S. Matile, Angew. Chem. 2008, 120, 935-937; Angew. Chem. Int. Ed. 2008, 47, 921-923.

[221] Z. G. Zhang, P. R. Schreiner, Chem. Soc. Rev. 2009, 38, 1187-1198.

[222] I. T. Raheem, P. S. Thiara, E. A. Peterson, E. N. Jacobsen, J. Am. Chem. Soc. 2007, 129, 13404-13405.

[223] a) S. E. Reisman, A. G. Doyle, E. N. Jacobsen, J. Am. Chem. Soc. 2008, 130, 7198-7199; b) E. A. Peterson, E. N. Jacobsen, Angew. Chem. 2009, 121, 6446-6449; Angew. Chem. Int. Ed. 2009, 48, 63286331.

[224] A. R. Brown, W.-H. Kuo, E. N. Jacobsen, J. Am. Chem. Soc. 2010 132, 9286-9288.

[225] J. A. Birrell, J.-N. Desrosiers, E. N. Jacobsen, J. Am. Chem. Soc. 2011, 133, 13872-13875.

[226] K. Ohmatsu, M. Kiyokawa, T. Ooi, J. Am. Chem. Soc. 2011, 133, 1307-1309.

[227] R. J. Phipps, G. L. Hamilton, F. D. Toste, Nat. Chem. 2012, 4, 603614.
[228] S. Mayer, B. List, Angew. Chem. 2006, 118, 4299-4301; Angew. Chem. Int. Ed. 2006, 45, 4193-4195.

[229] C. Li, C. Wang, B. Villa-Marcos, J. Xiao, J. Am. Chem. Soc. 2008 $130,14450-14451$.

[230] G. L. Hamilton, T. Kanai, F. D. Toste, J. Am. Chem. Soc. 2008, 130, 14984-14986.

[231] S. Liao, B. List, Angew. Chem. 2010, 122, 638-641; Angew. Chem. Int. Ed. 2010, 49, 628-631.

[232] P. Dydio, C. Rubay, T. Gadzikwa, M. Lutz, J. N. H. Reek, J. Am. Chem. Soc. 2011, 133, 17176-17179.

[233] C. J. Serpell, J. Cookson, D. Ozkaya, P. D. Beer, Nat. Chem. 2011, 3, 478-483.

[234] A. Rajbanshi, B. A. Moyer, R. Custelcean, Cryst. Growth. Des. 2011, 11, 2702-2706.

[235] K. J. Bell, A. N. Westra, R. J. Warr, J. Chartres, R. Ellis, C. C. Tong, A. J. Blake, P. A. Tasker, M. Schröder, Angew. Chem. 2008, 120, 1769-1772; Angew. Chem. Int. Ed. 2008, 47, 1745-1748.

[236] J. W. Steed, Chem. Soc. Rev. 2010, 39, 3686-3699.

[237] M.-O. M. Piepenbrock, G. O. Lloyd, N. Clarke, J. W. Steed, Chem. Commun. 2008, 2644-2646.

[238] J. A. Foster, M.-O. M. Piepenbrock, G. O. Lloyd, N. Clarke, J. A. K. Howard, J. W. Steed, Nat. Chem. 2010, 2, 1037-1043.

[239] T. Becker, C. Y. Goh, F. Jones, M. J. McIldowie, M. Mocerino, M. I. Ogden, Chem. Commun. 2008, 3900-3902.

[240] J.-S. Shen, Q.-G. Cai, Y.-B. Jiang, H.-W. Zhang, Chem. Commun. 2010, 46, 6786-6788.

[241] D. Kim, S. Jon, H.-K. Lee, K. Baek, N.-K. Oh, W.-C. Zin, K. Kim, Chem. Commun.2005, 5509-5511.

[242] X.-X. Lu, H.-S. Tang, C.-C. Ko, J. K.-Y. Wong, N. Zhu, V. W.-W. Yam, Chem. Commun. 2005, 1572-1574.

[243] I. M. Jones, A. D. Hamilton, Angew. Chem. 2011, 123, 4693-4696; Angew. Chem. Int. Ed. 2011, 50, 4597-4600.

[244] K.-Y. Ng, V. Félix, S. M. Santos, N. H. Rees, P. D. Beer, Chem. Commun. 2008, 1281-1283.

[245] C. M. Keaveney, D. A. Leigh, Angew. Chem. 2004, 116, 1242-1244; Angew. Chem. Int. Ed. 2004, 43, 1222-1224.

[246] M. J. Barrell, D. A. Leigh, P. J. Lusby, A. M. Z. Slawin, Angew. Chem. 2008, 120, 8156-8159; Angew. Chem. Int. Ed. 2008, 47, 80368039.

[247] C. J. Serpell, R. Chall, A. L. Thompson, P. D. Beer, Dalton Trans. 2011, 40, 12052-12055.

[248] C.-F. Lin, C.-C. Lai, Y.-H. Liu, S.-M. Peng, S.-H. Chiu, Chem. - Eur. J. 2007, 13, 4350-4355.

[249] Y.-L. Huang, W.-C. Hung, C.-C. Lai, Y.-H. Liu, S.-M. Peng, S.-H. Chiu, Angew. Chem. 2007, 119, 6749-6753; Angew. Chem. Int. Ed. 2007, 46, 6629-6633.

[250] G. T. Spence, M. B. Pitak, P. D. Beer, Chem. - Eur. J. 2012, 18 , 7100-7108

[251] a) C. R. K. Glasson, G. V. Meehan, J. K. Clegg, L. F. Lindoy, P. Turner, M. B. Duriska, R. Willis, Chem. Commun. 2008, 1190-1192; b) I. S. Tidmarsh, B. F. Taylor, M. J. Hardie, L. Russo, W. Clegg, M. D. Ward, New. J. Chem. 2009, 33, 366-375.

[252] I. A. Riddell, M. M. J. Smulders, J. K. Clegg, Y. R. Hristova, B. Breiner, J. D. Thoburn, J. R. Nitschke, Nat. Chem. 2012, 4, 751-756.

[253] J. K. Clegg, J. Cremers, A. J. Hogben, B. Breiner, M. M. J. Smulders, J. D. Thoburn, J. R. Nitschke, Chem. Sci. 2013, 4, 68-76. 
[254] H. T. Chifotides, I. D. Giles, K. R. Dunbar, J. Am. Chem. Soc. 2013 135, 3039-3055.

[255] S. Freye, R. Michel, D. Stalke, M. Pawliczek, H. Frauendorf, G. H. Clever, J. Am. Chem. Soc. 2013, 135, 8476-8479. 
Entry for the Table of Contents (Please choose one layout)

Layout 2:

Anion Supramolecular

Chemistry

Nicholas H. Evans* and Paul D. Beer* Page - Page

Advances in Anion Supramolecular Chemistry: From Recognition to Chemical Applications

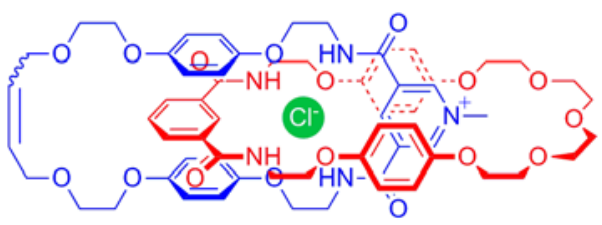

Since the Millennium, anion supramolecular chemistry has evolved substantially beyond anion receptor chemistry. Alongside the research that continues on the binding and sensing of anions, large strides have been made in areas which have previously been underdeveloped such as anion templation and membrane transportation and importantly in chemical applications including catalysis, ion extraction and responsive molecular systems. 